
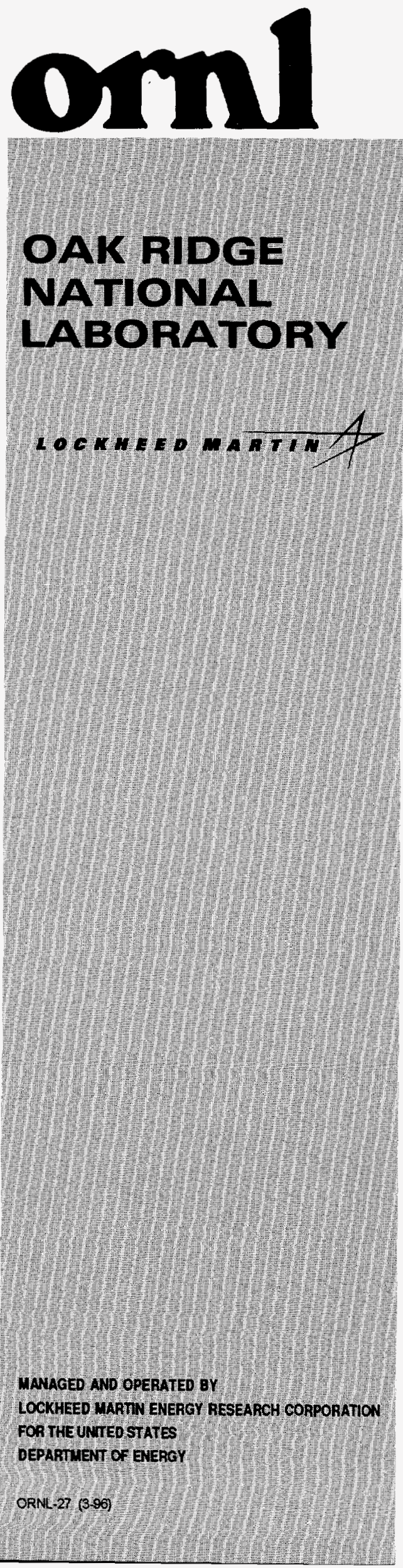

RECEIVES

\section{MAR 091998 \\ OSTI}

ORNL/TM-13530

\section{IN SITU TREATMENT OF MIXED CONTAMINANTS IN GROUNDWATER: \\ Application of Zero-Valence Iron and \\ Palladized Iron for Treatment of \\ Groundwater Contaminated with \\ Trichloroethene and Technetium-99}

\author{
N. E. KORTE \\ L. LIANG \\ B. GU \\ M. T. MUCK \\ J. L. ZUTMAN \\ R. M. SCHLOSSER \\ R. L. SIEGRIST \\ T. C. HOUK \\ Q. FERNANDO
}

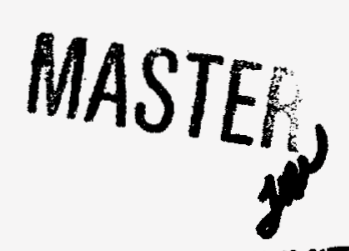

DISTRIBUTION OF THIS DOCUMENT IS UNLMMTED 
This report has been reproduced directly from the best available copy.

Available to DOE and DOE contractors from the Office of Scientific and Technical Information, P.O. Box 62, Oak Ridge, TN 37831; prices available from (615) 576-8401, FTS 626-8401.

Available to the public from the National Technical Information Service, U.S. Department of Commerce, 5285 Port Royal Rod., Springfield, VA 22161.

This report was prepared as an account of work sponsored by an agency of the United States Government. Neither the United States Government nor any agency thereot, nor any of their employees, makes any warranty, express or implied, or assumes any logal liability or responsibility for the accuracy. completeness, or usefulness of any information, apparatus, product, or process disclosed, or represents that its use would not infringe privately owned rights. Reference herein to any specific commercial product, process, or service by trade name, trademark, manufacturer, or otherwise, does not necessarily constitute or imply its endorsement, recommendation, or favoring by the United States Government or any agency thereof. The views and opinions of authors expressed herein do not necessarily state or reflect those of the United States Government or any agency thereof. 


\section{DISCLAIMER}

Portions of this document may be illegible electronic image products. Images are produced from the best available original document. 
ORNL/TM-13530

\title{
IN SITU TREATMENT OF MIXED CONTAMINANTS IN GROUNDWATER: \\ Application of Zero-Valence Iron and Palladized Iron for Treatment of Groundwater Contaminated with Trichloroethene and Technetium-99
}

\author{
N. E. KORTE ${ }^{1}$ \\ L. LIANG $^{2}$ \\ B. $\mathbf{G U ^ { 2 }}$ \\ M. T. MUCK ${ }^{3}$ \\ J. L. ZUTMAN ${ }^{3}$ \\ R. M. SCHLOSSER ${ }^{3}$ \\ R. L. SIEGRIST ${ }^{2,4}$ \\ T. C. HOUK \\ Q. FERNANDO ${ }^{6}$
}

Prepared: April 1997

Environmental Sciences Division Publication No. 4721

Prepared by the

Oak Ridge National Laboratory

Grand Junction, CO 81503

Managed by

LOCKHEED MARTIN ENERGY RESEARCH CORPORATION for the

U.S. DEPARTMENT OF ENERGY

under contract DE-AC05-96OR22464

${ }^{1}$ Oak Ridge National Laboratory, Environmental Sciences Division, Grand Junction, Colo. 81503

${ }^{2}$ Oak Ridge National Laboratory, Environmental Sciences Division, Oak Ridge, Tenn. 37831

${ }^{3}$ Oak Ridge National Laboratory, Life Sciences Division, Grand Junction, Colo. 81503

${ }^{4}$ Colorado School of Mines, Golden, Colo. 80401

${ }^{5}$ Portsmouth Gaseous Diffusion Plant, Piketon, Ohio 45661

${ }^{6}$ University of Arizona, Tucson, Ariz. 85721 


\section{Contents}

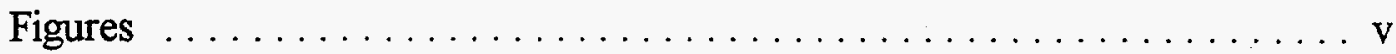

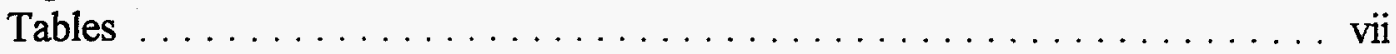

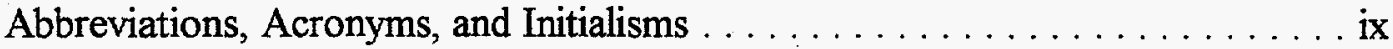

Acknowledgment . . . . . . . . . . . . . . . . . . . . . . . . . .

Executive Summary $\ldots \ldots \ldots \ldots \ldots \ldots \ldots \ldots \ldots \ldots \ldots \ldots \ldots \ldots$

1. Introduction $\ldots \ldots \ldots \ldots \ldots \ldots \ldots \ldots \ldots \ldots \ldots \ldots \ldots \ldots$ 1-1

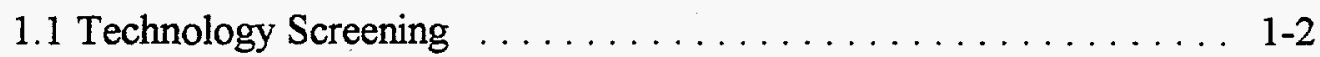

1.1.1 VOC Treatment Process Screening . . . . . . . . . . . . . 1-4

1.1.2 Radionuclide Treatment Process Screening . . . . . . . . . 1-5

2. Treatment Process Selection . . . . . . . . . . . . . . . . 2-1

2.1 Special Concerns of Recirculation and Coupled Treatment ... . . 2-1

2.2 Backup Treatment Approaches . . . . . . . . . . . . . . . 2-2

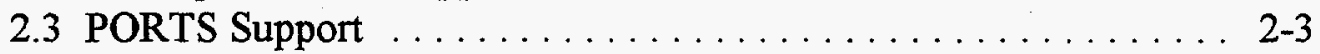

2.4 Commercial Partner Support . . . . . . . . . . . . . . 2-3

3. Laboratory Pilot Treatment Testing .................. 3-1

3.1 Dechlorination of Chlorinated Solvents by Zero-Valence Iron

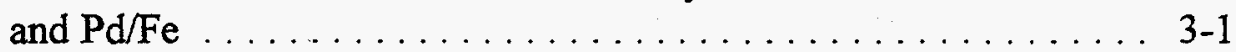

3.1.1 Batch Studies . . . . . . . . . . . . . . . . . . . . 3-2

3.2 Radionuclide/Trace Metal Removal with Fe Filings . . . . . . . . . 3-15

3.2.1 Batch Testing . . . . . . . . . . . . . . . . . 3-17

3.2.2 Column Studies with Fe and Resin . . . . . . . . . 3-17

4. Investigation of $\mathrm{Pd} / \mathrm{Fe}$ Surface $\ldots \ldots \ldots \ldots \ldots \ldots \ldots \ldots$ 4-1

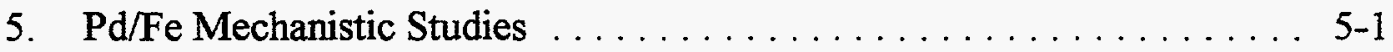

5.1 Experimental ... . . . . . . . . . . . . . . . . . . . 5-2

5.2 Carbon Cloth Cathodes $\ldots \ldots \ldots \ldots \ldots \ldots \ldots \ldots$. . . . . . . . .

5.3 Graphite Rod Electrodes $\ldots \ldots \ldots \ldots \ldots \ldots \ldots \ldots$ 5-7

5.4 Iron Wire Electrodes $\ldots \ldots \ldots \ldots \ldots \ldots \ldots . . . \ldots$. . . . . . . . . .

5.5 Palladium Gauze Electrodes . . . . . . . . . . . . . . . 5-7

5.6 Implications for the Reaction Mechanisms . . . . . . . . . . . 5-8

6. Longevity and Regeneration of $\mathrm{Pd} / \mathrm{Fe} \ldots \ldots \ldots \ldots \ldots \ldots$. . . . . . . . . . .

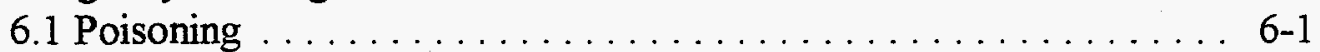

6.2 Loss of Palladium . . . . . . . . . . . . . . . . . . . 6-2

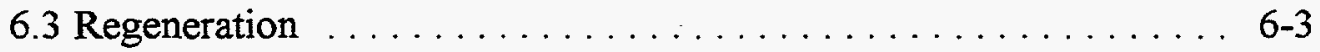

6.4 Discussion . . . . . . . . . . . . . . . . . . . . 6-6

7. Field Experiments . . . . . . . . . . . . . . 


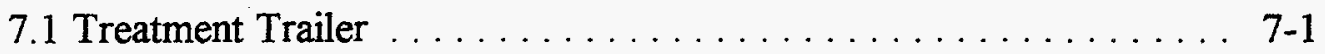

7.2 Treatment of $\mathrm{Tc}^{99}$ with Zero-Valence Iron $\ldots \ldots \ldots \ldots \ldots \ldots$ 7-5

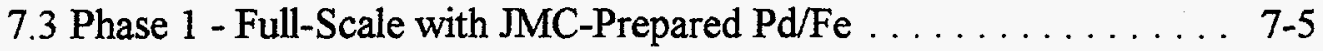

7.3.1 Pd/Fe Design Parameters . . . . . . . . . . . . . . . . 7-7

7.3.2 Field Test . . . . . . . .

7.3.3 Effects on Other Chemical Constituents .......... 7-10

7.4 Phase 2 - Small-Scale Experiment with JMC-Prepared Pd/Fe . . . . 7-11

7.5 Phase 3 - Small-Scale Field Test with Pd/Fe Prepared On-Site . . . 7-16

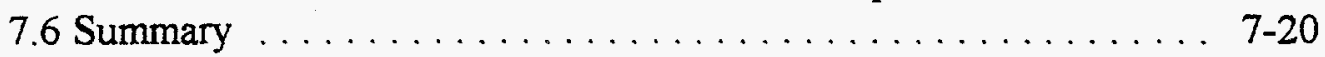

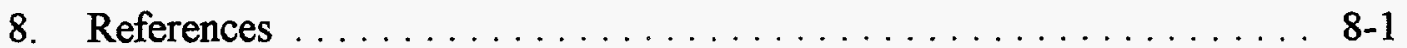


Figures

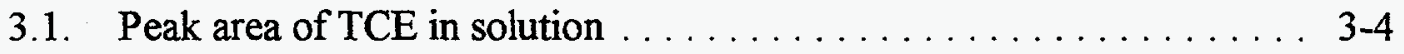

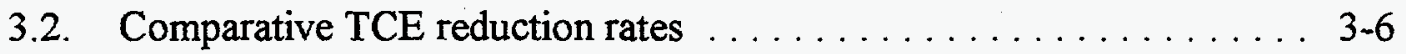

3.3. Peak area of dichloromethane $\ldots \ldots \ldots \ldots \ldots \ldots \ldots \ldots \ldots . . .4$

3.4 Mass of VOCs escaping from a 40-mL VOA vial with an adaptor cap and $10 \mathrm{~mL}$ of a high-level aqueous solution of VOCs ........ 3-8

3.5. Schematic diagram of zero-headspace extractor . . . . . . . . . 3-10

3.6. Kinetics and byproduct distribution from TCE degradation by zerovalence iron. Initial $\mathrm{pH}$ was 6.5 . Initial TCE concentration was 17.4 um $(2.3 \mathrm{ppm})$. The solution was buffered with $1 \mathrm{mM} \mathrm{NaHCO}_{3}$; $25 \mathrm{~g}$ of iron filings (Fisher, 40 -mesh) was added to $125-\mathrm{mL}$ solution.

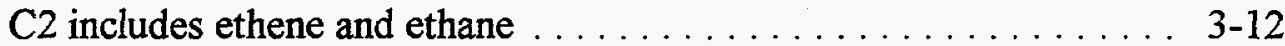

3.7. Kinetics and byproduct distribution from TCE reduction by palladized iron. Reduction of TCE with iron alone is shown as 1 . The conditions were $\mathrm{TCE}=15.3 \mathrm{um}(2 \mathrm{ppm}), \mathrm{NaHCO}_{3}=1 \mathrm{mM}, \mathrm{Ph}=6.525 \mathrm{~g}$ palladized (0.05\%) iron (iron is from Fisher, 40 mesh) in $125 \mathrm{~mL}$ of solution. $\mathrm{C} 2$ is a combination of ethene and ethane ......... 3-13

3.8. TCE analysis with ${ }^{14} \mathrm{C}$ tracer with scintillation counting. Experiment was conducted with $10 \mathrm{~g}$ iron filings (Fisher, 40 mesh) in 50-mL TCE solution. The solution contained $1 \mathrm{mM} \mathrm{NaHCO}, 71.6 \mathrm{um}$ $(9.4 \mathrm{ppm}) \mathrm{TCE} .{ }^{14} \mathrm{C}$ tracer was added to the TCE solution. The initial $\mathrm{pH}$ was 6.5

3.9. Te sorption by Master Builder iron filings $\ldots \ldots \ldots \ldots \ldots \ldots$ 3-18

3.10. Tc sorption by Fisher iron filings $\ldots \ldots \ldots \ldots \ldots \ldots \ldots \ldots .3-19$

3.11. Batch test removal of $\mathrm{Tc}^{99}$ using iron filings, PGDP well No. $66 \ldots \ldots 3-21$

3.12. Batch test removal of $\mathrm{Tc}^{99}$ using iron filings, PGDP well No. $186 \ldots 3-22$

3.13. Tc removal from Fisher iron filings column. Note: $\mathrm{C} / \mathrm{Co}=$ measured activity divided by the initial activity $\ldots \ldots \ldots \ldots \ldots \ldots \ldots \ldots \ldots \ldots \ldots$

3.14. Tc removal from resin column $\ldots \ldots \ldots \ldots \ldots \ldots \ldots \ldots \ldots . . \ldots \ldots$

3.15. Removal of $\mathrm{Tc}^{99}$ in a column experiment at PGDP ........ 3-27

4.1. Micro-PIXE surface analysis of $\mathrm{Pd} / \mathrm{Fe}$ filings $\ldots \ldots \ldots \ldots \ldots \ldots, 4-2$

4.2. XPS results for a clean, unreacted palladized iron film . . . . . . . 4-4

4.3. XPS results for a $\mathrm{Pd} / \mathrm{Fe}$ film following reaction with TCE $\ldots \ldots \ldots$. . . .

4.4. XPS results for a $\mathrm{Pd} / \mathrm{Fe}$ film after reaction with $\mathrm{PCB}$ and an aqueous rinse

4.5. (a) Binding energies of the $P d 3 d_{3 / 2}$ and the $P d 3 d_{5 / 2}$ peaks in the $x$-ray photoelectron spectrum of elemental Pd deposited on the iron surface. (b) $\mathrm{Pd} 3 \mathrm{~d}$ peaks of elemental $\mathrm{Pd}$ and $\mathrm{Pd}^{2+}$ species after deposition of a very low surface of palladium. The presence of Pd-O-Fe bonds is evident from the binding energies of the $\mathrm{Pd}^{2+}$ species. (c) $\mathrm{Pd} 3 \mathrm{~d}$ peaks after the iron surface with the Pd-O-Fe bonds was allowed to stand overnight in an ultra high vacuum 
4.6. $\mathrm{Fe} 2 \mathrm{p}$ photoelectron spectrum of an iron surface covered with a thin hydroxylated iron oxide film. The presence of elemental iron is confirmed by the presence of $\mathrm{Fe} 2 \mathrm{p}$ peaks at 707.1 and $720.3 \mathrm{eV}$

4.7. Pd 3d photoelectron spectrum of a heavy deposit of elemental palladium on a hydroxylated iron oxide surface. The peak shapes and peak widths show that only elemental palladium is present

4.8. (a) $\mathrm{Fe} 2 \mathrm{p}$ photoelectron spectrum of the hydroxylated iron oxide film. The presence of a shoulder at $707.1 \mathrm{eV}$ indicates that presence of elemental iron in addition to the multiple oxidation states of iron. (b) The $\mathrm{Fe} 2 \mathrm{p}$ photoelectron spectrum of the hydroxylated iron oxide film after its thickness was allowed to increase in moist air for 3 weeks. The $\mathrm{Fe}$ $3 p$ peaks of elemental iron are obscured by the thick hydroxylated iron oxide film

4.9. (a) Full-scan photoelectron spectrum of the $\mathrm{Pd} / \mathrm{Fe}$ surface. (b) Full scan photoelectron spectrum of the $\mathrm{Pd} / \mathrm{Fe}$ surface after exposure to an aqueous solution of saturated TCE. (c) Full-scan photoelectron spectrum of the $\mathrm{Pd} / \mathrm{Fe}$ surface in panel $\mathrm{b}$ washed twice with $3 \mathrm{M} \mathrm{HCl}$

5.1. Reaction vessel for electrochemical experiments used to evaluate mechanism of reduction by $\mathrm{Pd} / \mathrm{Fe}$.

5.2. Production of phenol at palladized carbon cloth electrodes under conditions of controlled potential of -0.700 volts vs SCE (-X), controlled current of $5.6 \mathrm{~mA} \mathrm{(-1-)}$, and at a constant current of $5.6 \mathrm{~mA}$ at a palladized graphite cathode (-+-). Degradation of 4-CP at palladized carbon cloth electrodes under conditions of controlled potential

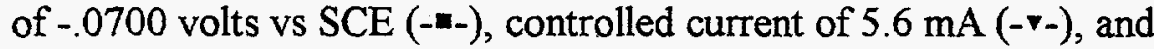
at a constant current of $5.6 \mathrm{~mA}$ at a palladized graphite cathode (-0-). . 5-6

5.3. Proposed mechanisms for the hydrodehalogenation of 4-CP to phenol.

a) Direct reduction at electrode surface. b) Hydrogenation at palladium catalyst surface. c) Adsorption of 4-CP at electrode substrate followed by hydrogenation at palladium island/electrode surface. . . . . . 5 5-9

6.1. Study of the lifetime of $\mathrm{Pd} / \mathrm{Fe}$ (time vs volume). . . . . . . . . . 6 6-4

6.2. Complexing acids are proposed for surface regeneration and metal/ radionuclide removal . . . . . . . . . . . . . . . . . . . 6-5

7.1. Schematic of treatment trailer used for field tests. . . . . . . . . . 7-2

7.2 Detailed view of columns used for field tests $\ldots \ldots \ldots \ldots \ldots \ldots$ 7-3

7.3 Plan view of treatment trailer layout $\ldots \ldots \ldots \ldots \ldots \ldots \ldots \ldots \ldots .47$

$7.4 \mathrm{Tc}(\mathrm{pCi} / \mathrm{g})$ distribution in Fe columns 580,000 gal of water treated . . 7-6

7.5 Number of times influent TCE concentration was reduced by $1 / 2$ as it passed through the $\mathrm{Pd} / \mathrm{Fe}$ treatment columns. . . . . . . . . 7-15

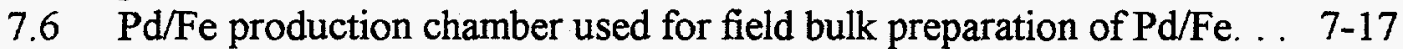

7.7 Comparison of field and laboratory prepared $\mathrm{Pd} / \mathrm{Fe}$ in laboratory batch tests 


\section{Tables}

1.1 Desired features of an in situ treatment module train $\ldots \ldots \ldots \ldots$ 1-3

1.2 Candidate processes for VOC and radionuclide removal or destruction 1-4

3.1 Observed rate constants for chlorinated ethenes in the presence of iron

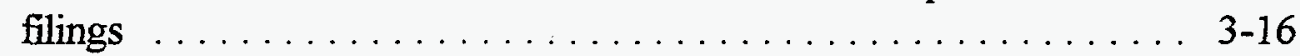

3.2 Laboratory analysis of $\mathrm{Tc}$ and iron filings batch samples, $\mathrm{pCi} / \mathrm{L} \ldots$. . 3-20

7.1 Phase 2 results, $\mathrm{ppb}$ - low concentration influent, $0.5 \mathrm{gal} / \mathrm{min} \ldots \ldots$ 7-14 


\section{Abbreviations, Acronyms, and Initialisms}

\begin{tabular}{|c|c|}
\hline $\mathrm{cm}$ & centimeter \\
\hline CMSs & corrective measure studies \\
\hline 4-CP & 4-chlorophenol \\
\hline 1,1-DCE & 1,1-dichloroethene \\
\hline $1,2-\mathrm{DCE}$ & 1,2-dichloroethene \\
\hline DO & dissolved oxygen \\
\hline DOE & U.S. Department of Energy \\
\hline ESCA & Electron Spectroscopy for Chemical Analysis \\
\hline $\mathrm{eV}$ & electron volt \\
\hline $\mathrm{Fe}$ & iron \\
\hline FID & flame ionization detector \\
\hline g & gram \\
\hline gal & gallon \\
\hline GC & gas chromatography \\
\hline h & hour \\
\hline HPLC & high-pressure liquid chromatography \\
\hline ISTR & In Situ Treatment/Recirculation \\
\hline JMC & Johnson-Matthey Corporation \\
\hline $\mathrm{K}_{2} \mathrm{PdCl}_{6}$ & potassium hexachloropalladate \\
\hline $\mathrm{KCP}$ & Kansas City Plant \\
\hline $\mathrm{keV}$ & kiloelectron volt \\
\hline $\mathrm{kg}$ & kilogram \\
\hline $\mathrm{L}$ & liter \\
\hline $\mathrm{mA}$ & milliampere \\
\hline $\mathrm{mCi}$ & millicurie \\
\hline $\mathrm{mg}$ & milligram \\
\hline $\min$ & minute \\
\hline $\mathrm{mL}$ & milliliter \\
\hline $\mathrm{mM}$ & millimole \\
\hline mol & mole \\
\hline $\mathrm{nm}$ & nanometer \\
\hline ORNL & Oak Ridge National Laboratory \\
\hline PCBs & polychlorinated biphenyls \\
\hline $\mathrm{pCi}$ & picocurie \\
\hline $\mathrm{Pd}$ & palladium \\
\hline $\mathrm{Pd} / \mathrm{Fe}$ & palladized iron \\
\hline PETC & Pittsburgh Energy Technology Center \\
\hline PGDP & Paducah Gaseous Diffusion Plant \\
\hline PIXE & Proton Induced X-Ray Emission \\
\hline PORTS & Portsmouth Gaseous Diffusion Plant \\
\hline $\mathrm{ppb}$ & parts per billion \\
\hline
\end{tabular}




$\begin{array}{ll}\text { ppm } & \text { parts per million } \\ \text { PTFE } & \text { polytetrafluoroethylene } \\ \text { Pt/Fe } & \text { platinized iron } \\ \text { RBS } & \text { Rutherford Backscattering Spectrometry } \\ \text { RCT } & \text { Research Corporation Technologies } \\ \text { s } & \text { second } \\ \text { SCE } & \text { saturated calomel electrode } \\ \text { SERS } & \text { Raman Spectroscopy, Surface Enhanced Raman Spectroscopy } \\ \text { SRBs } & \text { sulfur-reducing bacteria } \\ \text { Tc } & \text { technetium } \\ \text { TCE } & \text { trichloroethene } \\ \mu A & \text { micrampere } \\ \mu \text { m } & \text { micrometer } \\ \text { UofA } & \text { University of Arizona } \\ \text { UV } & \text { ultraviolet } \\ \text { VOCs } & \text { volatile organic compounds } \\ \text { vs } & \text { versus } \\ \text { XPS } & \text { X-Ray Photoelectron Spectroscopy } \\ \text { ZHEs } & \text { zero-headspace extractors }\end{array}$




\section{Acknowledgment}

Identifying, testing, and implementing innovative technologies will be required in order to meet the expectations identified in the Ten Year Plan. The Portsmouth Gaseous Diffusion Plant (PORTS) has hosted and funded many technology demonstrations. The cooperative working relationship with the regulator community, a history of successfully moving from the demonstration stage to remediation of an existing unit, and the available technical support have combined to make PORTS an ideal site for field demonstrating new ideas.

Many individuals and organizations have contributed to the successful completion of this project. Without the financial support and management assistance of the U.S. Department of Energy (DOE) Office of Environmental Restoration and Lockheed Martin Energy Systems (LMES) at PORTS, this project could not have been accomplished. The project team is grateful to the following PORTS individuals for their support to the project:
E. Gillespie
- DOE
J. Sheppard
- DOE
L. Kanter
- DOE
D. Taylor
- LMES
R. Barnett
- LMES (In Memorium)
D. Igou
- LMES
T. Houk
- LMES
J. Ervin
- LMES
G. Budzin
- LMES
B. Abke
- LMES
H. Sydnor
- LMES
P. Burleson
- LMES
M. Pelfrey
- Lockheed Martin Utility Services 


\section{Executive Summary}

This report describes the innovative treatment aspects of the project, In Situ Treatment of Mixed Contaminants in Groundwater. This project was a three and one-half year effort comprised of laboratory work performed at Oak Ridge National Laboratory (ORNL) and the University of Arizona (UofA) and fieldwork performed at the Department of Energy's (DOE) Portsmouth Gaseous Diffusion Plant (PORTS). Core funding for the overall project, which emphasized deployment of horizontal recirculation wells and simultaneous treatment of radioactive and hazardous organic wastes, was provided by DOE-EM-50, Office of Science and Technology, Subsurface Contaminants Focus Area. The plan in the original EM-50 project was to utilize conventional treatment approaches. However, ancillary funding from PORTS, several other DOE facilities, and private companies enabled innovative technologies using zero-valence iron and palladized iron $(\mathrm{Pd} / \mathrm{Fe})$ to be tested as part of this project.

Laboratory research conducted at ORNL and the UofA led to the discovery that zero-valence iron treated with a trace of palladium (Pd) (nominally $0.05 \%$ ) rapidly dechlorinated a wide range of hydrocarbons. Other research at ORNL and elsewhere has shown that many metals and radionuclides either precipitate or are adsorbed by zero-valence iron. Technetium (Tc) is particularly amenable to treatment of this type. Consequently, a combined approach using zero-valence iron for $\mathrm{Tc}$ and palladized iron ( $\mathrm{Pd} / \mathrm{Fe}$ ) for trichloroethene (TCE) was applied to a groundwater waste stream at the PORTS facility.

Laboratory research preparatory to the field tests demonstrated that $\mathrm{Pd} / \mathrm{Fe}$ dechlorinated TCE one to two orders of magnitude faster than untreated iron. Further studies examined the nature of the $\mathrm{Pd} / \mathrm{Fe}$ surface and evaluated the reaction mechanism. Work with $\mathrm{x}$-ray photoelectron spectroscopy demonstrated that $\mathrm{Pd}$ attaches to the iron surface in a two-step process whereby a Pd-oxygen bond forms first with $\mathrm{Pd}$ in the +2 oxidation state. The $\mathrm{Pd}$ is then rapidly further reduced to the elemental state as it plates on the Fe surface.

Mechanistic studies have demonstrated that $\mathrm{Pd} / \mathrm{Fe}$ reduces chlorinated hydrocarbons by hydrogenation. Hydrogen gas, formed because of the corrosion of $\mathrm{Fe}$, is absorbed by the Pd. The chlorinated hydrocarbon adsorbs to the iron and is then reduced by hydrogen at the $\mathrm{Pd} / \mathrm{Fe}$ interface.

Laboratory studies with zero-valence iron revealed a very high capacity for immobilization of Tc. In a column study, approximately an order of magnitude more Tccontaminated water could be treated by the iron as compared to a conventional ion 
exchange resin. The primary removal mechanism is believed to be reductive precipitation.

In the field test, approximately 600,000 gal of water were treated. Treatment was straightforward and completely effective for Tc. The influent concentration of Tc was lower than anticipated $(<20 \mathrm{pCi} / \mathrm{L})$. Nevertheless, all of the Tc contained in the treated water was adsorbed by approximately 12 in. of a coarse zero-valence iron.

Initial full-scale tests with $\mathrm{Pd} / \mathrm{Fe}$ were unsuccessful because of problems in the manufacture. The $\mathrm{Pd} / \mathrm{Fe}$ was prepared at a commercial facility and a subsequent inspection revealed that several important aspects of the manufacture were performed incorrectly. In particular, exposure to oxygen both in the air and in water was prolonged leading to oxidation and eventual failure of the material. Thus, the backup treatment approach, granular activated carbon, was implemented for the remainder of the field test. However, two smaller tests were performed with $\mathrm{Pd} / \mathrm{Fe}$. A smaller amount of commercially-prepared $\mathrm{Pd} / \mathrm{Fe}$ was used to treat water containing $1 \mathrm{ppm}$ of TCE. Although this material was only half as reactive as typical laboratory preparations, treatment results matched the laboratory kinetics for approximately 100 hours, at which time an equipment malfunction terminated the test and ruined the $\mathrm{Pd} / \mathrm{Fe}$.

Next, $30 \mathrm{~kg}$ of $\mathrm{Pd} / \mathrm{Fe}$ was prepared at the field site by ORNL personnel. This $\mathrm{Pd} / \mathrm{Fe}$ had the expected kinetic reactivity, being approximately twice as reactive as the second batch of commercially-prepared material. This was an important finding because it demonstrated that bulk preparations were possible. Previously, the largest batch of $\mathrm{Pd} / \mathrm{Fe}$ that had been prepared with this level of reactivity was approximately $50 \mathrm{~g}$. Unfortunately, the overall project had to be terminated because of cost and schedule considerations before an adequate field test could be performed on this new $\mathrm{Pd} / \mathrm{Fe}$.

In summary, the innovative treatment approaches showed that zero-valence iron is a very effective media for removing Tc from groundwater. Laboratory work with $\mathrm{Pd} / \mathrm{Fe}$ demonstrated the material's significant potential for treatment of chlorinated hydrocarbons. Unfortunately, the field studies did not provide an adequate test. The fieldwork did, however, yield the following important findings: laboratory kinetic data from batch tests could be used to predict field reactivity of commercially-prepared $\mathrm{Pd} / \mathrm{Fe}$ and a field-prepared bulk preparation matched the reactivity of $\mathrm{Pd} / \mathrm{Fe}$ prepared at the laboratory scale. These important findings will be used as the point of departure for additional research and testing. 


\section{Introduction}

This report constitutes the second of three final reports for the project entitled "In Situ Treatment of Mixed Contaminants in Groundwater." This report is limited to the innovative treatment aspects of the program. A report on pilot testing of the horizontal recirculation system was the first report of the series (Muck et al. 1996). A comprehensive report that focuses on the engineering, cost and hydrodynamic aspects of the project has also been prepared (Korte et al. 1997a).

The overall goal of this portion of the project was to package one or more unit processes, as modular components in vertical and/or horizontal recirculation wells, for treatment of volatile organic compounds (VOCs) [e.g., trichloroethene (TCE)] and radionuclides [e.g., technetium $(\mathrm{Tc})^{99}$ ] in groundwater. The project was conceived, in part, because the coexistence of chlorinated hydrocarbons and radionuclides had been identified as the predominant combination of groundwater contamination in the U.S. Department of Energy (DOE) complex (Riley et al. 1992). Thus, a major component of the project was the development of modules that provide simultaneous treatment of hydrocarbons and radionuclides. The project was a $31 / 2$-year effort that included screening, modeling, laboratory experimentation, and field demonstration. The project objectives included: (1) evaluation of horizontal wells for inducing groundwater recirculation, (2) development of below-ground treatment modules for simultaneous removal of VOCs and radionuclides, and (3) demonstration of a coupled system (treatment module with recirculation well) at a DOE field site where both VOCs and radionuclides are present in the groundwater.

The project was a direct extension of prior work with the DOE International Technology Exchange Program. Several countries, notably the former West Germany, have significant environmental restoration and waste management research and development programs. Confronted with contaminated land from the world wars and the postwar industrialization period, researchers have been actively developing and implementing technologies for effective environmental restoration. An investigation of German developments by Oak Ridge National Laboratory (ORNL) staff (Siegrist et al. 1993) determined that recirculation technologies had near-term potential for application at DOE sites. In addition, the investigation of German technologies also identified needs that would increase the applicability and utility of recirculation systems: (1) testing and demonstration of horizontal recirculation wells and (2) modular packaging of unit processes for downhole treatment of multiple contaminant classes. Accordingly, this project was initiated with funding from DOE's Office of Science and Technology, subsurface contamination focus area (EM-50). 
The initial project plan focused on coupling conventional treatment processes. However, the project team's simultaneous involvement with treatment media research enabled inclusion of innovative processes employing zero-valence iron and palladized iron $(\mathrm{Pd} / \mathrm{Fe})$. The evaluation of innovative treatment in this project could not have been accomplished without the project infrastructure provided by DOE-EM-50. However, specific funding for the zero-valence iron and $\mathrm{Pd} / \mathrm{Fe}$ work was provided by DOE-EM-40 from the Portsmouth Gaseous Diffusion Plant (PORTS) and Paducah Gaseous Diffusion Plant (PGDP), the Kansas City Plant (KCP) and by a private partner, Research Corporation Technologies (RCT). Field testing was performed at DOE's PORTS site near Piketon, Ohio.

\subsection{Technology Screening}

The initial project activity was the screening and preliminary evaluation of candidate treatment processes for use in treating mixed contaminants (VOCs and radionuclides). Treating mixed contaminants presents unusual difficulties. Typically, VOCs are the most abundant contaminants, but the presence of radionuclides results in additional health concerns that must be addressed by a treatment approach vastly different from that used for VOCs. Furthermore, the presence of radionuclides may yield mixed-solid wastes if the VOCs are treated by conventional means (e.g., pump-and-treat with aboveground carbon adsorption). These issues were specifically addressed in the evaluation of candidate treatment processes for testing in this program. Because no research or development of a particular process was to be performed, the technology review focused on technologies that could be readily adapted and integrated for use with mixed contaminants. The objective was to couple emerging or available processes into treatment modules for use in situ. To guide the evaluation and screening effort, major groundwater plumes at DOE's PORTS and PGDP sites were chosen as primary candidates for an eventual field demonstration.

This evaluation and screening effort led to selection of a set of promising treatment processes for initial study. These processes were selected from those that were commercially available or emerging, because they appeared compatible with an in situ treatment module system and offered a high probability of successful performance in that application. Table 1.1 summarizes the features desired in the treatment module. A safe, effective, and efficient process was the overall goal. Efficient removal and destruction processes are desirable in order to limit the treatment time (objectives 1 and 2). Successful completion of the project included general-public and site-worker protection (objective 3). Objective 4 reflected project cost and resource effectiveness. Processes that destroy and/or concentrate contaminants may achieve desired minimization of secondary waste streams (objectives 5 through 7). Most processes targeted single contaminants or classes 
Table 1.1. Desired features of an in situ treatment module train

1. Remove/destroy VOCs (e.g., TCE) by $90 \%$ in one pass.

2. Reduce radionuclide (e.g., $\mathrm{Tc}^{99}$ ) concentration by $90 \%$ in one pass.

3. Minimize occupational exposure of site workers and potential exposure of general public.

4. Demonstrate that the reliability/operability/maintainability of the processing system is high.

5. Minimize secondary waste streams.

6. Destroy VOCs in preference to removal.

7. Concentrate radionuclides.

8. Processes must retain operability in the presence of multiple classes of mixed waste.

9. No mixed waste produced.

10. Demonstrate a process that has general application to DOE sites.

of compounds. This project sought to develop approaches that would work effectively in the presence of multiple contaminants (objective 8). Generation of mixed waste was undesirable (objective 9). Obviously, an effective design for general DOE use was desirable (objective 10).

This identification of treatment technologies was accomplished through a group effort that included meetings and contacts with technology experts, additional small-group meetings, and literature searches. Once technologies were selected, individual experts were requested to provide evaluations. The technology reviewers were provided with a specific reporting format and with ranges of contaminant concentrations and treatment-unit flow rates representative of the potential field sites (Korte et al. 1994). Based on the selection of the PORTS and PGDP facilities as probable field-test sites, chlorinated hydrocarbons and $\mathrm{Tc}^{99}$ were the target contaminants.

Table 1.2 lists the processes that were evaluated. These processes were identified by attendees at an initial scoping meeting. The candidate processes were selected based on known treatment rates and efficiencies and compatibility with in situ treatment of the target analytes. The planned approach was to package the technologies as modular components for use with horizontal or vertical recirculation wells. The modules were to be located in situ and to be used independently or in combination to treat the mixed contaminants. 
Table 1.2. Candidate processes for $\mathrm{VOC}$ and radionuclide removal or destruction

\begin{tabular}{ll}
\hline \multicolumn{1}{c}{ Candidate processes } & Target \\
\hline Stripping, with aboveground treatment of the gas stream & VOCs \\
Advanced oxidation processes, UV/peroxide & VOCs \\
$\begin{array}{l}\text { Photocatalytic destruction }\left(\mathrm{TiO}_{2} \text { ), liquid-phase }\right. \\
\text { destruction }\end{array}$ & VOCs \\
Reductive dechlorination using zero-valence metal & \\
Radionuclide precipitation & VOCs \\
Reduction and sorption using zero-valence metal & Radionuclides \\
Selective ion exchange & Radionuclides \\
Selective sorption (ion exchange and adsorption) & Radionuclides \\
Organic sorbent mixtures & Radionuclides \\
Biodegradation in situ with injection of treatment agents & VOCs, \\
Surfactant-enhanced bioremediation & radionuclides \\
Reduction/sorption by Al and Fe $\mathrm{O}_{3}$ & VOCs \\
Photocatalytic membrane & VOCs, \\
\hline
\end{tabular}

\subsubsection{VOC Treatment Process Screening}

The VOC candidate process screening resulted in the selection of air stripping as the process for use in the initial treatment program. Reductive dechlorination with zero-valence metals and organic sorbents were retained for further consideration because of ongoing research being conducted by this project's investigators. The other candidate processes were eliminated because they were deemed too cumbersome for downhole use or because treatment success was too uncertain (Korte et al. 1994). 


\subsubsection{Radionuclide Treatment Process Screening}

The radionuclide candidate process screening resulted in the selection of selective ion exchange as the appropriate process for the initial treatment program. Sorption with zero-valence metals and sorption with organic sorbents were retained for further consideration as above. The other processes were eliminated again because they were too cumbersome or because success was too uncertain. 


\section{Treatment Process Selection}

It was recognized at the outset of the project, that research into new treatment methods was very active. Indeed, other research being conducted by the principal investigators for this project resulted in the application of zero-valence metals in the treatment scheme rather than air stripping/ion exchange as initially selected with the screening process. The other research being conducted included a series of DOE-EM-40 funded literature, laboratory, and field studies funded by the Pittsburgh Energy Technology Center (PETC), PGDP, PORTS, and the KCP. Each of these entities was interested in the potential application of zero-valence iron to chlorinated solvent degradation and/or metal or radionuclide removal. The work that was conducted was used to support corrective measures studies (CMSs) for hazardous waste sites under the purview of the particular facility. The performance of this work led to the discovery that $\mathrm{Pd} / \mathrm{Fe}$ degraded chlorinated hydrocarbons an order of magnitude or more faster than untreated zero-valence iron (Muftikian et al. 1995; Korte et al. 1997b). Moreover, Pd/Fe degraded polychlorinated biphenyls (PCBs) and dichloromethane which are not degraded by zero-valence iron. This discovery was performed in conjunction with researchers at the University of Arizona (UofA). RCT, a venture capital/technology transfer company filed a patent on the process, which was issued in March of 1997 (No. 5,611,936), on behalf of the UofA and began a program to license the patent to the private sector.

In the meantime, studies supporting CMS activities at PORTS and PGDP demonstrated that zero-valence iron was effective at removing $\mathrm{Tc}^{99}$ (Clausen et al. 1995; Gu et al. 1996; Muck et al. 1995). Consequently, the decision was made to test zero-valence iron for $\mathrm{Tc}^{99}$ removal and $\mathrm{Pd} / \mathrm{Fe}$ for the destruction of chlorinated hydrocarbons (see Sect. 2.3 and 2.4).

\subsection{Special Concerns of Recirculation and Coupled Treatment}

Treating groundwater in a recirculation mode with coupled processes involves difficulties not encountered for conventional ex-situ treatment. The selection of treatment methods must address the effects the processes have on each other and on the aquifer. For example, air stripping does not couple very well with the use of $\mathrm{Fe}$ to remove $\mathrm{Tc}^{99}$. The primary mechanism for $\mathrm{Tc}$ removal by $\mathrm{Fe}$ is believed to be reductive precipitation ( $\mathrm{Gu}$ et al. 1996). Thus, oxygen removal is necessary before $\mathrm{Tc}$ can be reduced, but oxygen is also the principal clogging agent for $\mathrm{Fe}$ columns or barriers (Mackenzie et al. 1997). Thus, to use air stripping with $\mathrm{Fe}$ without risk of clogging the well or aquifer would require the use of nitrogen as 
the stripping fluid. Using nitrogen would have added significantly to the cost and complication of treatment.

Treated, recirculated, groundwater might also change the subsurface environment. For example, the Gallia aquifer at PORTS, which was being treated in this project, is relatively low in oxygen and contains dissolved $\mathrm{Fe}$ in some locations. With air stripping, there was concern that oxygen injected during reinjection would both precipitate $\mathrm{Fe}$ and stimulate growth of $\mathrm{Fe}$-oxidizing bacteria-a widely-recognized problem in southern Ohio. Such problems could lead to clogging of the well and the aquifer. In addition, with ion exchange there is the problem that the resin would absorb a certain amount of VOC-containing water and, hence, would always have to be tested to determine if it were a mixed waste. Likewise, stripping is always accompanied by scaling from metal precipitation, sedimentation, and microbial growth. These solid phases would surely contain $\mathrm{Tc}^{99}$ and require additional testing.

After reviewing these considerations, it was concluded that $\mathrm{Fe}, \mathrm{Pd} / \mathrm{Fe}$, ion exchange resin, and granular activated carbon would provide combinations compatible with each other and with the Gallia aquifer. For example, in the $\mathrm{Fe}-$ $\mathrm{Pd} / \mathrm{Fe}$ system, any oxygen in the groundwater would initially be removed by the $\mathrm{Fe}$, which would simultaneously remove the $\mathrm{Tc}^{99}$ (see Sect. 3.2). Water entering the $\mathrm{Pd} / \mathrm{Fe}$, therefore, would be free of both oxygen and $\mathrm{Tc}{ }^{99}$. Thus, the $\mathrm{Pd} / \mathrm{Fe}$ would be protected from clogging and would not become a mixed waste. The $\mathrm{Fe}$ also had the facility of slowly reducing chlorinated VOCs such that, after a few hours or days of storage following removal from the system, it would contain only $\mathrm{Tc}^{99}$ and would not be a mixed waste. The only effect on the aquifer would be the injection of soluble Fe which was already present.

\subsection{Backup Treatment Approaches}

The laboratory and field tests had provided a high degree of certainty that elemental Fe would be effective for removing $\mathrm{Tc}^{99}$. Nevertheless, there was concern regarding clogging because of the formation of iron oxides, sulfates, and carbonates. Thus, a commercial ion exchange resin was considered the back-up for the treatment of $\mathrm{Tc}^{99}$.

Field use of $\mathrm{Pd} / \mathrm{Fe}$ for VOC destruction was considered much more uncertain than the use of $\mathrm{Fe}$ to remove Tc. The material had never been prepared in bulk and Johnson-Matthey Corporation (JMC), the supplier hired by RCT, used proprietary preparation methods. Although the laboratory tests were promising, there were indications that the JMC-prepared material might not be sufficiently rugged. Thus, granular activated carbon was considered the backup. 
Some discussion is appropriate for the selection of carbon. Carbon is often considered an inferior approach for VOC cleanup because the contaminants are transferred from one media to another. However, carbon is particularly useful for using in situ in a horizontal well as this project was attempting to demonstrate. For example, carbon is light in weight and available in bulk. Thus, it could be easily deployed in canisters of various sizes including those which would fit in the arm of a horizontal well. In addition, carbon was also deemed the most useful surrogate for $\mathrm{Pd} / \mathrm{Fe}$ in an operational sense. The $\mathrm{Fe}$ would still remove the oxygen and $\mathrm{Tc}^{99}$ and would dechlorinate residual VOCs when taken off line. The difference in the $\mathrm{Fe}-\mathrm{C}$ system as compared to the $\mathrm{Fe}-\mathrm{Pd} / \mathrm{Fe}$ system, therefore, is that the VOC portion of the treatment relied on sorption and removal rather than on destruction. In other words, the carbon would have to be treated for removal of the sorbed VOCs. It should be noted that any of these configurations satisfied the initial intent of the project which was aimed at coupled, conventional treatment. Innovative treatment only became possible because of the additional work performed with funding from the additional sources mentioned in the Introduction.

\subsection{PORTS Support}

The project could not have been conducted without the strong and resolute support of the PORTS facility. PORTS funded much of the site preparation and well construction and provided direct funding to ORNL. Overall support from PORTS amounted to more than one million dollars. Most of that support was for infrastructure and construction of the horizontal wells. Support for treatment research was limited to approximately $\$ 30 \mathrm{~K}$ for the In Situ Treatment/Recirculation (ISTR) project. Those funds were used for laboratory work at ORNL and the UofA. PORTS, however, also funded treatability studies needed for a CMS that included laboratory treatment of $\mathrm{Tc}^{99}$ with iron and dechlorination of TCE with $\mathrm{Pd} / \mathrm{Fe}$ (Muck et al. 1995; Korte et al. 1995a). That work had considerable synergy with the ISTR project requirements and, indeed, was necessary for the field test of $\mathrm{Fe}$ and $\mathrm{Pd} / \mathrm{Fe}$. Funding for these efforts was approximately $\$ 150 \mathrm{~K}$.

\subsection{Commercial Partner Support}

As noted in the Introduction, a patent has been issued for the $\mathrm{Pd} / \mathrm{Fe}$ technology on behalf of the UofA by RCT. RCT, therefore, had an interest in seeing that the material was used and provided a trailer for the field test. This trailer, described in Sect. 5.1, was provided as a gift to ORNL and the DOE and is now available for use at other sites. RCT's direct investment, specific to the project at PORTS, was approximately $\$ 55 \mathrm{~K}$. 
Similarly, JMC, as one of the few suppliers of precious metal materials, has an interest in the development of a commercial market for $\mathrm{Pd} / \mathrm{Fe}$. Consequently, JMC tested several preparation processes at no cost to the project. Small quantities were prepared and submitted to ORNL for testing. Ultimately, JMC prepared two bulk shipments at their factory in New Jersey. The initial bulk shipment was purchased by RCT at an estimated cost of $\$ 12 \mathrm{~K}$. However, JMC expended considerable internal time at no cost to the project. Subsequently, JMC and RCT shared the cost of a second smaller bulk shipment. Finally, JMC provided ORNL, free of charge, the Fe and Pd salt used in the third and final $\mathrm{Pd} /$ Fe preparation used in this project. That final preparation was performed onsite at PORTS by ORNL personnel. JMC's direct support to the project exceeded $\$ 10 \mathrm{~K}$ but internal activities accounted for considerably more. 


\section{Laboratory Pilot Treatment Testing}

The DOE-EM-50 portion of this project did not include laboratory research because the stated objective was to couple conventional treatment processes. However, synergism with related projects enabled laboratory research to affect the choice of treatment method. The laboratory work was funded by various DOEEM-40 entities as noted in the Introduction.

\subsection{Dechlorination of Chlorinated Solvents by Zero-Valence Iron and $\mathrm{Pd} / \mathrm{Fe}$}

The dehalogenation of chlorinated solvents by zero-valence iron has become the subject of intensive research and development as a potentially cost-effective, passive treatment for contaminated groundwater (Gillham and O'Hannesin 1992, Gillham and O'Hannesin 1994; O'Hannesin and Gillham 1992; O'Hannesin et al. 1995; Vogan et al. 1994; Korte et al. 1995b; Liang et al. 1995; 1997). This treatment process is based on the fact that zero-valence iron is an effective reducing agent for many redox-reactive species. Thermodynamically, dehalogenation occurs through a dual-electron transfer from $\mathrm{Fe}^{0}$ to the halogenated hydrocarbons, resulting in an oxidized $\mathrm{Fe}$ ion, a dehalogenated hydrocarbon, and a halogen ion, $\mathrm{X}^{-}$:

$$
\mathrm{Fe}^{0}+\mathrm{R}-\mathrm{X}+\mathrm{H}^{+}=>\mathrm{Fe}^{2+}+\mathrm{R}-\mathrm{H}+\mathrm{X}^{-}
$$

Although detailed reaction pathways and mechanisms are still being investigated, the reaction is believed to be a heterogeneous surface reaction. As such, degradation rates vary among Fe filings obtained from different sources as a result of differences in surface characteristics such as specific surface area; surface chemical composition, and extent of surface oxidation (Gillham and O'Hannesin 1994; Horney et al. 1995; Liang et al. 1997). Laboratory studies have suggested that complete dechlorination (for example: from TCE to ethylene or ethane) in a single step is unlikely and that stepwise dechlorination must take place on the metal surface (O'Hannesin 1993; Gillham and O'Hannesin 1994; Matheson and Tratnyek 1994; Sivavec and Horney 1995; Liang et al. 1995; Puls et al. 1995). More recently, a $\beta$-elimination process with formation of the intermediate chloroacetylene has been suggested as the dominant reaction pathway for TCE (Sivavec et al. 1997). These laboratory studies also show that compounds containing fewer chlorines such as chloroethene (vinyl chloride) are more difficult to dechlorinate than the more highly chlorinated compounds such as TCE.

In collaboration with the UofA, researchers in the Environmental Sciences Division at ORNL found that a bimetallic preparation of Fe with a small amount 
of palladium (Pd) (nominally $0.05 \%$ by weight) was a superior reductant for TCE (Korte et al. 1995b, 1997b; Muftikian et al. 1995; Liang et al. 1997; Grittini et al. 1996). The bimetallic system yielded dechlorination kinetics that were one to two orders of magnitude faster than those for zero-valence iron alone. Although palladization increases the cost of the reactive $\mathrm{Fe}$, the amount of filings required to achieve the same level of dechlorination is significantly reduced due to more rapid degradation rates. Furthermore, more complete dechlorination has been observed with the bimetallic substrate than with $\mathrm{Fe}$ alone (Liang et al. 1997).

\subsubsection{Batch Studies}

For preliminary experiments with $\mathrm{Pd} / \mathrm{Fe}$, the one-carbon chlorinated compounds and the unsaturated two-carbon chlorinated compounds were obtained as follows: TCE and $\mathrm{CCl}_{4}$ from Fisher Scientific Co., Fair Lawn, New Jersey; 1,1-dichloroethene (1,1-DCE), cis-1,2-dichloroethene (1,2-DCE) and trans-1,2-DCE from Chem Service Inc., West Chester, Pennsylvania; perchloroethene from Sigma Chemical Co., St. Louis, Missouri; and $\mathrm{CHCl}_{3}$ and $\mathrm{CH}_{2} \mathrm{Cl}_{2}$ from Mallinckrodt Specialty Chemicals Co., Paris, Kentucky. The purity of these compounds was checked by gas chromatography (GC). Besides the peak that originated from the organic compound of interest, no other peaks that could be attributed to organic impurities were detected [limit of detection 1 parts per million (ppm)].

Elemental $\mathrm{Fe}$ of varying degrees of purity and with varying amounts of surface oxides and elemental impurities was used in this work. The $\mathrm{Fe}$ was obtained from three different commercial sources: Fe filings were obtained from Baker and Adamson, New York, New York, Fe particles $(10 \mu \mathrm{m}$ in diameter and $99.9 \%$ pure) from Aldrich Chemical Co., Milwaukee, Wisconsin; and Fe filings (40 mesh), from Fisher Scientific Co. After the $\mathrm{Fe}$ was acid washed with $\mathrm{HCl}$ and palladized with potassium hexachloropalladate $\left(\mathrm{K}_{2} \mathrm{PdCL}_{6}\right)$, no significant differences were found in preliminary batch experiments. $\mathrm{K}_{2} \mathrm{PdCL}_{6}$ was obtained from Aldrich Chemical Co.

To prepare $\mathrm{Pd} / \mathrm{Fe}$ for laboratory use, a $10 \mathrm{~g}$ sample of $\mathrm{Fe}$ was washed initially with five to six $25 \mathrm{~mL}$ portions of $6 \mathrm{M} \mathrm{HCl}$ solution followed by five to six $25 \mathrm{~mL}$ portions of distilled water. Subsequently, it has been determined that a single acid wash is sufficient. Fifteen to $20 \mathrm{mg}$ of $\mathrm{K}_{2} \mathrm{PdCL}_{6}$ were dissolved in 30 to $40 \mathrm{~mL}$ of distilled water. This red-orange solution of $\mathrm{K}_{2} \mathrm{PdCL}_{6}$, when added with stirring to the acid-washed $\mathrm{Fe}$, turned pale yellow after the redox reaction (2) had occurred.

$$
2 \mathrm{Fe}^{0}+\mathrm{PdCl}_{6}^{-2} \rightarrow 2 \mathrm{Fe}^{+2}+\mathrm{Pd}^{0}+6 \mathrm{Cl}^{-}
$$

The $\mathrm{Pd} / \mathrm{Fe}$ was washed 3 to 4 times with distilled water and used, without drying, in the dechlorination experiments. 
A $12 \mathrm{~mL}$ glass vial equipped with a Teflon septum fitted into a cap was used for the preliminary batch dechlorination reactions. The $\mathrm{Pd} / \mathrm{Fe}, 3.6 \mathrm{~g}$ of the $10 \mu \mathrm{m}$ particles from Aldrich Chemical Co., or $3.6 \mathrm{~g}$ of Fe filings from Baker and Adamson, or $10 \mathrm{~g}$ of 40-mesh Fe particles from Fisher Scientific Co., was placed in contact with $10 \mathrm{~mL}$ of a solution of the halogenated organic compound, (20 ppm in water), in the glass vial. After the vial was shaken vigorously, samples were withdrawn with a syringe for $\mathrm{GC}$ analysis. It is recognized that collecting repetitive samples from a glass vial capped with a Teflon septum results in some loss of sample. However, as shown in Fig. 3.1 the experiments were sufficiently reproducible and the difference in reaction rates of palladized and unpalladized $\mathrm{Fe}$ was sufficiently large that effects due to leakage could be discounted for the purposes of this comparison.

The results of the batch experiments shown in Fig. 3.1 indicate that $10 \mathrm{~g}$ of $\mathrm{Pd} / \mathrm{Fe}$ ( $5 \mathrm{mg} \mathrm{Pd}$ on $10 \mathrm{~g} \mathrm{Fe}, 40$ mesh from Fisher Scientific Co.) can dechlorinate $10 \mathrm{~mL}$ of a $20 \mathrm{ppm}$ solution of TCE in approximately $3 \mathrm{~min}$, whereas $10 \mathrm{~g}$ of the same $\mathrm{Fe}$, but unpalladized, ( 40 mesh Fisher Scientific Co.) reacts much more slowly. Similar results were obtained with the $10 \mu \mathrm{m}$ particles of palladized and unpalladized Fe (Fig. 3.1). In these batch experiments, the concentration of TCE in the solution was followed as a function of time. The initial rapid and subsequent gradual decrease of the TCE in the solution, (Fig. 3.1) in the presence of unpalladized $\mathrm{Fe}$, is caused in part by the equilibration of the TCE between the headspace and the solution and not by the reaction of the TCE with unpalladized Fe. This was confirmed by the absence of any detectable reaction products in the first $30 \mathrm{~min}$. When the reaction was followed for much longer periods of time with $10 \mu \mathrm{m}$ particles of unpalladized $\mathrm{Fe}$, intermediate reaction products, 1,1-DCE and 1,2-DCE (cis and trans) were identified in addition to ethene. With palladized $10 \mu \mathrm{m}$ particles of $\mathrm{Fe}$, however, the only reaction product that was identified was ethane. Any reaction products that were present at concentrations less than $1 \mathrm{ppm}$ could not be detected in these preliminary experiments.

The $\mathrm{pH}$ of an aqueous solution in contact with $\mathrm{Pd} / \mathrm{Fe}$ was monitored for $14 \mathrm{~min}$ and was observed to increase from 6.68 to 8.51 . In addition, hydrogen gas (confirmed by GC) was evolved when the $\mathrm{Pd} / \mathrm{Fe}$ was contacted with water. The extent to which reactions 3)-(6) occur accounts for the changes in $\mathrm{pH}$ that occur during the time in which $\mathrm{Pd} / \mathrm{Fe}$ is in contact with the aqueous solution.

$$
\begin{aligned}
& \mathrm{Fe}^{0} \rightarrow \mathrm{Fe}^{-2}+2 \mathrm{e}- \\
& 2 \mathrm{e}^{-}+1 / 2 \mathrm{O}_{2}+\mathrm{H}_{2} \mathrm{O} \rightarrow 20 \mathrm{H}^{-} \\
& \mathrm{Fe}^{-2}+\mathrm{H}_{2} \mathrm{O} \rightarrow \mathrm{Fe}(\mathrm{OH})^{+}+\mathrm{H}^{+} \\
& \mathrm{Fe}^{0}+2 \mathrm{H}^{+} \rightarrow \mathrm{Fe}^{+2}+\mathrm{H}_{2}
\end{aligned}
$$




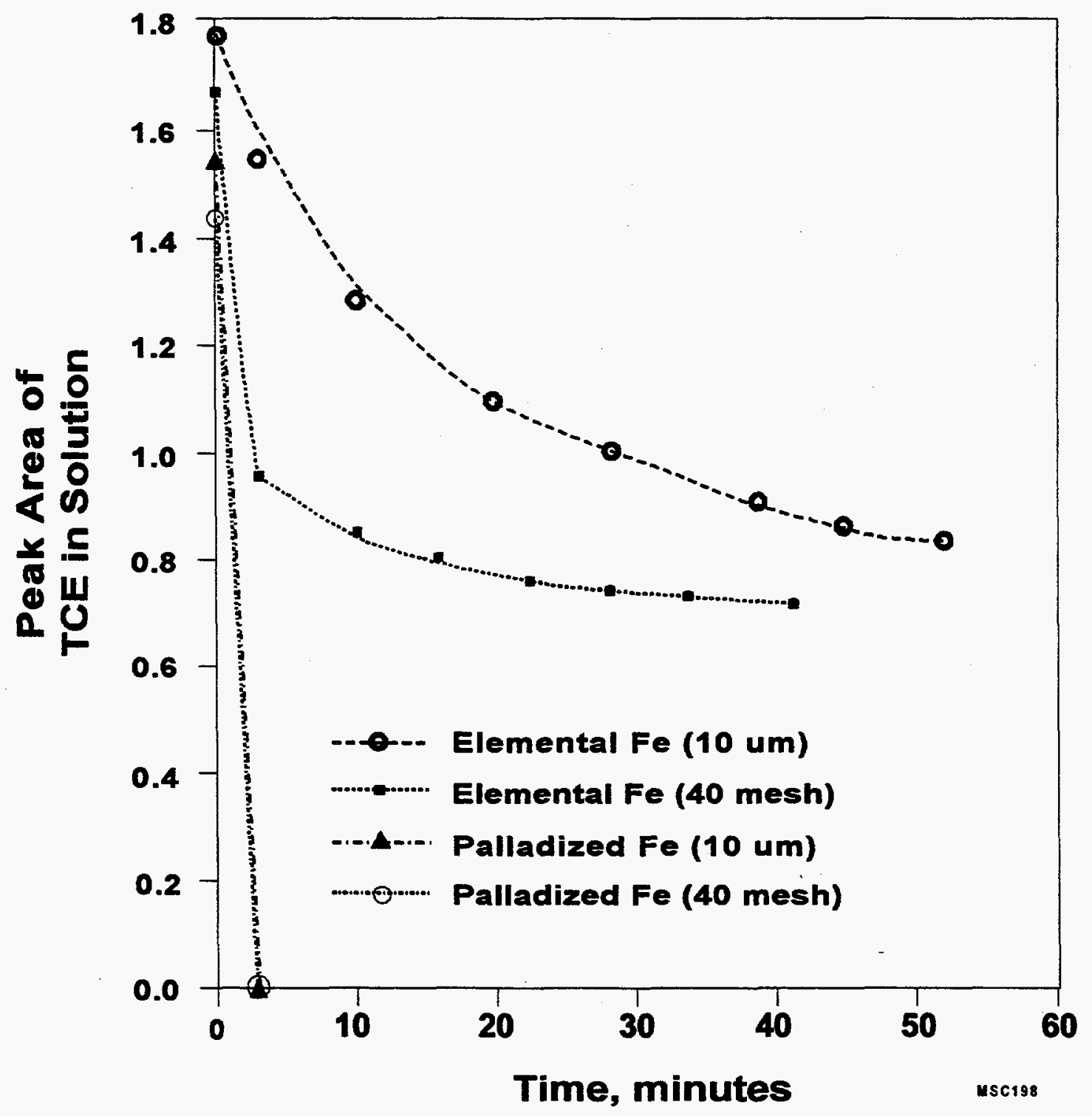

Fig. 3.1. Peak area of TCE in solution. 
The rate of the hydrodechlorination of TCE may be governed by a number of factors: the surface area of the $\mathrm{Pd}$, the $\mathrm{Pd}: \mathrm{Fe}$ ratio on the Fe surface, the extent of surface oxidation, the extent of mixing, the concentration of the TCE, the $\mathrm{pH}$ of the solution and the dissolved oxygen (DO) in the solution. In these preliminary experiments, no attempts were made to quantify the effect of each of these factors on the reaction rate. However, it is significant to note that data obtained subsequently show little or no effect of surface area (West et al. 1997) when the Fe is palladized.

As noted previously, the reductive dechlorination of TCE occurs on the metal surface. The electrons released as a result of the oxidation of the elemental $\mathrm{Fe}$ (equation 3), and the hydrogen gas produced (equations 3,5, and 6) may participate in the rapid reductive hydrodechlorination of TCE. Hydrogen probably plays a lesser role when Fe is the reductant (Matheson and Tratnyek 1994) but is vital to the reaction with $\mathrm{Pd} / \mathrm{Fe}$ (Chapter 5, Cheng et al. in press). It is obvious that a complex sequence of reactions governs the reaction rate and that the following equation merely represents the stoichiometry of the overall hydrodechlorination of TCE.

$$
2 \mathrm{Cl}_{2} \mathrm{C}=\mathrm{C}(\mathrm{H}) \mathrm{Cl}+3 \mathrm{Fe}^{0}+5 \mathrm{H}_{2}-2 \mathrm{C}_{2} \mathrm{H}_{6}+6 \mathrm{Cl}^{-}+3 \mathrm{Fe}^{+2}
$$

The hydrodechlorination of perchloroethene, 1,1-DCE, and cis and trans 1,2-DCE also occur rapidly with $\mathrm{Pd} / \mathrm{Fe}$. These reductions also yield the reaction products, $\mathrm{C}_{2} \mathrm{H}_{6}, \mathrm{Fe}^{+2}$ and $\mathrm{Cl}^{-}$as shown in equation 7. Moreover, as shown on Fig. 3.2, subsequent experiments with improved analytical capability demonstrated that when $\mathrm{Pd} / \mathrm{Fe}$ is compared to untreated $\mathrm{Fe}$, under identical conditions, the DCE isomers are not detected and chloroethene persists at a concentration one order of magnitude less.

The dechlorination of the one-carbon compounds, $\left(\mathrm{CCl}_{4}, \mathrm{CHCl}_{3}\right.$, and $\left.\mathrm{CH}_{2} \mathrm{Cl}_{2}\right)$, was also studied with $\mathrm{Pd} / \mathrm{Fe}$. The rate of the dechlorination of $\mathrm{CCl}_{4}$ is much faster than that of the two-carbon unsaturated compounds (e.g., TCE). As the number of chlorine atoms decreases, from carbon tetrachloride to chloroform and finally to dichloromethane, (Fig. 3.3) the rate of the dechlorination reaction decreases. It should be noted, however, that dichloromethane is not dechlorinated with $\mathrm{Fe}$ alone (Gillham and O'Hannesin 1994).

In order to perform more detailed studies, additional care was taken because of the volatility of the compounds under study. Recent research at ORNL has focused on the handling of water and soil samples contaminated with VOCs such as TCE and chloroethene (Gu et al. 1995; West et al. 1995; Siegrist et al. 1997). These studies have shown that the leakage of VOCs from containers, though generally recognized, can be quite severe, and that rigorous precautions are required to ensure there are no losses of volatile contaminants. An example of leakage from 40-mL vial is shown in Fig. 3.4. Considering that chloroethene's vapor pressure 


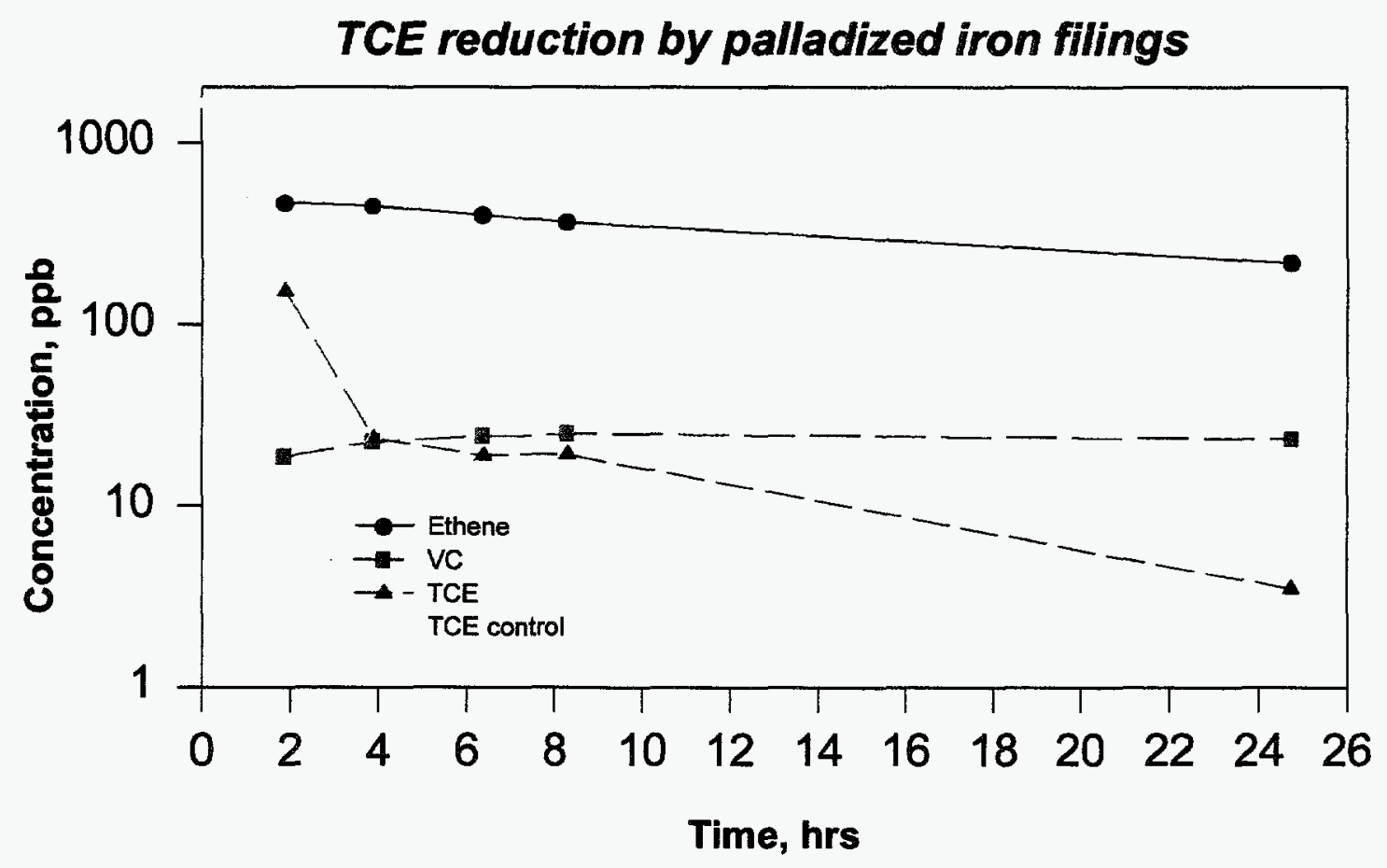

TCE reduction by iron filings

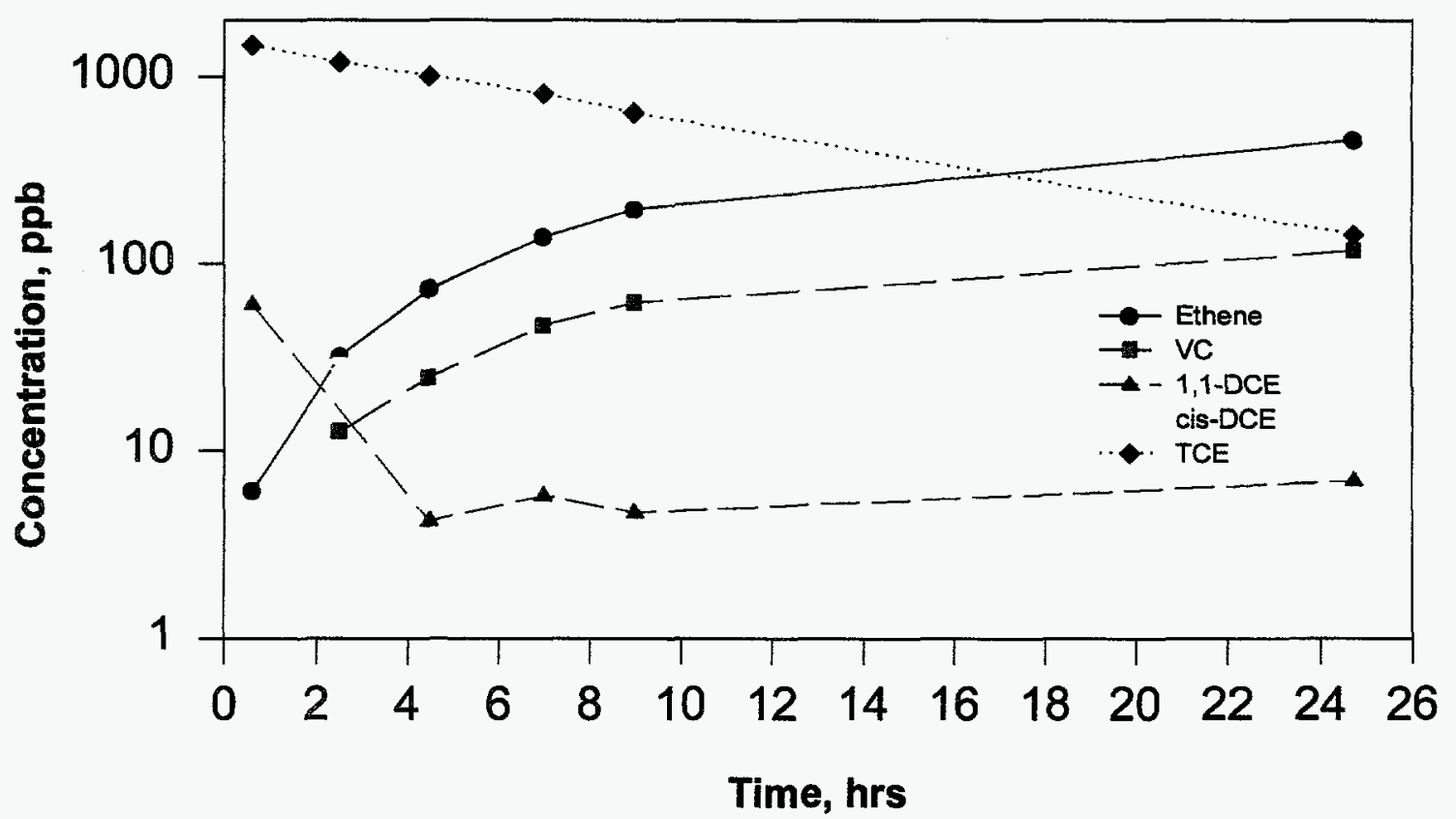

Fig. 3.2. Comparative TCE reduction rates. 


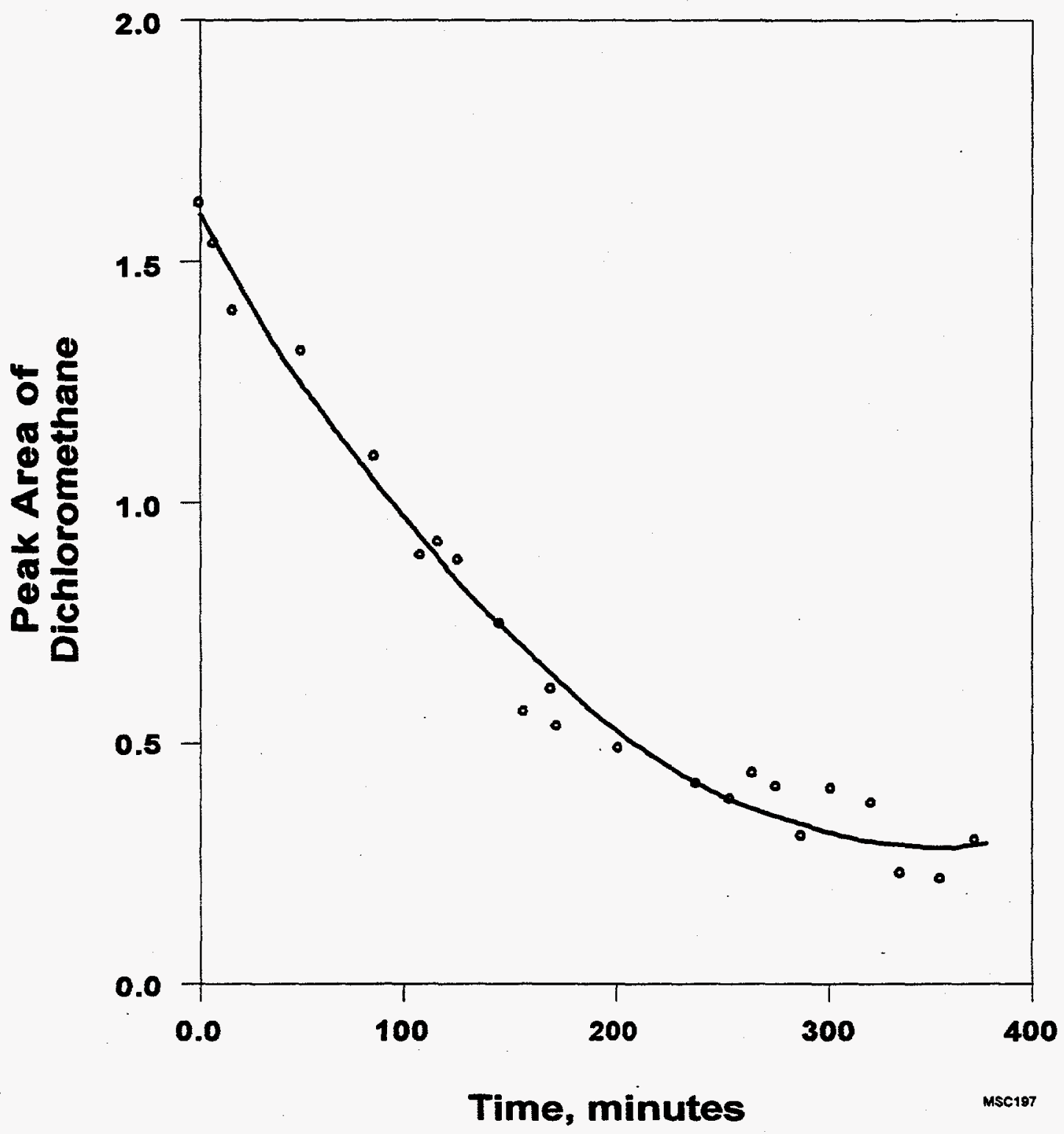

Fig. 3.3. Peak area of dichloromethane. 


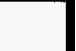


(2600 $\mathrm{mm} \mathrm{Hg}$ ) is more than 40 times that of TCE (60 $\mathrm{mm} \mathrm{Hg}$ ) (Barbee 1994), loss of chloroethene when conducting batch experiments is a potential problem.

The concern regarding loss of byproducts is also based on the fact that researchers in the field have not always reported a high mass balance for carbon as indicated by reported values of $73 \%$ (Orth and Gillham 1995) and approximately $90 \%$ (Sivavec and Horney 1995). Chloride mass balances near 100\% have been reported (Haitko and Baghel 1995), but an excellent mass balance for $\mathrm{Cl}^{-}$does not necessarily mean that chloroethene is not above acceptable levels.

Thus, more detailed batch studies were performed with zero-headspace extractors [(ZHEs), Associated Design and Manufacturing Co., Alexandria, Virginia]. The ZHEs prevent losses due to leakage (Siegrist et al. 1997). Figure 3.5 is a schematic diagram of a ZHE. The reagents are contained in Sect. 1, and headspace is excluded by forcing the piston up with pressurized gas.

In these batch experiments, $25 \mathrm{~g}$ of 40 -mesh Fe filings (Fisher Scientific, Pittsburgh, Pennsylvania) were added to the ZHEs, which contained $125 \mathrm{~mL}$ of an aqueous solution (nominally $2 \mathrm{mg} / \mathrm{L}$ of TCE). A solution without the addition of the $\mathrm{Fe}$ filings was prepared in a ZHE as a control. The ZHEs were mounted on a rack and rotated at 30 revolutions $/ \mathrm{min}$. Samples were collected at various intervals without exposing the fluid to the atmosphere. The $\mathrm{Pd} / \mathrm{Fe}$ was prepared as described previously.

Sampling and analysis of TCE and its products were performed as follows. At selected time intervals, 5-mL aqueous samples were collected from the ZHEs and immediately injected into a purge-and-trap concentrator (Tekmar 3000, Tekmar, Cincinnati, Ohio). Samples from the concentrator were analyzed for reaction byproducts by GC (HP-5890 Series II, Hewlett-Packard, Wilmington, Delaware) with a flame ionization detector (FID). The initial oven temperature was $30^{\circ} \mathrm{C}$, and ramped to $150^{\circ} \mathrm{C}$. The detector temperature was $300^{\circ} \mathrm{C}$ and the carrier gas was helium with a flow rate of $7 \mathrm{~mL} / \mathrm{min}$. The $\mathrm{GC}$ was equipped with a $0.53-\mathrm{mm}$ capillary column (DB-624, J\&W Scientific, Folsom, California).

Experiments were also performed with ${ }^{14} \mathrm{C}$-labeled TCE. The labeled samples were analyzed with a scintillation counter (Packard $2000 \mathrm{CA}$, Packard Instrument Co., Downers Grove, Illinois). These experiments were designed to evaluate the physical loss of TCE in the experimental apparatus (ZHEs). The same experimental conditions were maintained as for the unlabeled samples, except that a 


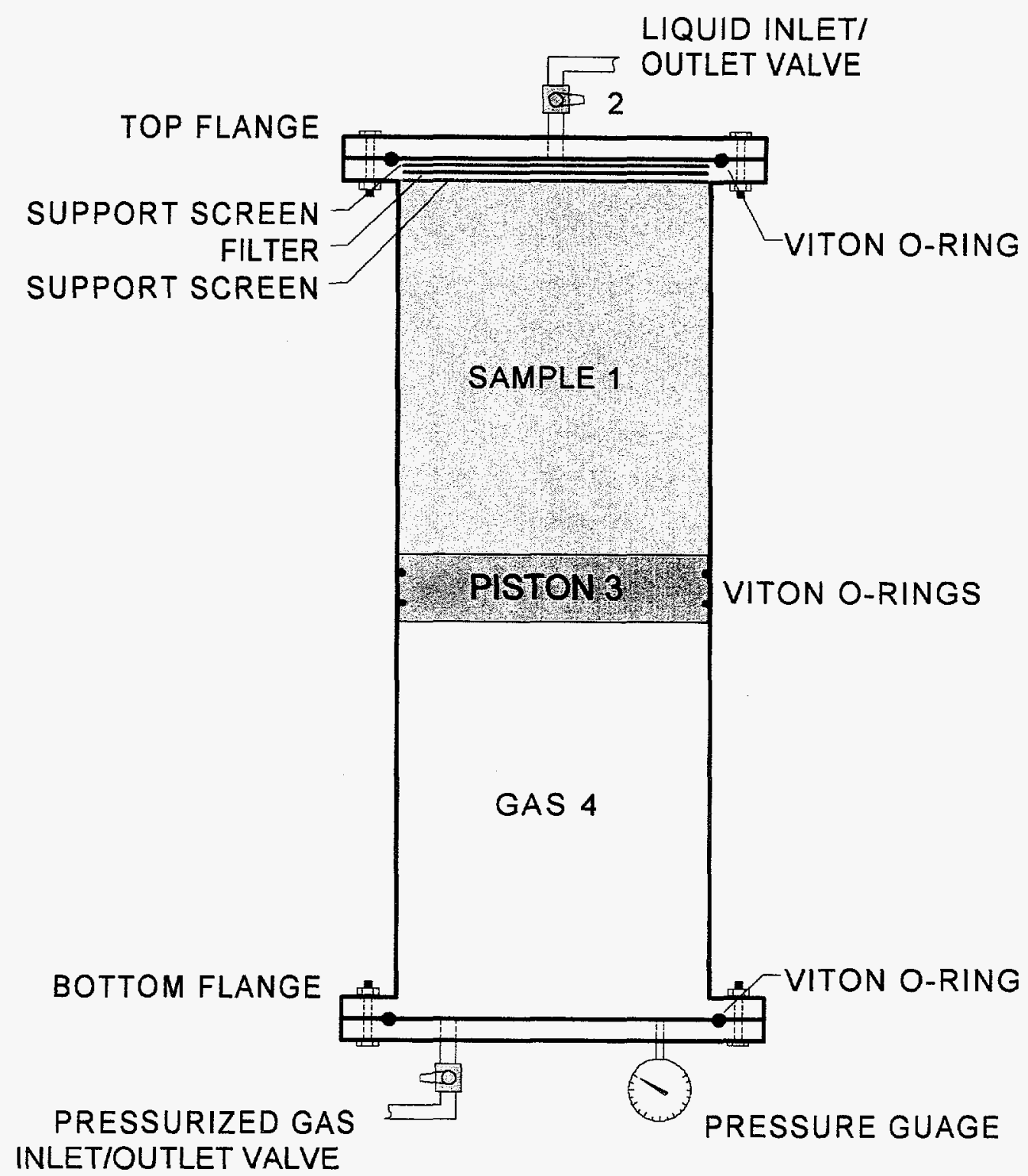

Fig. 3.5. Schematic diagram of a zero-headspace extractor. 
small fraction of ${ }^{14} \mathrm{C}$-labeled TCE was introduced into the TCE solution. Samples were collected for simultaneous $\mathrm{GC}$ analysis and scintillation counting. For the latter, $9 \mathrm{~mL}$ of the scintillation cocktail Ecolume (ICN Biomedicals Inc., Irvine, California) were added to the $1 \mathrm{~mL}$ of sample.

\section{Results}

\section{Persistence of Byproducts}

Figure 3.6 presents typical results for the reaction of Fe filings with TCE. The control showed no loss of TCE. The ethene content in the treated samples increased rapidly as the TCE was degraded. It should be noted that it was not possible to distinguish ethene from ethane with the experimental apparatus available. Thus, these two compounds are reported as total $\mathrm{C} 2$ in Figs. 3.6 and 3.7, which represent the formation and persistence of the byproducts. During the length of this experiment, the cis-1,2-DCE began to decline and the chloroethene persisted. Trans-1,2-DCE was not detected. Experiments with an initial TCE concentration of $5 \mathrm{ppm}$ were performed for as long as 73 days. Under those conditions the cis-1,2-DCE decreased to less than 10 parts per billion (ppb), but the amount of chloroethene stabilized at approximately $140 \mathrm{ppb}$ on day three and remained constant throughout the experiment.

Figure 3.7 presents results from the same experiment as in Fig. 3.6, except $\mathrm{Pd} / \mathrm{Fe}$ was used to accomplish the dechlorination. As with the untreated Fe, chloroethene that formed during the reaction with the $\mathrm{Pd} / \mathrm{Fe}$ persisted for as long as the experiment was continued. In contrast to the untreated $\mathrm{Fe}$, the persistent concentration of chloroethene was an order of magnitude less, averaging approximately $10 \mathrm{ppb}$ for these experiments. It is important to note that no DCE isomers were observed with the $\mathrm{Pd} / \mathrm{Fe}$, while both 1,1-DCE and cis-1,2-DCE were observed during the reaction with untreated $\mathrm{Fe}$. If DCE isomers are produced during the reaction with $\mathrm{Pd} / \mathrm{Fe}$, they were degraded to nondetectable levels prior to collection of the first sample.

\section{Mass Balance}

Carbon mass balance was initially attempted by means of ${ }^{14} \mathrm{C}$-TCE. However, as shown in Fig. 3.8, both control and treated samples lost TCE. Parallel analyses by $\mathrm{GC}$ did not indicate any loss from the control samples. The loss of ${ }^{14} \mathrm{C}-\mathrm{TCE}$, therefore, apparently occurred in the scintillation cocktail after removal of sample from the ZHEs. The greater leakage from the treated samples (Fig. 3.8) is attributed to the escape of the more volatile byproducts, such as chloroethene, ethene, ethane, and the DCEs. Consequently, experiments with labeled TCE were 


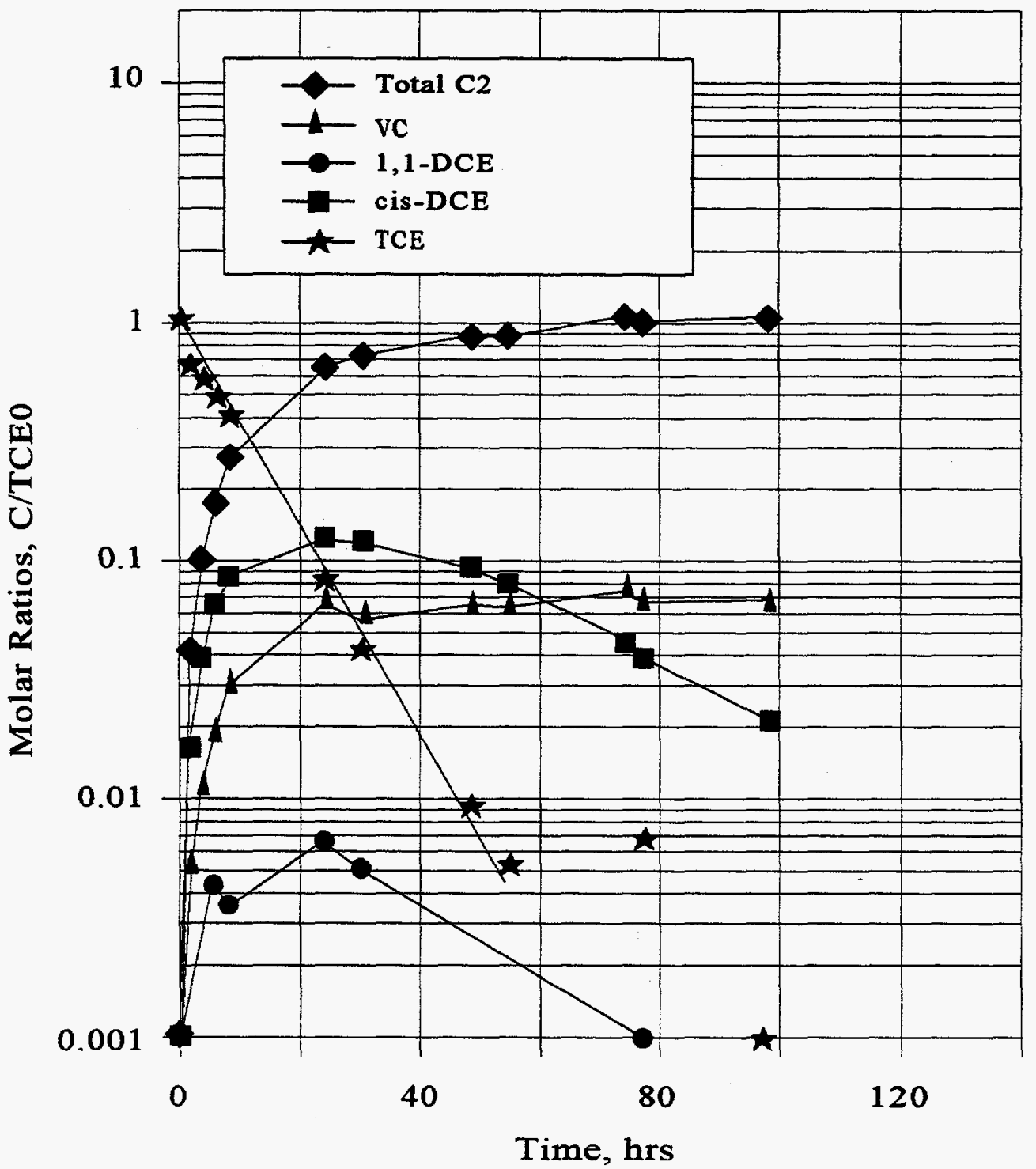

MSC191

Fig. 3.6. Kinetics and byproduct distribution from TCE degradation by zerovalence iron. Initial $\mathrm{pH}$ was 6.5 . Initial TCE concentration was $17.4 \mathrm{um}(2.3 \mathrm{ppm})$. The solution was buffered with $1 \mathrm{mM} \mathrm{NaHCO} ; 25 \mathrm{~g}$ of iron filings (Fisher, 40-mesh) was added to $125-\mathrm{mL}$ solution. $\mathrm{C} 2$ includes ethene and ethane. 


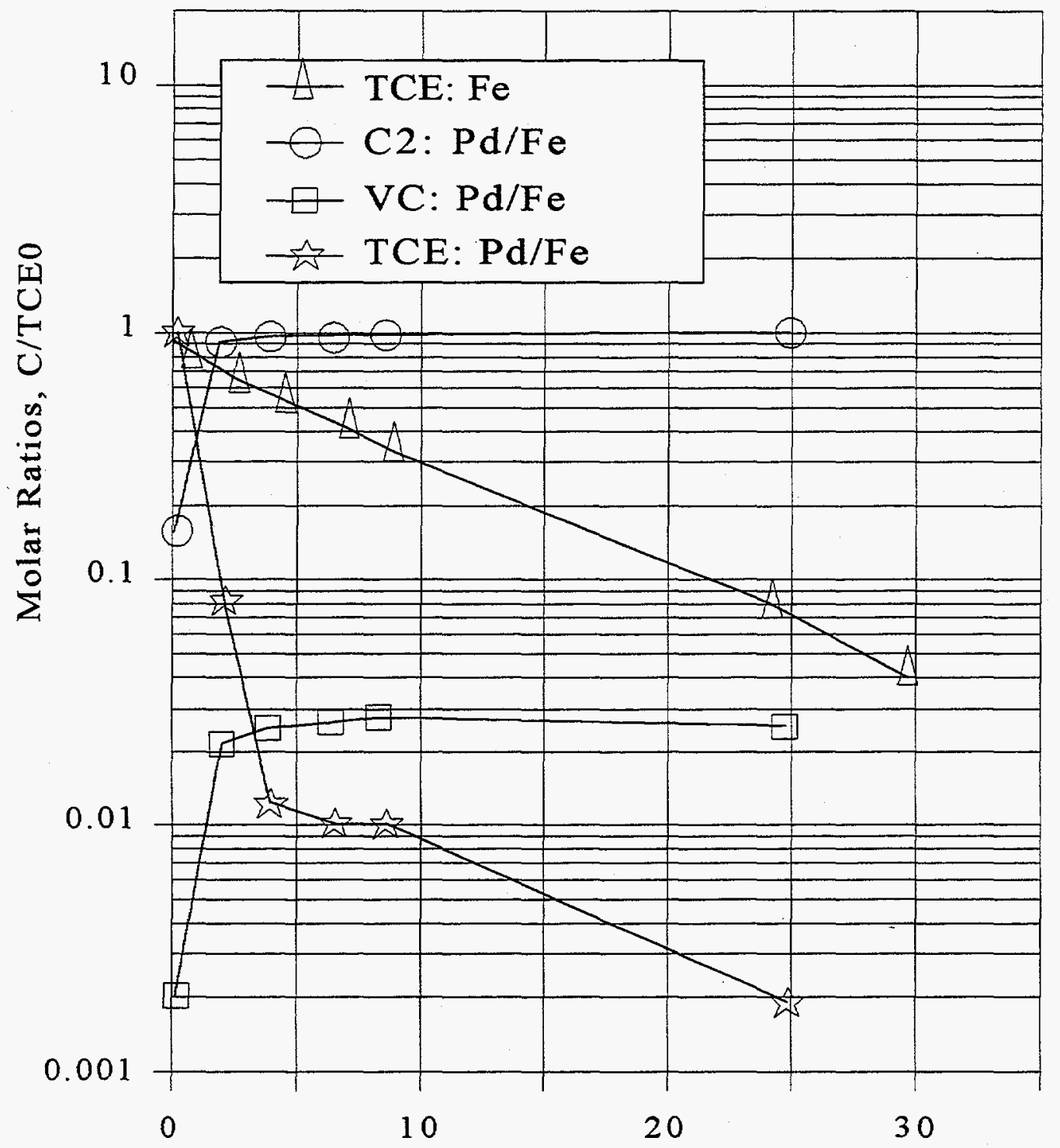

Time, hrs

$\operatorname{MSC1} 90$

Fig. 3.7. Kinetics and byproduct distribution from TCE reduction by palladized iron. Reduction of TCE with iron alone is shown as $\mathbf{m}$. The conditions were TCE $=15.3$ um ( $2 \mathrm{ppm}$ ), $\mathrm{NaHCO}_{3}=1 \mathrm{mM}, \mathrm{Ph}=6.525 \mathrm{~g}$ palladized $(0.05 \%)$ iron (iron is from Fisher, 40 mesh) in $125 \mathrm{~mL}$ of solution. $\mathrm{C} 2$ is a combination of ethene and ethane. 


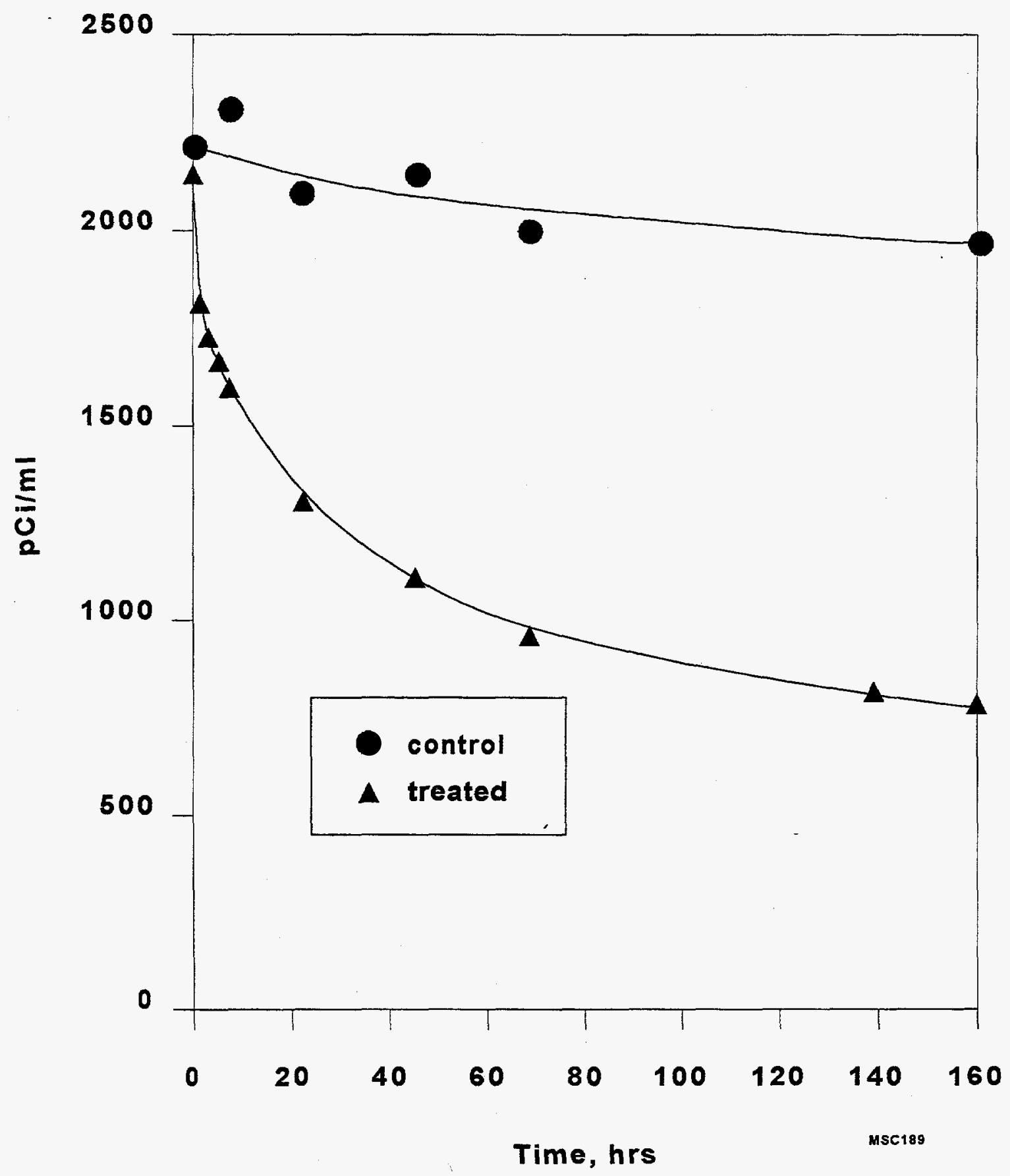

Fig. 3.8. TCE analysis with ${ }^{14} \mathrm{C}$ tracer with scintillation counting. Experiment was conducted with $10 \mathrm{~g}$ iron filings (Fisher, $40 \mathrm{mesh}$ ) in 50-mL TCE solution. The solution contained $1 \mathrm{mM} \mathrm{NaHCO}, 71.6 \mathrm{um}(9.4 \mathrm{ppm})$ TCE. ${ }^{14} \mathrm{C}$ tracer was added to the TCE solution. The initial $\mathrm{pH}$ was 6.5 . 
discontinued. Problems with labeled TCE have been reported previously (Gu et al. 1995).

As shown in Fig. 3.8, the concentration of TCE without addition of Fe remained constant in the ZHEs for the duration of the experiments. Unfortunately, the carbon balance for the reaction in the ZHEs was hampered by the inability to separate ethene and ethane. Ethane has a higher response factor with the FID detector, although it is believed to be present in lower concentrations than ethene. In addition, separate $\mathrm{GC}$ analyses indicated that the ratio of ethane to ethene increased with time. With calibration performed with ethene, the carbon mass balance was greater than $100 \%$. The overestimation of total carbon increases with time because the ethane-to-ethene ratio increases. Keeping in mind that the carbon mass balance is slightly greater than $100 \%$, after $24 \mathrm{hrs}$ the byproduct mixture from the reaction of $\mathrm{Fe}$ with TCE contained approximately $12 \%$ cis-1,2DCE, $8 \%$ chloroethene, and $<1 \%$ of 1,1-DCE.

\section{Half-lives}

The data in Figs. 3.6 and 3.7, which compare results from experiments that used similar amounts of chloroethene, cis-DCE, and trans-DCE as starting materials, were used to calculate half-lives for the reductive dechlorination of TCE (Table 3.1). The TCE half-life with untreated Fe was $7.4 \mathrm{hrs,} \mathrm{which} \mathrm{compares} \mathrm{reason-}$ ably well with other reported values from batch reactions (Gillham and O'Hannesin 1994; Sivavec and Horney 1995) conducted under somewhat different conditions. For $\mathrm{Pd} / \mathrm{Fe}$, the TCE half-life under the same experimental conditions was $35 \mathrm{~min}$. The more rapid reaction is consistent with the observation that chlorinated intermediates were less persistent with time.

In summary, these experiments established that the bimetallic system, $\mathrm{Pd} / \mathrm{Fe}$ was preferable to elemental $\mathrm{Fe}$ for the rapid and complete hydrodechlorination of one carbon and two carbon chlorinated compounds. The combination of Pd, the "promoter" metal, and Fe, the "base" metal, appears to be a useful bimetallic system for the rapid hydrodechlorination of one-carbon and two-carbon chlorinated compounds.

\subsection{Radionuclide/Trace Metal Removal with Fe Filings}

Laboratory studies focused on the treatment of $\mathrm{Tc}^{99}$ because it is the principal inorganic contaminant at the PORTS and PGDP sites. The most commonly found oxidation states of $\mathrm{Tc}$ are zero-valence $\mathrm{Tc}, \mathrm{Tc}^{+4}$, and $\mathrm{Tc}^{+7}$. The most stable chemical species of $\mathrm{Tc}$ in aqueous solution is pertechnetate $\left(\mathrm{TcO}_{4}{ }^{-}\right)$, which can be quite mobile in the environment under oxidizing conditions. The mobility is a 
Table 3.1. Observed rate constants for chlorinated ethenes in the presence of iron filings

\begin{tabular}{|c|c|c|c|c|}
\hline Compound & $\begin{array}{c}\text { Initial conc } \\
\qquad \mu \mathrm{m}\end{array}$ & $\begin{array}{l}\text { ntration } \\
\mathrm{mg} / \mathrm{L}\end{array}$ & $\begin{array}{l}\text { Observed rate, hour }{ }^{-1} \text { for } \\
\text { zero-valence iron }\end{array}$ & Half-life \\
\hline Chloroethene ${ }^{a}$ & 25.0 & 1.56 & 0.0107 & 64.7 \\
\hline cis-DCE & 28.6 & 2.8 & 0.0196 & 35.2 \\
\hline trans-DCE & 27.3 & 2.6 & 0.0504 & 13.7 \\
\hline \multirow[t]{2}{*}{ TCE } & 26.3 & 3.5 & 0.0931 & 7.41 \\
\hline & & \multicolumn{3}{|c|}{ Rate $\left(\right.$ hour ${ }^{-1}$ ) for $\mathrm{Pd} / \mathrm{Fe}$} \\
\hline TCE & 15.58 & 2 & 1.17 & 0.59 \\
\hline
\end{tabular}

${ }^{a}$ Dissolved in methanol

Note: $200 \mathrm{~g} / \mathrm{L}$ of Fisher 40 -mesh $\left(327 \mathrm{~m}^{2} / \mathrm{L}\right) \mathrm{Fe}$ filings, $1 \mathrm{mM}$ bicarbonate solution.

Initial $\mathrm{pH}=6.5$

consequence of the negative charge, which results in a repulsion from most soil surfaces because they are also negatively charged.

Experiments with elemental $\mathrm{Fe}$, ferrous sulfide, and various other metals suggest that Tc precipitation and sorption is possible under both aerobic and anaerobic conditions (Bostick and Evans-Brown 1988; Bostick et al. 1990). In a reducing environment, the solubility of Tc ranges from $1.32 \times 10^{-8}$ to $2.56 \times 10^{-9} \mathrm{~mol} / \mathrm{L}$ and is controlled by the solid species $\mathrm{TcO}_{2} \cdot \mathrm{nH}_{2} \mathrm{O}$, with $\mathrm{n}=1.63 \pm 0.28$ (Meyer et al. 1987; Wildung et al. 1979; Lieser and Bauscher 1987). The solubility minimum occurs at a pH of approximately 3 . In other words, the sorption of $\mathrm{Tc}$ in an anaerobic environment is primarily due to the formation of insoluble $\mathrm{TcO}_{2}$ and in some cases $\mathrm{Tc}_{2} \mathrm{~S}_{7}$ (Cataldo et al. 1978; Lee and Bondietti 1983; Walton et al. 1986).

Under aerobic conditions, soil does not tend to adsorb Tc and other metal oxyanions unless the organic matter content is high and/or Fe and aluminum oxides are present (Bowen 1966; Korte et al. 1976; Wildung et al. 1977; Wildung et al. 1986; Schulte and Scoppa 1987). (The Gallia formation, the target contaminated zone at PORTS, does contain high levels of Fe oxyhydroxides in some locations.) In summary, although Tc can be removed from water with synthetic sorbents, 
research has shown that materials that reduce $\mathrm{Tc}$ show the greatest removal efficiencies (Bostick and Evans-Brown 1988; Del Cul et al. 1992; Cantrell 1995).

Work reported in the literature has focused on wastes with high concentrations of Tc (e.g., raffinate with Tc concentration of $13 \mathrm{mg} / \mathrm{L}$ or $228 \mathrm{mCi} / \mathrm{L}$ ). There are no literature data on the treatment of groundwater that contains the relatively low concentrations of $\mathrm{Tc}$ (on the order of hundreds or thousands of $\mathrm{pCi} / \mathrm{L}$ ) that are observed at PORTS.

\subsubsection{Batch Testing}

A series of batch studies were performed with water from a contaminated well at PORTS (Muck et al. 1995). Figures 3.9, 3.10, and Table 3.2 present the results from laboratory analyses of these batch studies. The first set of samples which was collected over a five-day period consisted of the following: equipment rinsate samples; samples of untreated groundwater (I); control samples (C); Master Builder Fe filing samples (FeM); and Fisher Fe filing samples (FeF). The field blank sample for all four equipment rinsate samples showed no detectable concentrations of Tc. All of the batch tests using Fe filings show a marked decrease in Tc concentrations (Figs. 3.9 and 3.10). The Tc removal at the end of the tests was approximately $80 \%$.

Batch experiments conducted with contaminated groundwater at the PGDP also indicated that removal of $\mathrm{Tc}$ with $\mathrm{Fe}$ filings was feasible. Forty-mesh Fe filings provided by Master Builder were used in the experiments (Clausen and Richards 1994). The half-life of soluble Tc in contact with Fe ranged from less than $1 / 2 \mathrm{~h}$ to $8 \mathrm{~h}$. The data also indicated that approximately $40 \%$ removal of Tc occurs essentially instantaneously (Figs. 3.11 and 3.12 ). This suggests that $\mathrm{Tc}$ is precipitating. The tailing effect of activity levels with time could be due to a slower secondary precipitation mechanism or sorption of Tc to the Fe surface.

\subsubsection{Column Studies with Fe and Resin}

Column experiments were conducted to evaluate the capacity of zero-valence iron in comparison to Bio-Rad MSZ-1 resin-a resin, similar to those used within DOE for Tc removal. Fe filings (Fisher Scientific) with a mesh size of 40 (average diameter of $420 \mu \mathrm{m}$ ) were used for the experiments. The resin was analytical grade, monodispersed (average diameter of $550 \mu \mathrm{m}$ ), and chemically similar to the technical grade Dowex hydroxide-form resin that is used at the PORTS facility.

Glass columns of 1-cm diameter were used in the experiments, with the lengths adjusted from $4 \mathrm{~cm}$ to $12 \mathrm{~cm}$. Solution was introduced at the bottom inlet and 


\section{Tc Batch Samples}

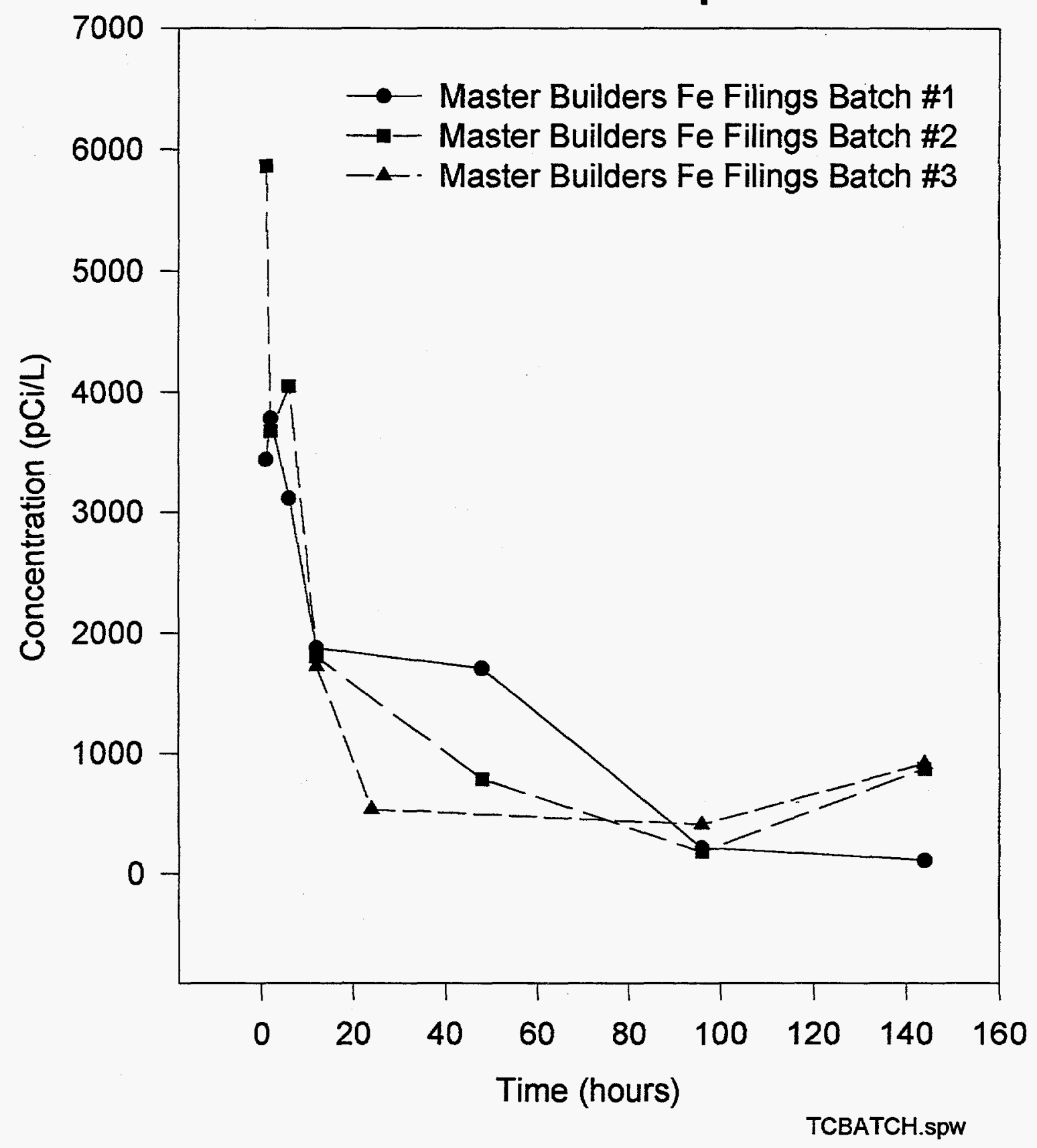

Fig. 3.9. Tc sorption by Master Builder iron filings. 


\section{Tc Batch Samples}

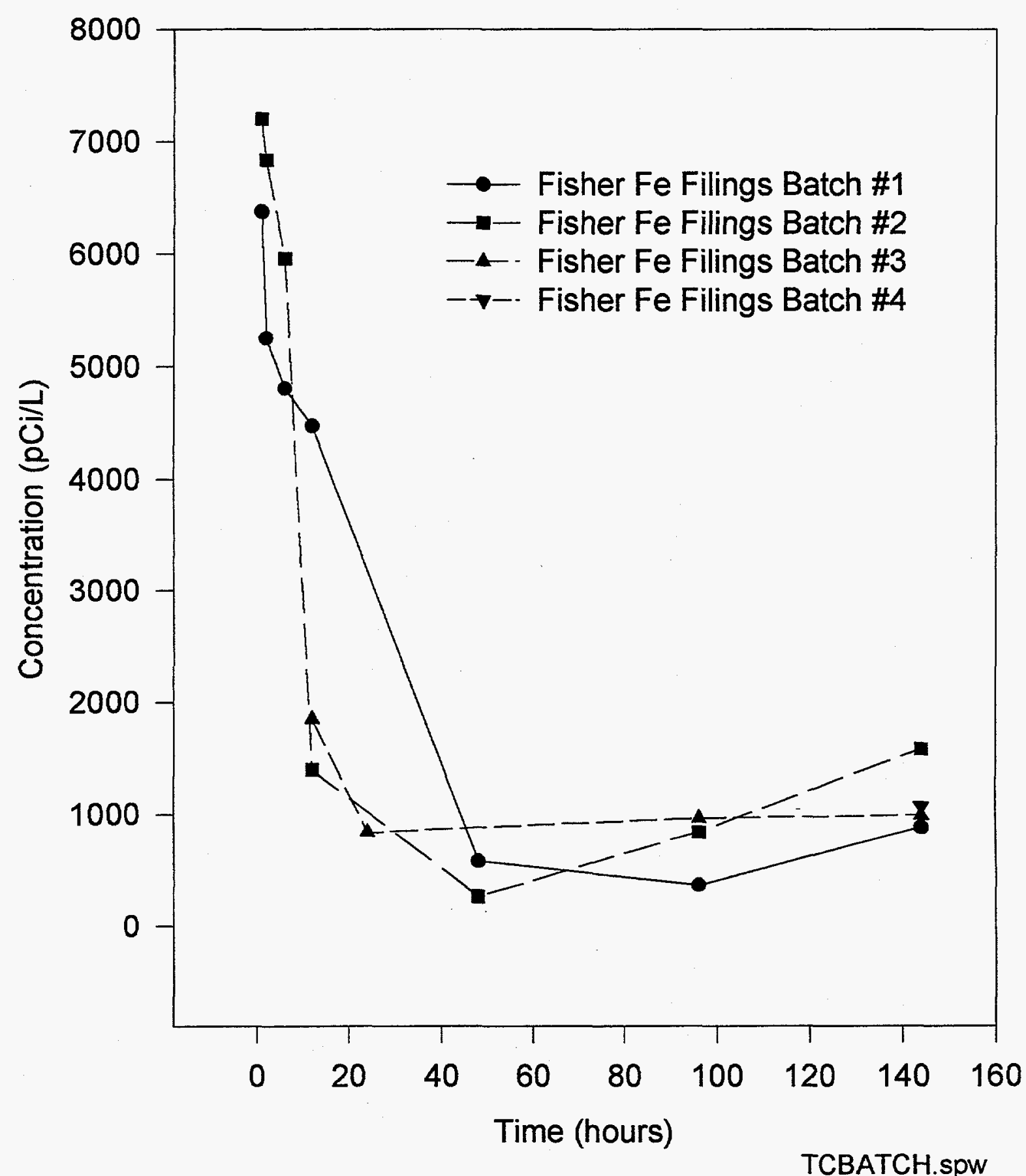

3.10. Tc sorption by Fisher iron filings. 
Table 3.2. Laboratory analysis of $\mathrm{Tc}$ and iron filings batch samples, $\mathrm{pCi} / \mathrm{L}$

\begin{tabular}{|c|c|c|c|c|c|c|c|c|c|c|}
\hline Batch & $0 \mathrm{~h}$ & $1 \mathrm{~h}$ & $2 \mathrm{~h}$ & $6 \mathrm{~h}$ & $12 \mathrm{~h}$ & $24 \mathrm{~h}$ & $48 \mathrm{~h}$ & $72 \mathrm{~h}$ & $96 \mathrm{~h}$ & $144 \mathrm{~h}$ \\
\hline I-1 & 4,578 & $\cdots$ & -- & - & $\ldots$ & $\ldots$ & - & - & $\cdots$ & $\ldots$ \\
\hline $\mathrm{I}-2$ & 6,709 & $\cdots$ & $\ldots$ & --- & $\cdots$ & $\cdots$ & -- & $\cdots$ & $\cdots$ & -- \\
\hline I-3 & 7,155 & -- & -- &..- &.- & -- &.- & -- & -- & --- \\
\hline $\mathrm{I}-4$ & 6,771 & $\cdots$ & $\cdots$ & -- & $\cdots$ & $\ldots$ & -- & -- & -- & $\ldots$ \\
\hline $\mathrm{I}-5$ & 6,742 & -- & $\ldots$ & -- & $\cdots$ & $\ldots$ & $-\cdots$ & -- & $\cdots$ & $\cdots$ \\
\hline $\mathrm{C}-1$ & $\ldots$ & - & -- & $\cdots$ & -- & 9,233 & $\cdots$ & -- & $\ldots$ & 8,742 \\
\hline $\mathrm{C}-2$ & $\ldots$ & $\cdots$ & $\cdots$ & -- & --- & 4,999 & $\ldots$ & -- & --- & 9,581 \\
\hline $\mathrm{C}-3$ & -- & $\ldots$ & $\cdots$ & $\cdots$ & -- & $-\cdots$ & $\cdots$ & $\cdots$ & -- & 7,271 \\
\hline$C-4$ & $\cdots$ & - & $\cdots$ & $-\cdots$ & $\cdots$ & $\cdots$ & $\ldots$ & -- & $\cdots$ & 7,582 \\
\hline FeM-1 & -- & 3,438 & 3,782 & 3,113 & 1,876 & $\cdots$ & 1,706 & $\cdots$ & 221 & 112 \\
\hline FeM-2 & $-\cdots$ & 5,864 & 3,676 & 4,051 & 1,804 & - & 785 & $\cdots$ & 183 & 874 \\
\hline FeM-3 & -- & $\cdots$ & $\cdots$ & -- & 1,725 & 535 & $\ldots$ & -- & 410 & 915 \\
\hline FeF-1 & -- & 6,378 & 5,248 & 4,806 & 4,474 & $\cdots$ & 578 & $\cdots$ & 363 & 880 \\
\hline $\mathrm{FeF}-2$ & $=$ & 7,201 & 6,834 & 5,958 & 1,397 & -- & 261 & -- & 839 & 1,581 \\
\hline FeF-3 & $\ldots$ & - & $\cdots$ & -- & 1,849 & 839 & $\cdots$ & $\cdots$ & 963 & 988 \\
\hline $\mathrm{FeF}-4$ & $\cdots$ & $\cdots$ & $\cdots$ & -- & $\ldots$ & -- & $\cdots$ & -- & -- & 1,070 \\
\hline
\end{tabular}

The notation "-.." indicates that there was no sample for the given time period.

The field blank sample and all four equipment rinsate samples showed no detectable concentration of $\mathrm{Tc}$, with a detection limit of $22 \mathrm{pCi} / \mathrm{L}$ (44 $\mathrm{pCi} / \mathrm{L}$ for the field blank).

Examples of sample notation:

$\mathrm{I}-2=$ initial groundwater sample number 2

$\mathrm{C}-3=$ control batch sample number 3

FeM-1 = Master Builder iron filings batch sample number

FeF-2 = Fisher iron filings batch sample number 2 


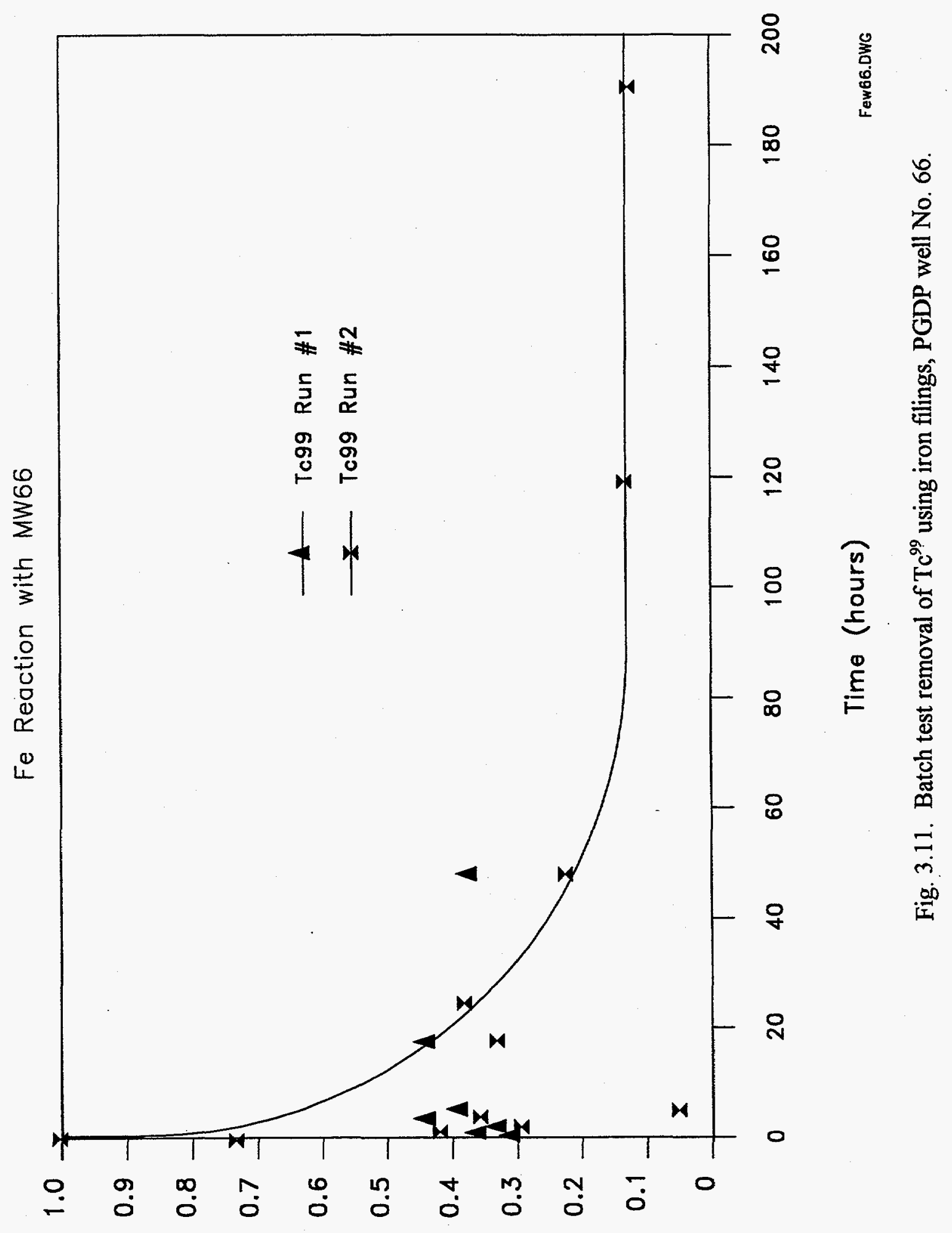




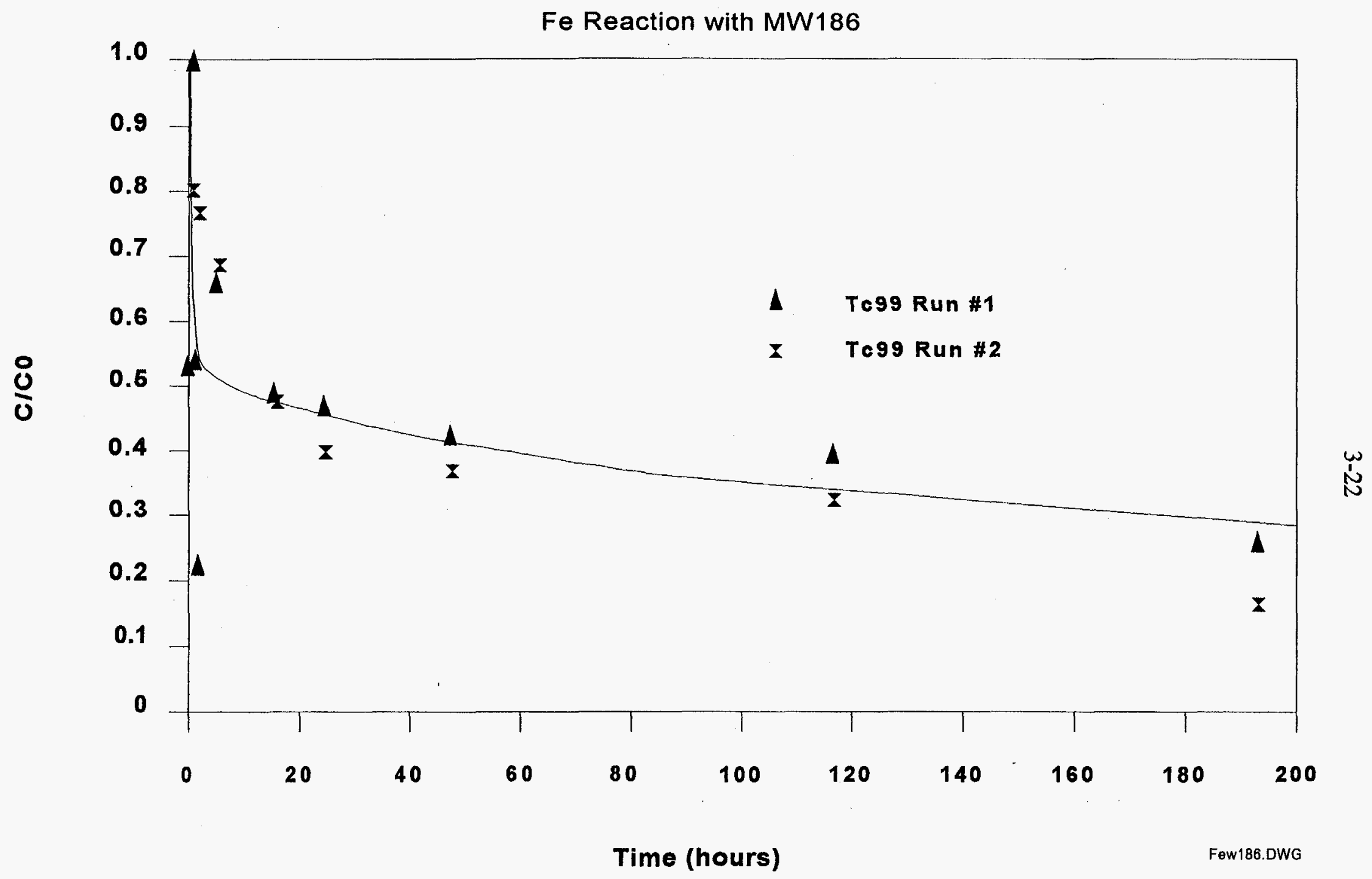

Fig. 3.12. Batch test removal of $\mathrm{Tc}^{99}$ using iron filings, PGDP well No. 186. 
pumped upward with a high-pressure liquid chromatography pump. The flow rate was varied from $1 \mathrm{~mL} / \mathrm{min}$ to approximately $10 \mathrm{~mL} / \mathrm{min}$. Tracer tests with $\mathrm{Cl}^{-}$ showed that there was little longitudinal dispersion indicating that the columns were uniformly packed.

Simulated PORTS groundwater spiked with $\mathrm{Tc}^{95 \mathrm{~m}}$ was used. Preliminary testing $\left(292 \mathrm{pCi} / \mathrm{mL}\right.$ of $\mathrm{Tc}^{95 \mathrm{~m}}$ ) showed that $\mathrm{Fe}$ was able to remove $\mathrm{Tc}$ at very low concentrations (equivalent to $0.23 \mathrm{pCi} / \mathrm{L}$ of $\mathrm{Tc}^{99}$ ).

Figure 3.13 shows the breakthrough curve of $\mathrm{Tc}^{99}$ and $\mathrm{Tc}^{95 \mathrm{~m}}$ from a column $1-\mathrm{cm}$ in diameter and 4-cm long packed with $10 \mathrm{~g}$ of Fe. The flow rate was $9.2 \mathrm{~mL} / \mathrm{min}$ which corresponds to a pore velocity of $19.5 \mathrm{~cm} / \mathrm{min}$ and a residence time of $0.21 \mathrm{~min}$. The initial concentration of $\mathrm{Tc}^{99}$ was $1,031 \mathrm{pCi} / \mathrm{L}$ and the initial concentration of $\mathrm{Tc}^{95 \mathrm{~m}}$ was $469.7 \mathrm{pCi} / \mathrm{mL}$.

At the beginning of the experiment, gas bubbles (presumably hydrogen) were observed due to electrolysis of water by Fe. The rising of gas bubbles from the column disturbed the plug flow characteristics of the column, and preferential flow paths for the water were created. This explains the relatively high concentrations of $\mathrm{Tc}^{99}$ and $\mathrm{Tc}^{95 \mathrm{~m}}$ at the beginning of the experiment (before 150 pore volumes). After the gas bubbles disappeared from the column, a baseline was established. This baseline was maintained for approximately 2,000 pore volumes, with only occasional minor deflections. The initial $\mathrm{pH}$ was 6.2 . The effluent $\mathrm{pH}$ increased immediately to 9.5 , then decreased to approximately 6.5 . At the beginning of the experiment, the electrolysis of water controlled the water chemistry and produced the high $\mathrm{pH}$ that was observed.

During the course of the experiment, precipitation of ferric oxides and hydroxides was observed on the surface of the Fe in the column. This reaction was accompanied by a drop in $\mathrm{pH}$ and an increase in pressure. Any physical disturbance of the column released this back-pressure and altered transport of the radionuclides. It was this mechanical disturbance that was responsible for the fluctuations on the breakthrough curve.

Although an initial deviation from the baseline was observed at approximately 2,000 pore volumes, it was not until 5,000 pore volumes, that approximately $1 \%$ of the $\mathrm{Tc}^{99}$ and $\mathrm{Tc}^{95 \mathrm{~m}}$ came through the column. This quantity of $\mathrm{Tc}^{99}$ is approximately $10 \mathrm{pCi} / \mathrm{L}$, which is very near the background concentration. Based on this breakthrough curve, $\mathrm{Tc}^{99}$ loading on the column at 5,000 pore volumes was calculated to be $900 \mathrm{pCi} / \mathrm{g}$.

Subsequently, a column test was performed with a coarse Fe (Peerless, Inc., Detroit, Michigan) which was ultimately used in the field test. With simulated 
Tc removal from iron column

(Fisher, $\mathbf{4 0}$ mesh iron filings)

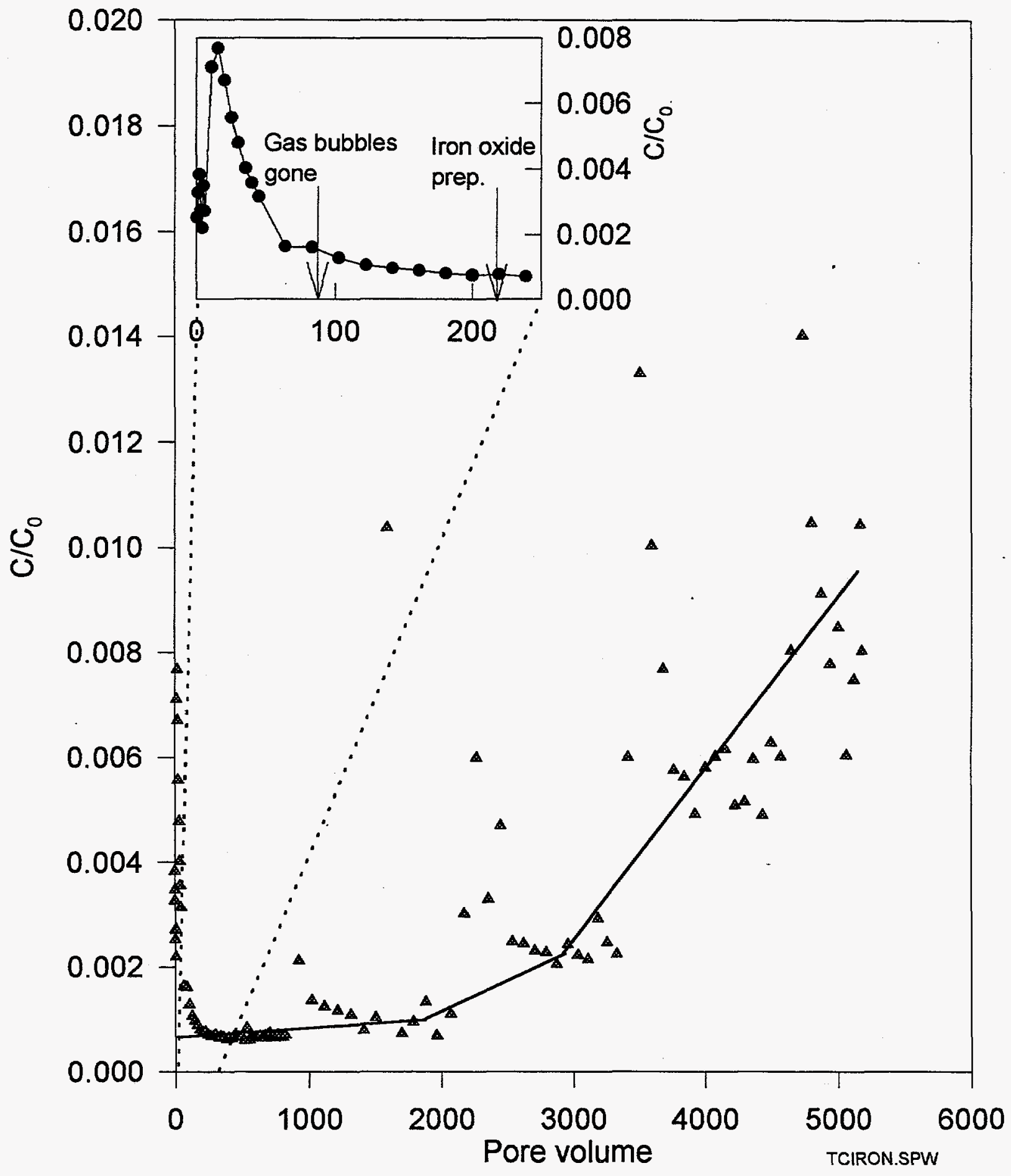

Flow rate $=9.2 \mathrm{ml} / \mathrm{min}, \mathrm{Tc}-99$ initial conc. $=1,031 \mathrm{pCi} / \mathrm{L}$

Column size $1 \times 4 \mathrm{~cm}$, pore volume $=1.9 \mathrm{ml}$ Line shows general breakthrough trend

Fig. 3.13. Tc removal from Fisher iron filings column. Note: $\mathrm{C} / \mathrm{Co}=$ measured activity divided by the initial activity. 
PORTS groundwater spiked at $1754 \mathrm{pCi} / \mathrm{L}$, a $1 \mathrm{~cm} \mathrm{x} 4 \mathrm{~cm}$ column was run at $2 \mathrm{~mL} / \mathrm{min}$ and no Tc was detected in the effluent after two weeks. This water was aerobic, in contrast to the water that would be treated onsite. Thus, some clogging did occur (back pressure of approximately 350 pounds per square in.).

Nevertheless, the high removal efficiency for Tc supported the decision to use Peerless Fe in the field test.

Experiments similar to those with zero-valence iron were conducted using BioRad MSZ-1 resin (equivalent to Dowex OH-type resin). The simulated PORTS groundwater was pumped upward through a 1-cm $\times 4-\mathrm{cm}$ column at a flow rate of $9.2 \mathrm{~mL} / \mathrm{min}$. Because of the difference in porosity. as compared to the Fe column, the pore velocity in the resin column was $14.65 \mathrm{~cm} / \mathrm{min}$, and the residence time was $0.27 \mathrm{~min}$. Because the resin is an ion exchange media, a high $\mathrm{pH}(11.5)$ was observed in the effluent throughout the experiment. A whitish precipitate and increased back-pressure of the medium were also observed.

Figure 3.14 shows the breakthrough of $\mathrm{Tc}^{99}$ from the resin column. An abovebackground reading for $\mathrm{Tc}^{99}$ was registered at the beginning of the experiment, and a substantial increase in the effluent concentration, approximately $3 \%$ of both $\mathrm{Tc}^{99}$ and $\mathrm{Tc}^{95 \mathrm{~m}}$, occurred at 200 pore volumes. The resin loading at 200 pore volumes was calculated as $500 \mathrm{pCi} / \mathrm{g}$.

An experiment with a slower flow rate and a longer resin column was also conducted. The flow rate was set at $2 \mathrm{~mL} / \mathrm{min}$, which corresponds to a pore velocity of $3.18 \mathrm{~cm} / \mathrm{min}$. The residence time for the $12-\mathrm{cm}$-long column was 3.77 min-more than an order of magnitude higher than the previous experiment (Fig. 3.14). For 600 pore volumes, both $\mathrm{Tc}^{99}$ and $\mathrm{Tc}^{95 \mathrm{~m}}$ were removed to background levels. The loading of $\mathrm{Tc}^{99}$ and $\mathrm{Tc}^{95 \mathrm{~m}}$ based on this experiment, was approximately $1,550 \mathrm{pCi} / \mathrm{g}$.

A column experiment was also conducted at PGDP using groundwater contaminated with Tc (Clausen and Richards 1994). The column was filled with 40-mesh Master Builder Fe filings. The experiment was conducted at a flow rate of approximately $40 \mathrm{~mL} / \mathrm{min}$, which resulted in a residence time of $1 \mathrm{~h}$. The average influent $\mathrm{Tc}$ activity was $1,448 \mathrm{pCi} / \mathrm{L}$. No breakthrough of Tc had occurred after 72 pore volumes had passed through the column (Fig. 3.15). Equipment malfunction resulted in termination of the test before kinetic information could be obtained.

To summarize, the results from column experiments with $\mathrm{Fe}$ and resin suggested that: 


\section{Tc removal from resin column}

(bio-red msz 1, Dowex-OH, X8)

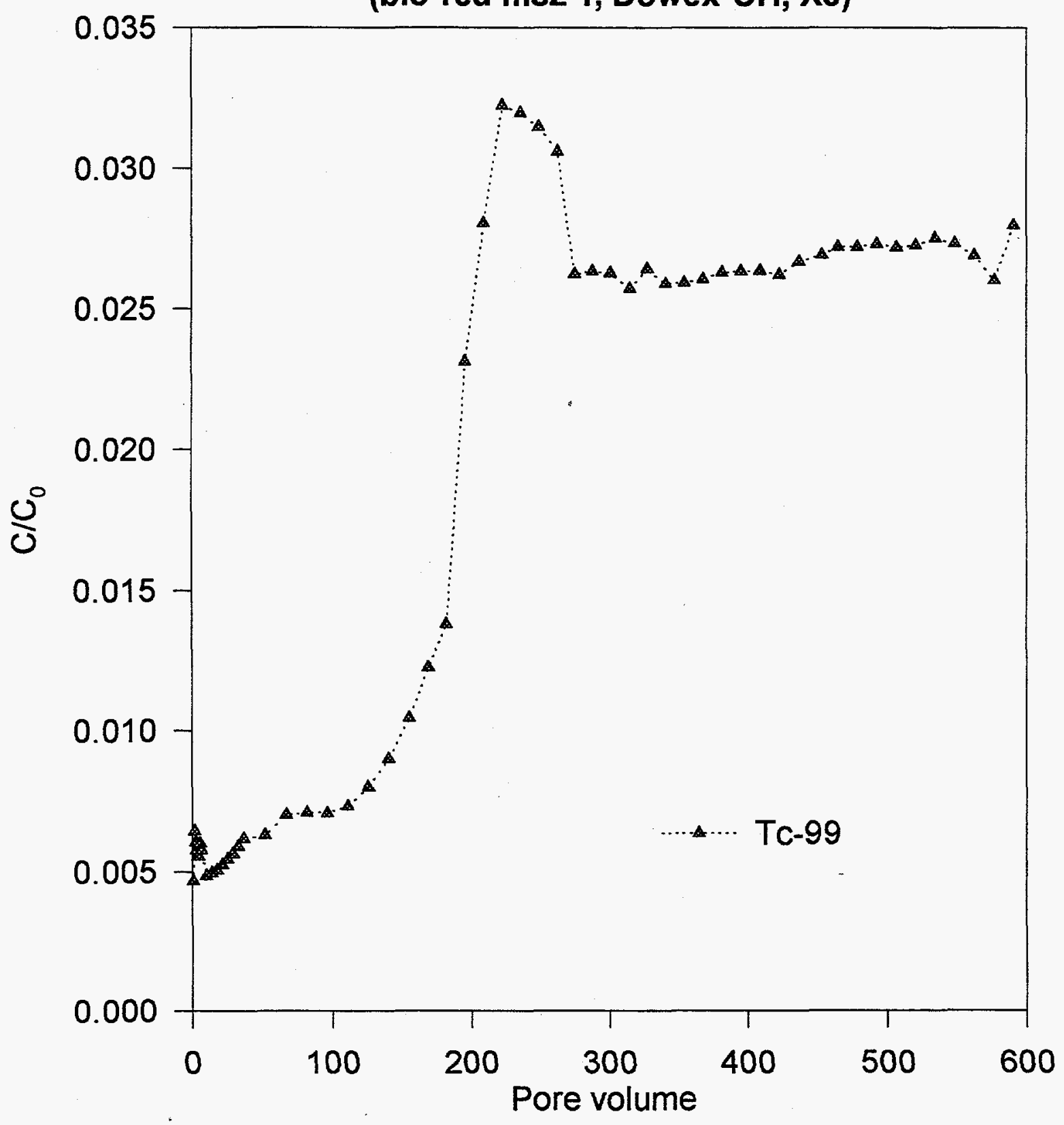

Flow rate $=9.2 \mathrm{ml} / \mathrm{min}$,

Tc-99 initial conc. $=1,031 \mathrm{pCi} / \mathrm{L}$

Column size $1 \times 4 \mathrm{~cm}$, pore volume $=2.5 \mathrm{ml}$

Fig. 3.14. Tc removal from resin column. 


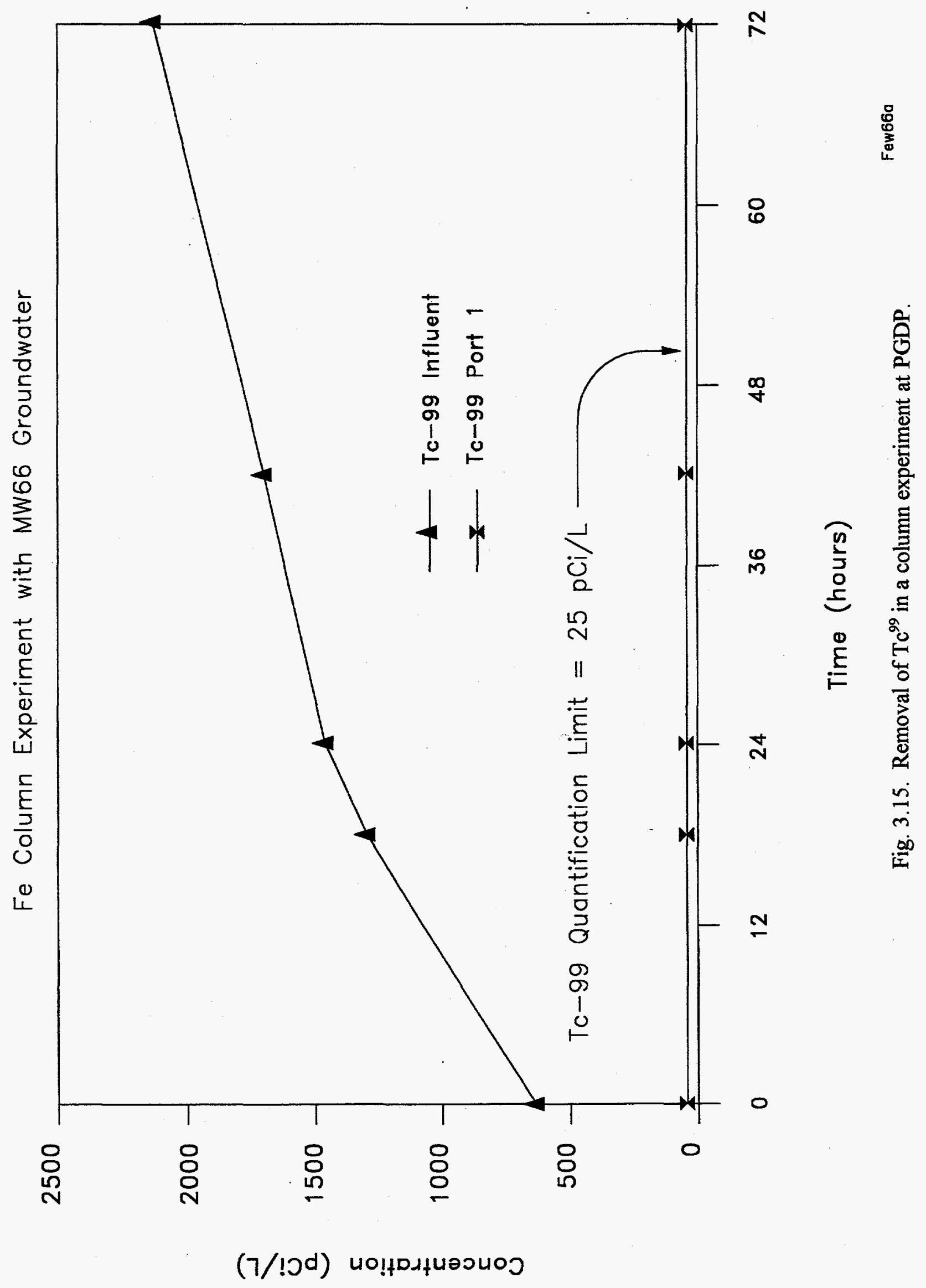


- At high flow rates (15 to $20 \mathrm{~cm} / \mathrm{min}$ ), and residence times of less than a minute, the $\mathrm{Fe}$ was much more efficient than the resin.

- Sorption of $\mathrm{Tc}^{99}$ and $\mathrm{Tc}^{95 \mathrm{~m}}$ on the resin is slow. These experiments indicated that a residence time of at least $3.8 \mathrm{~min}$ is required.

- Zero-valence iron rapidly removes Tc. Fe can treat thousands of bed volumes of contaminated groundwater before $1 \%$ of the influent contaminant leaves the reactor. 


\section{Investigation of $\mathrm{Pd} / \mathrm{Fe}$ Surface}

The dechlorination of hydrocarbons with $\mathrm{Pd} / \mathrm{Fe}$ is believed to be a heterogeneous reaction that initially requires adsorption on the metallic surface. Consequently, a study of the metallic surface is essential to fully understand and optimize the reaction. This section summarizes the surface analytical measurements that have been performed. The purpose of the measurements was to examine the longevity of the $\mathrm{Pd} / \mathrm{Fe}$ surface and to obtain additional information regarding the reaction mechanism.

The Pd/Fe surface has been investigated with the following techniques: Raman Spectroscopy, Surface Enhanced Raman Spectroscopy (SERS), Rutherford Backscattering Spectrometry (RBS), Proton Induced X-Ray Emission (PIXE), PIXE with a highly focused ion beam (Micro-PIXE), and X-ray Photoelectron Spectroscopy (XPS). Raman and SERS were found to be of limited use because these techniques lacked sufficient sensitivity. The other techniques have all provided useful data.

$R B S$ - Limited use of RBS demonstrated that the Pd does not penetrate into the $\mathrm{Fe}$ but is resident on the surface. Moreover, even under conditions of excess Pd, RBS has demonstrated that the Fe surface is never completely covered. The Pd always congregates in distinct "islands". Under highly-controlled conditions, it should be possible to determine the thickness of the Pd layer using RBS.

PLXE - PIXE was used to confirm the RBS results regarding the location of the Pd on the Fe surface. No unique information was obtained. PIXE is also used to calculate the concentration of $\mathrm{Pd}$ on the Fe surface.

Micro-PLXE - The use of a highly focused proton beam permits much greater resolution regarding the characteristics of the metallic surface. Micro-PIXE results also proved that the Pd was not uniformly distributed but formed "islands" on the Fe surface (Fig. 4.1). Additional studies, to determine the features of the Fe surface that cause the Pd clusters, can be performed in the future.

$X P S$ - The majority of the surface analyses performed to date have utilized XPS or Electron Spectroscopy for Chemical Analysis or ESCA. Most of this work has been reported previously by Muftikian et al. (1996). XPS is commonly used to examine the chemical state of elements on a surface. In this technique, the surface of the sample is sputtered with an argon ion beam and a characteristic photoelectron is ejected. The energy of the photoelectron is related to the binding energy of the electrons in the substance under study. 


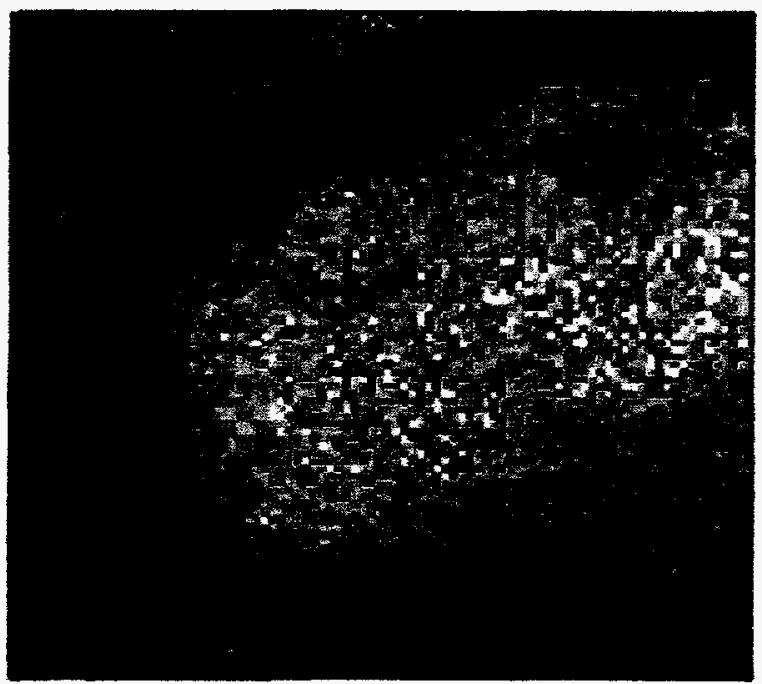

i071095.xry 2/20 cnts 22296 Pd K-alpha, beta 2300 sec Sample 1125 un $\times 125$ um

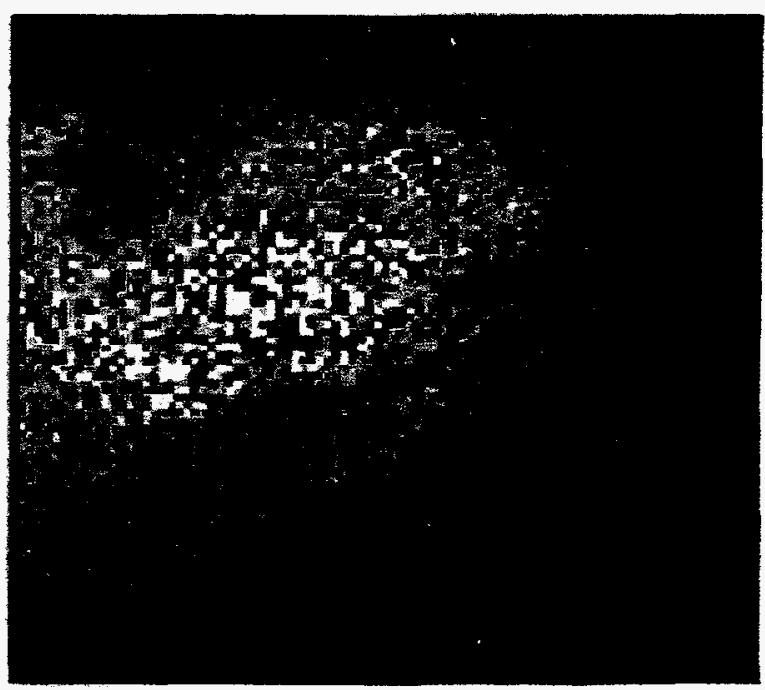

j071095.xry 2/22 cnts 22839 Pd $\mathrm{X}$-alpha, beta $2500 \mathrm{sec}$ Sample 1125 um $\times 125$ um

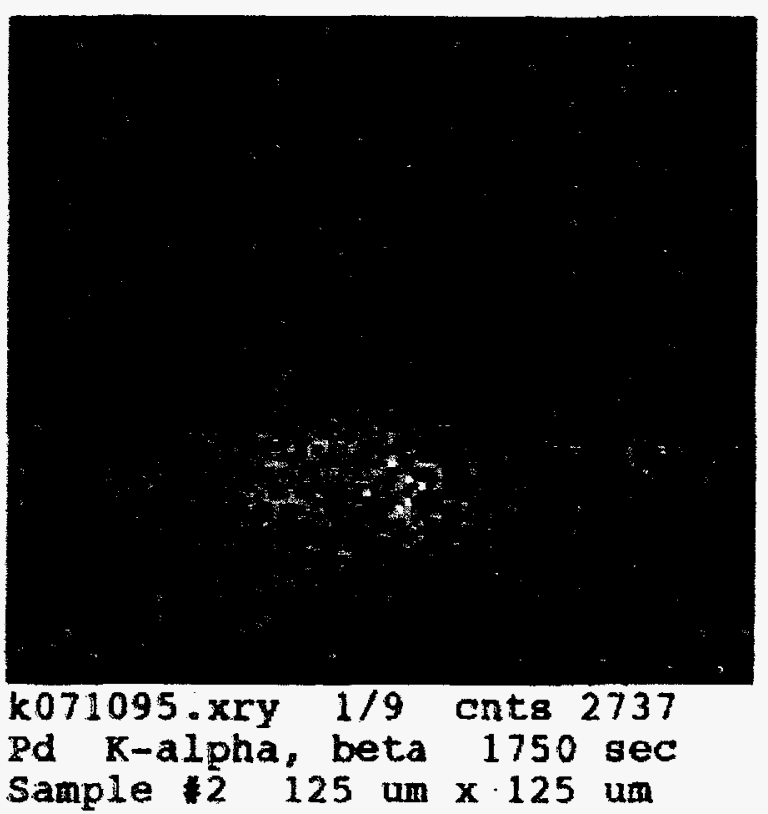

Fig. 4.1. Micro-PIXE surface analysis of $\mathrm{Pd} / \mathrm{Fe}$ filings. 
The XPS measurements for this project were performed with a Vacuum Generators ESCALAB MKII photoelectron spectrometer (East Grinstred, U.K.) with an $A l \kappa \alpha_{1,2}(1486.6 \mathrm{eV}) \mathrm{X}$-ray source and a hemispherical 150-mm mean radius electron analyzer with a take-off angle of $90^{\circ}$. The energy resolution $\mathrm{E}_{1 / 2}$ (full width at half maximum) of the XPS peaks was less than $1.0 \mathrm{eV}$ for the $\mathrm{Ag}$ $3 \mathrm{~d}_{5 / 2}$ peak with the $A l \kappa \alpha_{1,2}$ source that was operated with a power of $300 \mathrm{~W}$. The binding energies of the photoelectrons were determined by assuming that the carbon 1s electrons had a binding energy of $284.6 \mathrm{eV}$. The data were recorded digitally, and all peak scans were signal averaged until an acceptable signal-tonoise ratio was obtained. During the data acquisition, the pressure in the sample chamber did not exceed $5 \times 10^{-10}$ Torr.

The relative atomic ratios of $\mathrm{Pd}$, oxygen, and carbon on the $\mathrm{Pd} / \mathrm{Fe}$ surface were calculated from the $\mathrm{Pd} 3 \mathrm{~d}, \mathrm{O} 2 \mathrm{~s}$, and $\mathrm{C} 1 \mathrm{~s}$ peak areas after a standard background subtraction procedure was applied, and integration of the baseline-corrected peak area was performed. The peak areas were corrected for cross section, excitation, and inelastic mean free path by employing well-established algorithms (Briggs and Seah 1983). All reported ratios are relative to the $O 2 \mathrm{~s}$ peak area because this peak was free of any overlap with other XPS peaks. The more commonly used and more intense reference peak is the $\mathrm{O} 1 \mathrm{~s}$, but it overlaps with $\mathrm{Pd} 3 \mathrm{p}_{5 / 2}$ peak and, therefore, cannot be used to calculate elemental ratios. The calculated atomic ratios are only useful in identifying trends in the experimental results. For example, the Pd:Fe ratio increased as expected, from 0.07 to 0.4 , when the $\mathrm{Fe}$ surface was exposed to $\mathrm{K}_{2} \mathrm{PdCL}_{6}$ solution from 1 to $30 \mathrm{~s}$, whereas the O:Fe ratio remained approximately constant.

Sample preparation. A $1 \mathrm{~cm} \times 1 \mathrm{~cm}$ pure Fe foil, $0.254 \mathrm{~mm}$ thick, obtained from Aesar (Ward Hill, Massachusetts) was spot-welded to a stainless steel stub, and the surface of the foil was etched with $8 \mathrm{keV}$ argon ions from an argon ion gun. The argon ion beam was incident on the Fe surface at an angle of $\sim 15^{\circ}$ to the surface normal.

The Fe foil was exposed to a solution of $\mathrm{K}_{2} \mathrm{PdCL}_{6}$ in water and to the wash solutions by moving the sample into the load lock chamber. The chamber was brought up to a pressure of $1 \mathrm{~atm}$ with ultra-high-purity argon. The $\mathrm{K}_{2} \mathrm{PdCL}_{6}$ solution was added to the sample surface with the aid of a micropipet. The $\mathrm{Fe}$ surface was then rinsed with ultrapure water that was added from a second micropipet. The sample was pumped down in the load-lock chamber and then repositioned in the sample chamber, and the surface analysis was performed as described above.

Figure 4.2 presents results obtained from a thin film of $\mathrm{Pd} / \mathrm{Fe}$ prior to exposure to organic compounds. When the Pd/Fe surface is exposed to TCE (Fig. 4.3, com- 


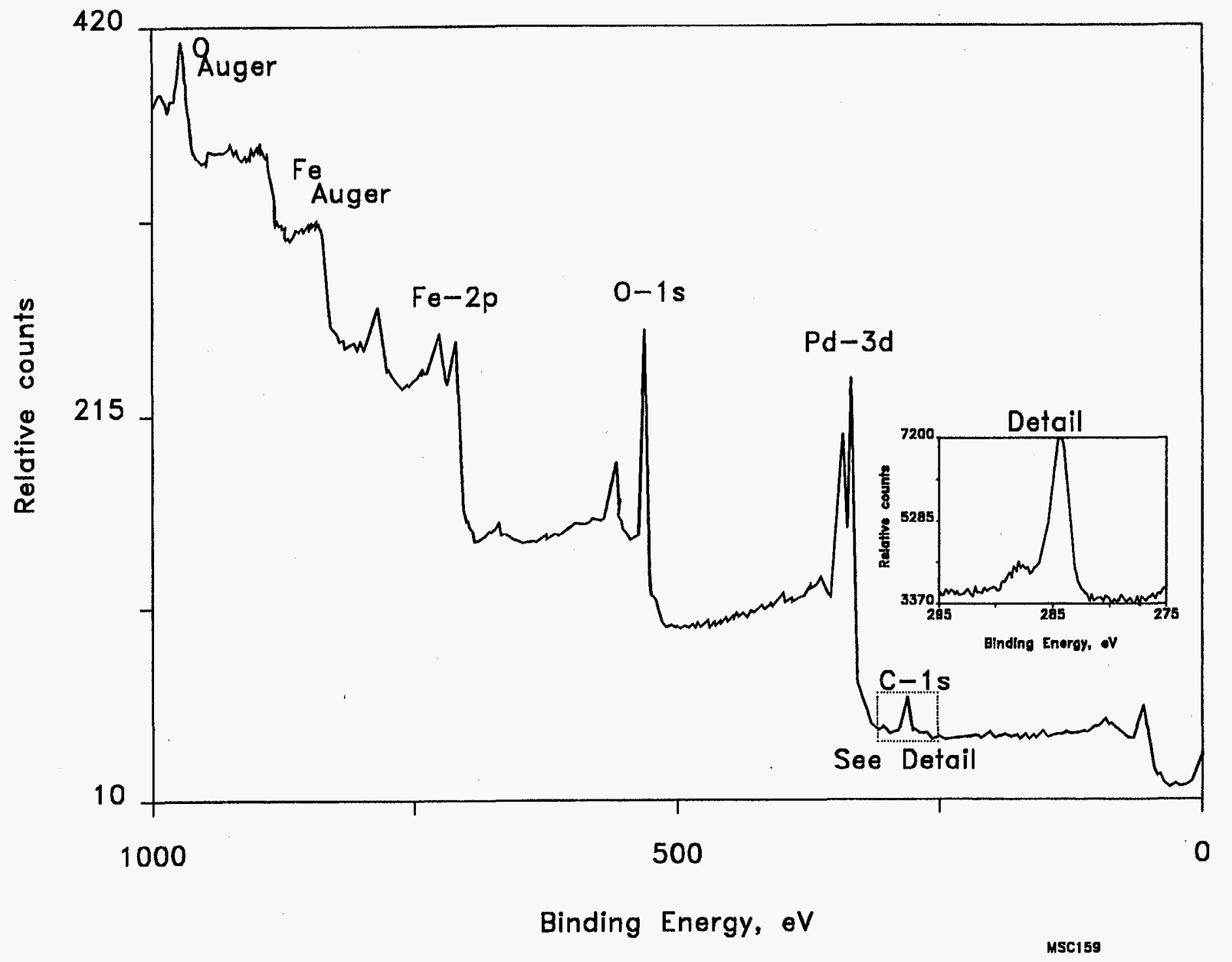

Fig. 4.2. XPS results for a clean, unreacted palladized iron film. 


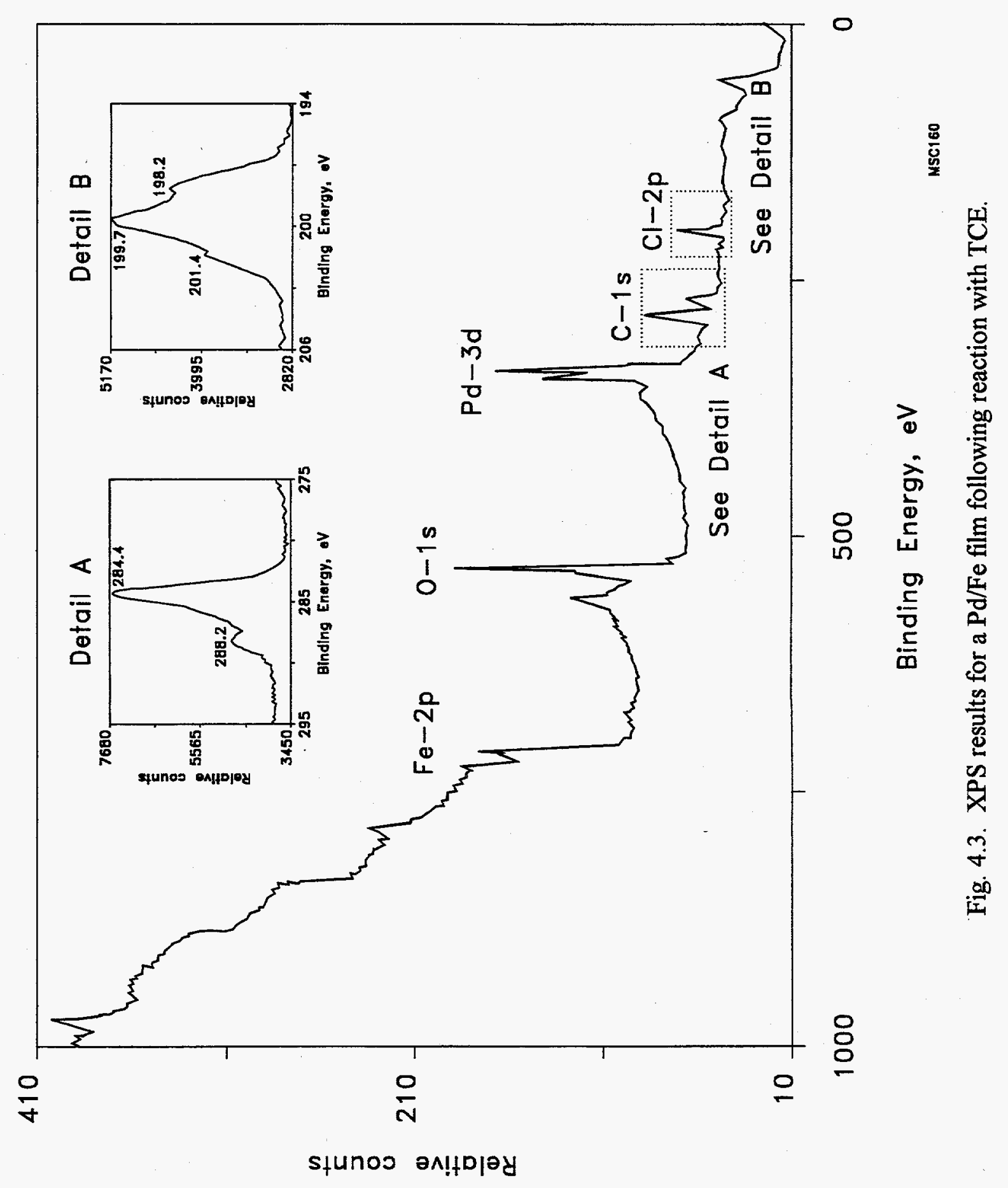


pare with Fig. 4.2), a larger carbon peak is observed and $\mathrm{Cl}$ is visible on the surface. In contrast, when PCBs are exposed to the surface (Fig. 4.4, compare with Fig. 4.2), only $\mathrm{C}$ is visible and the $\mathrm{Cl}$ peak is either minor or not apparent. It is not known whether there is no $\mathrm{Cl}$ present or whether the resolution is inadequate to observe it. (The presence or absence of chlorine at this step could have significant bearing on determining the reaction mechanism. Additional analyses of this type should be performed in the future.)

Note that after exposure to TCE, the complexity of the $\mathrm{Cl}$ peak on the $\mathrm{Pd} / \mathrm{Fe}$ surface (Fig. 4.3, inset $\mathrm{B}$ ) indicates that $\mathrm{Cl}$ may be present in two or more distinct states. Indeed, the data suggest the presence of several fragmented $\mathrm{C}-\mathrm{Cl}$ bonds on the $\mathrm{Pd} / \mathrm{Fe}$ surface. In addition, the Pd peak is shifted after reaction with TCE (Fig. 4.3) indicating that it is a probable binding site for the hydrocarbon. The Pd peak is not shifted after reaction with PCBs (Fig. 4.4). The significance of this finding is unknown and will require additional experiments to explain.

The shape (size and complexity) of the carbon peak after exposure to PCBs (Fig. 4.4, inset) suggests the presence of a number of carbon species that are bound to the $\mathrm{Pd} / \mathrm{Fe}$ surface. Finally, in the PCB reaction, unlike the TCE experiment, there is no detectable shift of the Pd peak and no discernible shifts in the Fe or $O$ peaks, meaning that it is not possible to determine to what atoms the carbon-containing species are bound.

Detailed examination of the data has shown that the outermost layer of the Fe film is composed of $\mathrm{FeO}(\mathrm{OH})$; the intermediate oxide layers formed on the elemental $\mathrm{Fe}$ surface have Fe:oxygen ratios varying from 1.5 to 1.3 , and the thicknesses of each of these layers were found to depend on the length of exposure of the $\mathrm{Fe}$ surface to oxygen and water vapor. It is reasonable to conclude, therefore, that the surface of the Fe foil used in this work is also covered by a hydroxylated oxide film.

Exposure of the clean Fe surface, after the hydroxylated film is removed by etching under vacuum with argon ions, to a solution of $\mathrm{K}_{2} \mathrm{PdCl}_{6}(0.010 \mathrm{~g}$ of $\mathrm{Pd} / 100 \mathrm{~mL}$ of ultrapure water) for varying lengths of time resulted in the deposition of $\mathrm{Pd}$ on the Fe surface as a result of the reactions described previously (see Sect. 3). The longer the time of contact between the Fe surface and the palladizing solution, the more $\mathrm{Pd}$ is deposited on the Fe surface. The presence of $\mathrm{Pd}^{0}$ on the $\mathrm{Fe}$ surface, after exposure of the $\mathrm{Fe}$ surface to the palladizing solution for about $30 \mathrm{~s}$, is confirmed by the binding energies of the Pd $3 \mathrm{~d}$ peaks in the photoelectron spectrum shown in Fig. $4.5 \mathrm{a}\left(\mathrm{Pd} 3 \mathrm{~d}_{3 / 2}=340.3\right.$ and $\mathrm{Pd} 3 \mathrm{~d}_{5 / 2}=335.0$ $\mathrm{eV})$. 


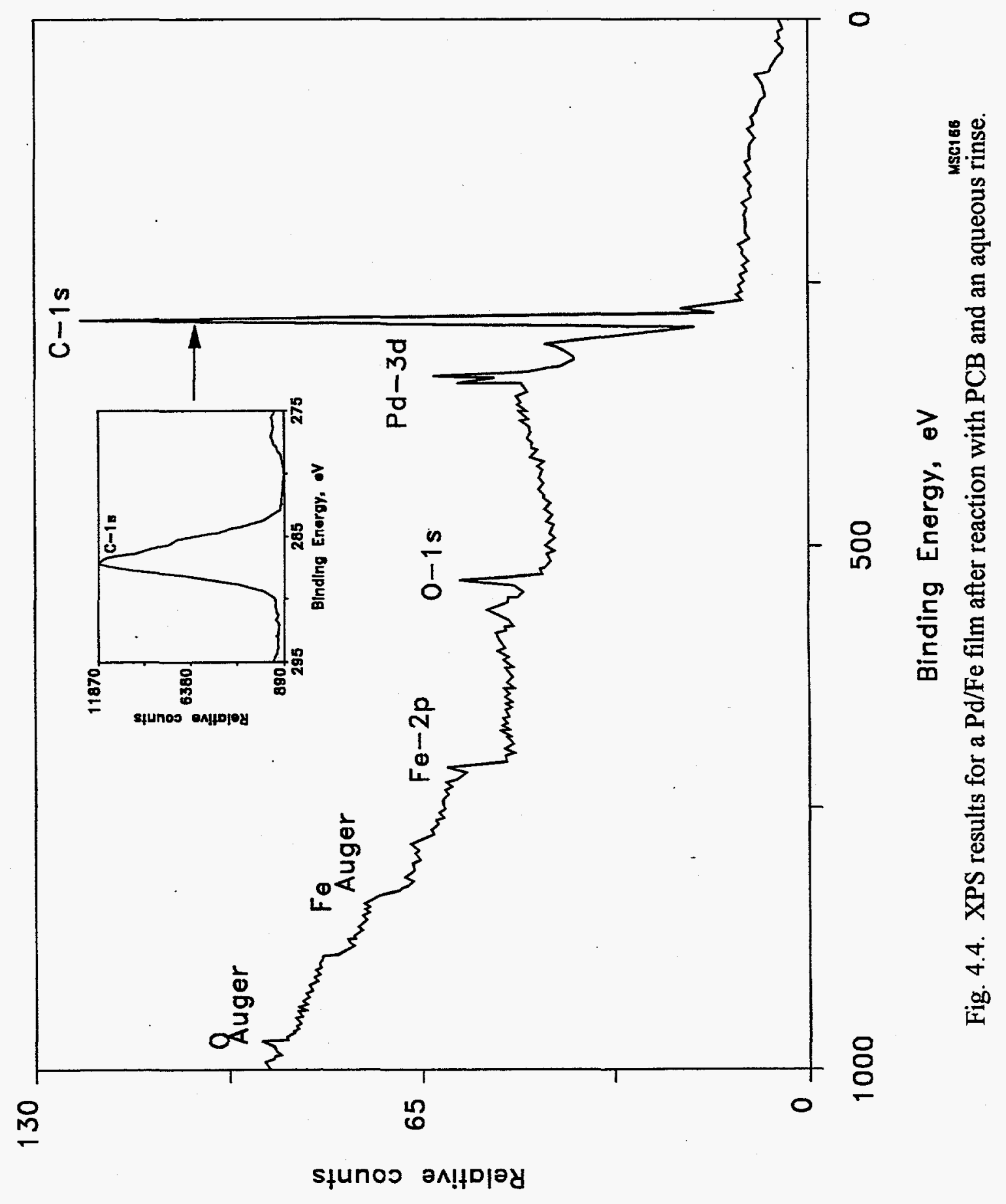




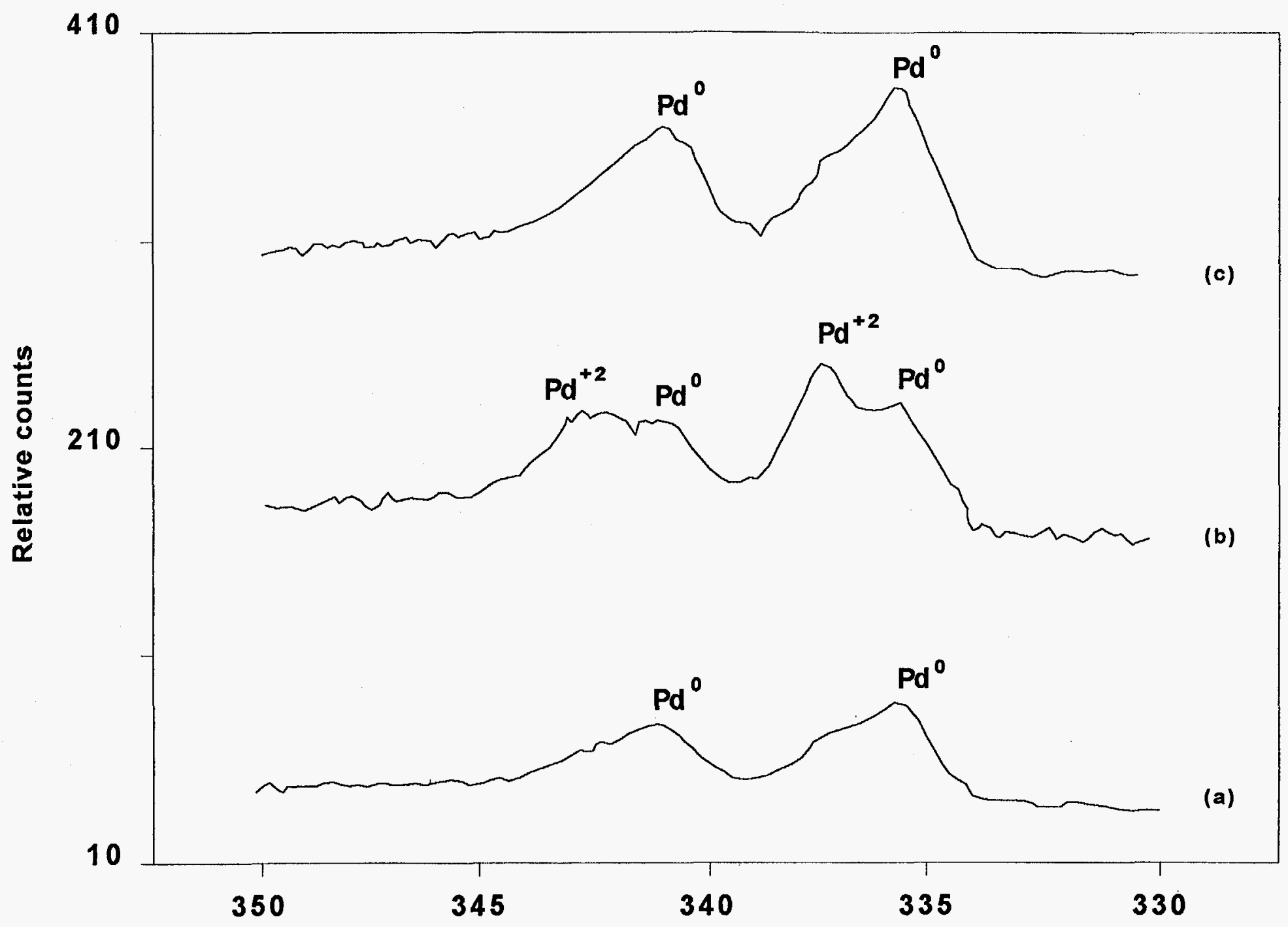

Binding Energy, oV

MSC203

Fig. 4.5. (a) Binding energies of the $P d 3 d_{3 / 2}$ and the $P d 3 d_{5 / 2}$ peaks in the $x$-ray photoelectron spectrum of elemental $P d$ deposited on the iron surface. (b) $\mathrm{Pd} 3 \mathrm{~d}$ peaks of elemental $\mathrm{Pd}$ and $\mathrm{Pd}^{2+}$ species after deposition of a very low surface of palladium. The presence of Pd-O-Fe bonds is evident from the binding energies of the $\mathrm{Pd}^{2+}$ species. (c) $\mathrm{Pd} 3 \mathrm{~d}$ peaks after the iron surface with the Pd-O-Fe bonds was allowed to stand overnight in an ultra high vacuum. 
If, however, the Fe surface is exposed to a very low concentration $(0.005 \mathrm{~g}$ of $\mathrm{Pd} /$ $100 \mathrm{~mL}$ ) of the palladizing solution for about $1 \mathrm{~s}$ or less, the presence of a higher oxidation state of $\mathrm{Pd}$, in addition to the $\mathrm{Pd}^{0}$, is clearly shown by the X-ray photoelectron spectrum of the Fe surface (Fig. 4.5b). This indicates that a hydroxylated film is formed on the Fe surface as soon as it is contacted with an aqueous solution and that the protons on the - $\mathrm{OH}$ groups readily exchange with $\mathrm{Pd}$ ions that are present in solution. A similar cation exchange phenomenon has been observed previously where the protons on the - $\mathrm{OH}$ groups on an Fe surface exchange with $\mathrm{K}^{+}$ions in solution (Kurbatov et al. 1992).

The Pd-O-Fe bonds that are formed on the Fe surface are unstable, and the Pd ions undergo further reduction to $\mathrm{Pd}^{0}$ by electrons yielded by the oxidation of $\mathrm{Fe}$ present in the relatively porous hydroxylated $\mathrm{Fe}$ oxide film. The spectra shown in Fig. $4.5(b, c)$ confirm the eventual formation of $\mathrm{Pd}^{0}$ on the Fe surface. The spectra in Fig. 4.5 were obtained when the Fe surface with the Pd-O-Fe bonds was allowed to stand overnight in a sample chamber maintained at ultra-high vacuum.

It is postulated from these results that $\mathrm{Pd}(\mathrm{IV})$ in the palladizing solution is first reduced to $\mathrm{Pd}^{2+}$ ions by the redox reaction:

$$
\mathrm{PdCl}_{6}{ }^{2-}+\mathrm{Fe}^{0} \rightarrow \mathrm{Fe}^{2+}+\mathrm{Pd}^{2+}+6 \mathrm{Cl}^{-}
$$

The $\mathrm{Pd}^{2+}$ then exchanges with protons from the hydroxylated $\mathrm{Fe}$ oxide surface and is reduced further as shown in equations 9 and 10:

$$
\begin{gathered}
2 \mathrm{FeOH}+\mathrm{Pd}^{2+}-2 \mathrm{FeOPd}+2 \mathrm{H}^{+} \\
2 \mathrm{H}^{+}+2 \mathrm{FeOPd}+\mathrm{Fe}^{0} \rightarrow \mathrm{Fe}^{2+}+2 \mathrm{FeOH}+\mathrm{Pd}^{0}
\end{gathered}
$$

The hydroxylated layer on the Fe oxide surface has a highly complex structure that probably consists of many types of structures with -OH groups. Thus, equations 8 and 10 are merely representations of overall reactions that occur when the $\mathrm{Pd}$ is deposited on the hydroxylated Fe oxide surface.

There are no significant changes in the Fe $2 p$ spectrum that was recorded in the course of the Pd deposition. Both the line shapes and peak maxima remain essentially unchanged. It is concluded, therefore, that the structure of the hydroxylated $\mathrm{Fe}$ oxide surface and the depth of the hydroxylated $\mathrm{Fe}$ oxide film remain the same because the $\mathrm{Fe} 2 \mathrm{p}_{1 / 2}$ and the $\mathrm{Fe} 2 \mathrm{p}_{3 / 2}$ peaks of the elemental Fe surface that lie beneath the hydroxylated oxide film are clearly observed in all the Fe $2 p$ spectra (Fig. 4.6). In other words, the Fe $2 p$ spectra remain unchanged during and after the deposition of $\mathrm{Pd}$. In addition, after the $\mathrm{Pd}(\mathrm{IV})$ is reduced to $\mathrm{Pd}^{0}$, the 


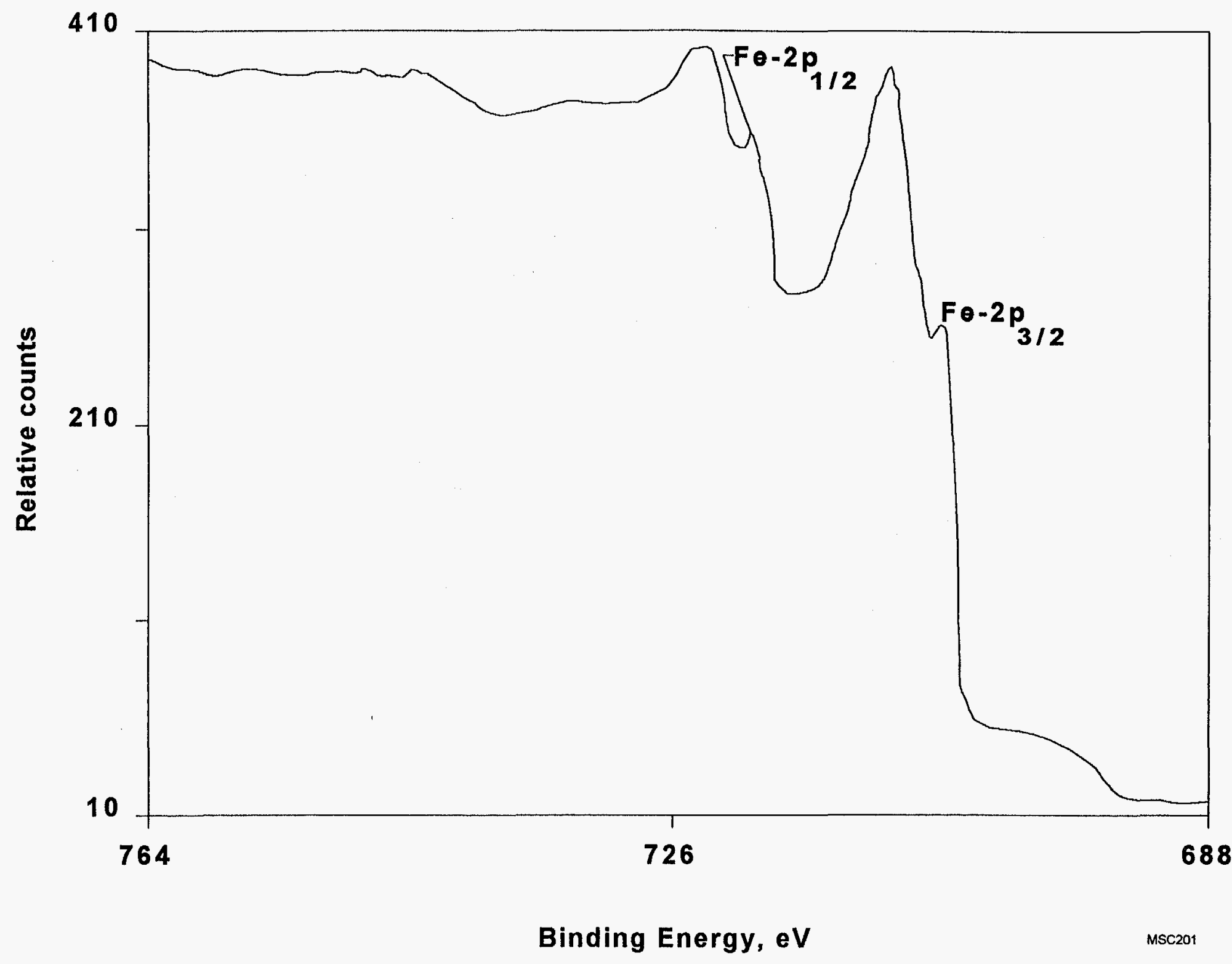

$\stackrel{t}{\stackrel{t}{0}}$

Fig. 4.6. Fe $2 p$ photoelectron spectrum of an iron surface covered with a thin hydroxylated iron oxide film. The presence of elemental iron is confirmed by the presence of Fe $2 p$ peaks at 707.1 and $720.3 \mathrm{eV}$. 
$\operatorname{Pd} 3 \mathrm{~d}$ spectra are unaffected by the presence of Fe or oxygen on the surface. Thus, it is concluded that the $\mathrm{Pd}$ atoms are located in the matrix of randomly distributed $\mathrm{Fe}$ and oxygen atoms on the $\mathrm{Fe}$ oxide surface and that there is no electronic interaction between the $\mathrm{Pd}$ and the $\mathrm{Fe}$ and oxygen atoms.

The Pd 3d and the Fe 2p spectra of the Fe surface after is it exposed to the palladizing solution $\left(0.05 \mathrm{~g}\right.$ of $\mathrm{Pd} / 100 \mathrm{~mL}$ of $\left.\mathrm{H}_{2} \mathrm{O}\right)$ for $5 \mathrm{~min}$. are shown in Figs. 4.7 and 4.8a, respectively. The binding energies and the shape of the $\mathrm{Pd} 3 \mathrm{~d}$ peaks indicate that the $\mathrm{Pd}$ is present on the $\mathrm{Fe}$ surface only in the elemental state, $\mathrm{Pd}^{0}$, and not as a combination of $\mathrm{Pd}^{0}$ atoms and $\mathrm{Pd}^{2+}$ ions. It is also evident that these $\mathrm{Pd}$ atoms are present in the surface film within a depth of about $40 \AA$, which is within the limit that can be probed by the XPS technique. The Fe $2 p$ spectrum (Fig. 4.8a) indicates that the surface of the elemental Fe is almost completely covered by the hydroxylated oxide film and the presence of elemental Fe below this film is barely visible as a shoulder at $706.8 \mathrm{eV}$. Exposure of this palladized Fe film to air for about three weeks resulted in an additional growth of the surface film, which almost completely obscured the elemental Fe (Fig. 4.8b). The Pd 3d spectrum, however, remained unchanged, thereby indicating that the Pd atoms were accessible to molecules in solution.

Effects of prolonged used of $\mathrm{Pd} / \mathrm{Fe}$ was evaluated by exposing a freshly prepared $\mathrm{Pd} / \mathrm{Fe}$ foil to an aqueous solution saturated with TCE until the product from the hydrodechlorination reaction (i.e., ethane) could no longer be detected. The fullscan photoelectron spectrum of the $\mathrm{Pd} / \mathrm{Fe}$ surface exposed to the aqueous solution saturated with TCE is shown in Fig. 4.9a. A significant decrease in the calculated $\mathrm{Pd} / \mathrm{Fe}$ ratio, from 0.6 to 0.02 , clearly indicates that there is an overall decrease in elemental Pd that is accessible to the aqueous solution of TCE. The Fe $2 p$ peak is obscured by the presence of the hydroxylated oxide film that has increased in thickness as a result of the prolonged exposure to the aqueous solution of TCE (Fig. 4.9b). It is also concluded that the elemental Pd is buried in the thick hydroxylated oxide film. A full scan of the photoelectron spectrum of the same sample washed twice with $3 \mathrm{M} \mathrm{HCl}$ is shown in Fig. 4.9c. The intensities of the Pd 3d peaks have increased by a factor of 3 from 0.02 to 0.06 and the underlying Fe surface has also been exposed because the thickness of the hydroxylated oxide film has been reduced. Indeed, the O:Fe ratio has been reduced by a factor of 2 from 0.06 to 0.03 . Thus, some of the reactivity of the $\mathrm{Pd} / \mathrm{Fe}$ surface is restored by the two-step acid wash. In none of these thin film experiments was a loss of Pd from the $\mathrm{Pd} / \mathrm{Fe}$ surface observed. 


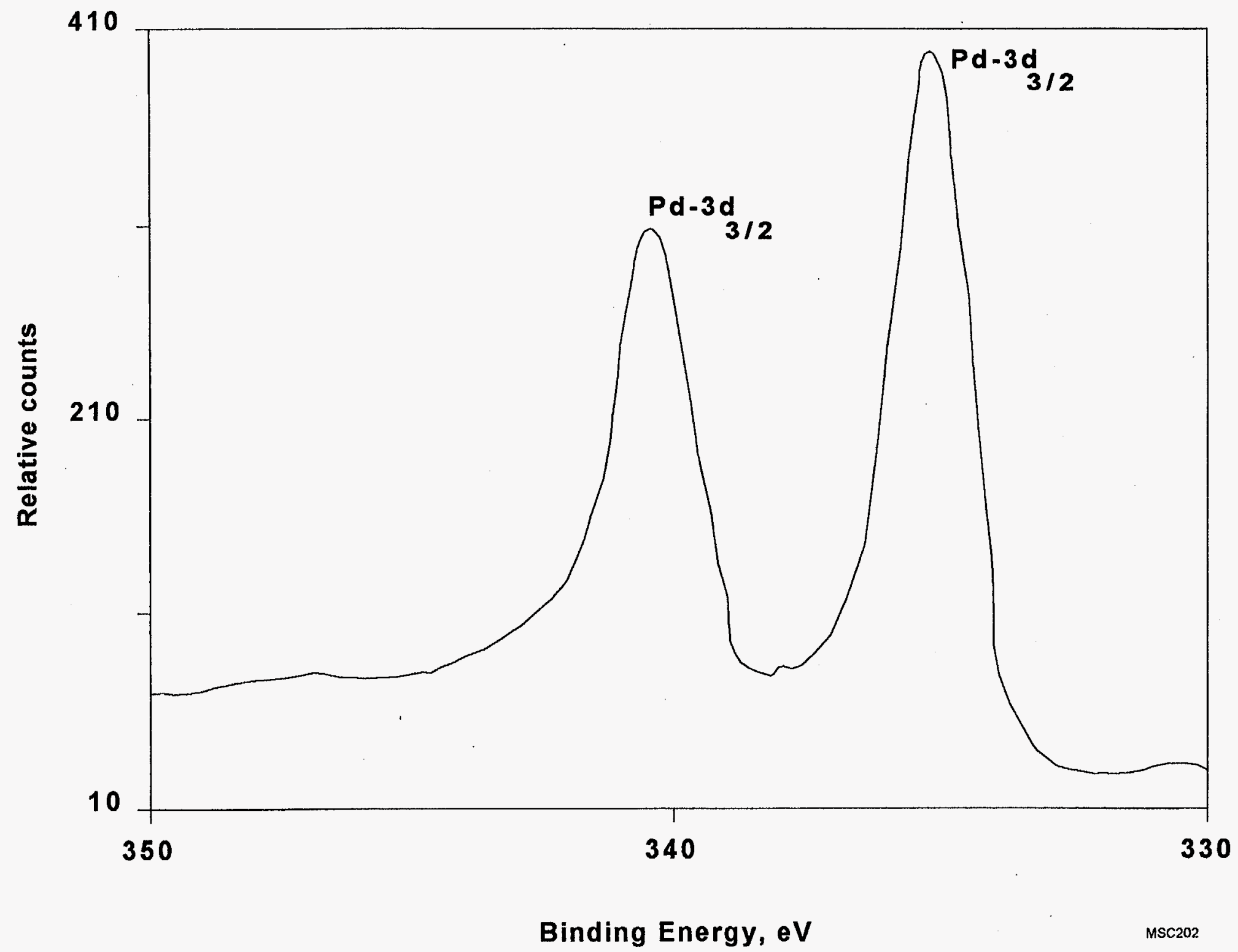

Fig. 4.7. Pd 3d photoelectron spectrum of a heavy deposit of elemental palladium on a hydroxylated iron oxide surface. The peak shapes and peak widths show that only elemental palladium is present. 


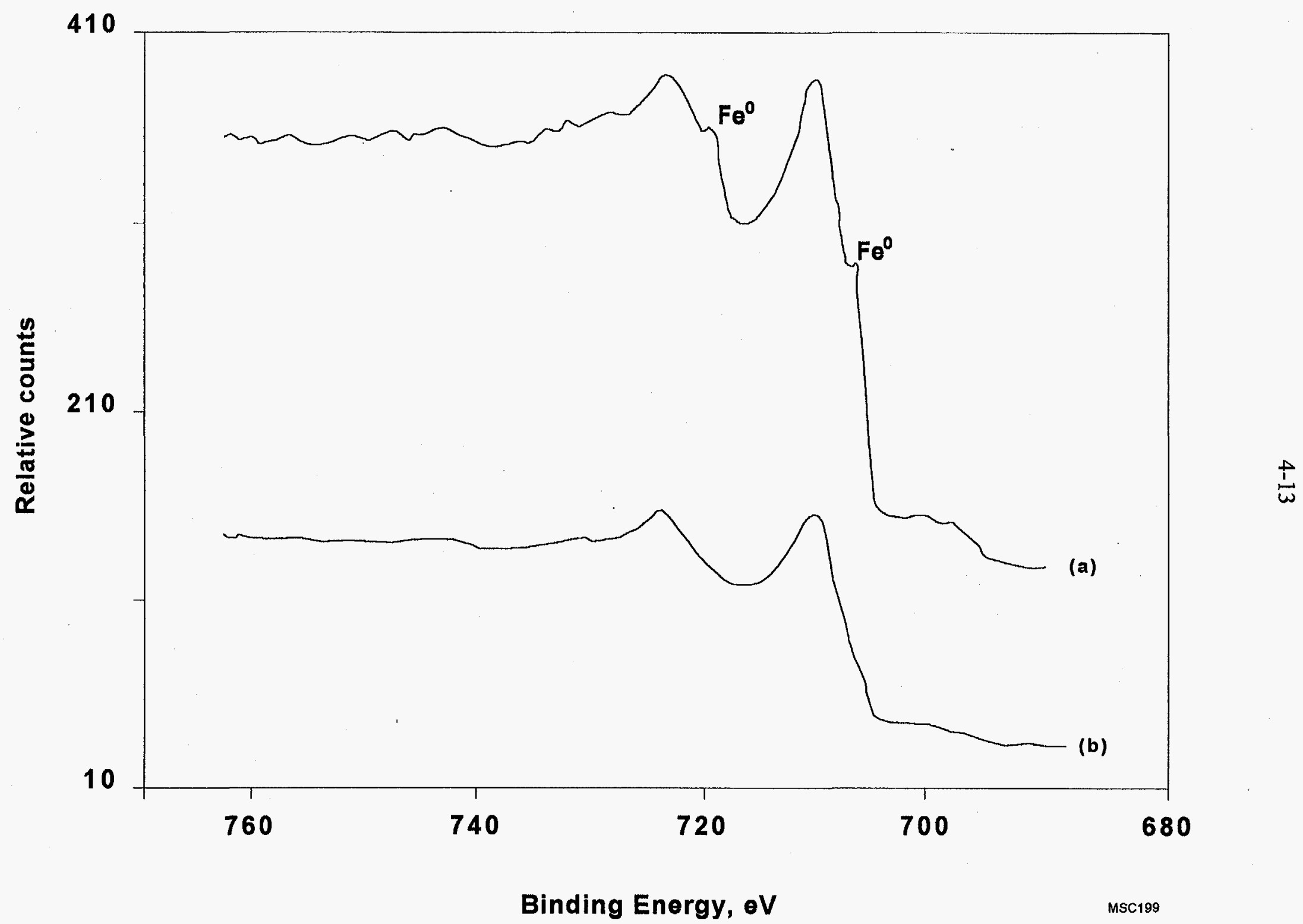

Fig. 4.8. (a) Fe $2 p$ photoelectron spectrum of the hydroxylated iron oxide film. The presence of a shoulder at $707.1 \mathrm{eV}$ indicates that presence of elemental iron in addition to the multiple oxidation states of iron. (b) The Fe $2 p$ photoelectron spectrum of the hydroxylated iron oxide film after its thickness was allowed to increase in moist air for 3 weeks. The $\mathrm{Fe} 3 p$ peaks of elemental iron are obscured by the thick hydroxylated iron oxide film. 


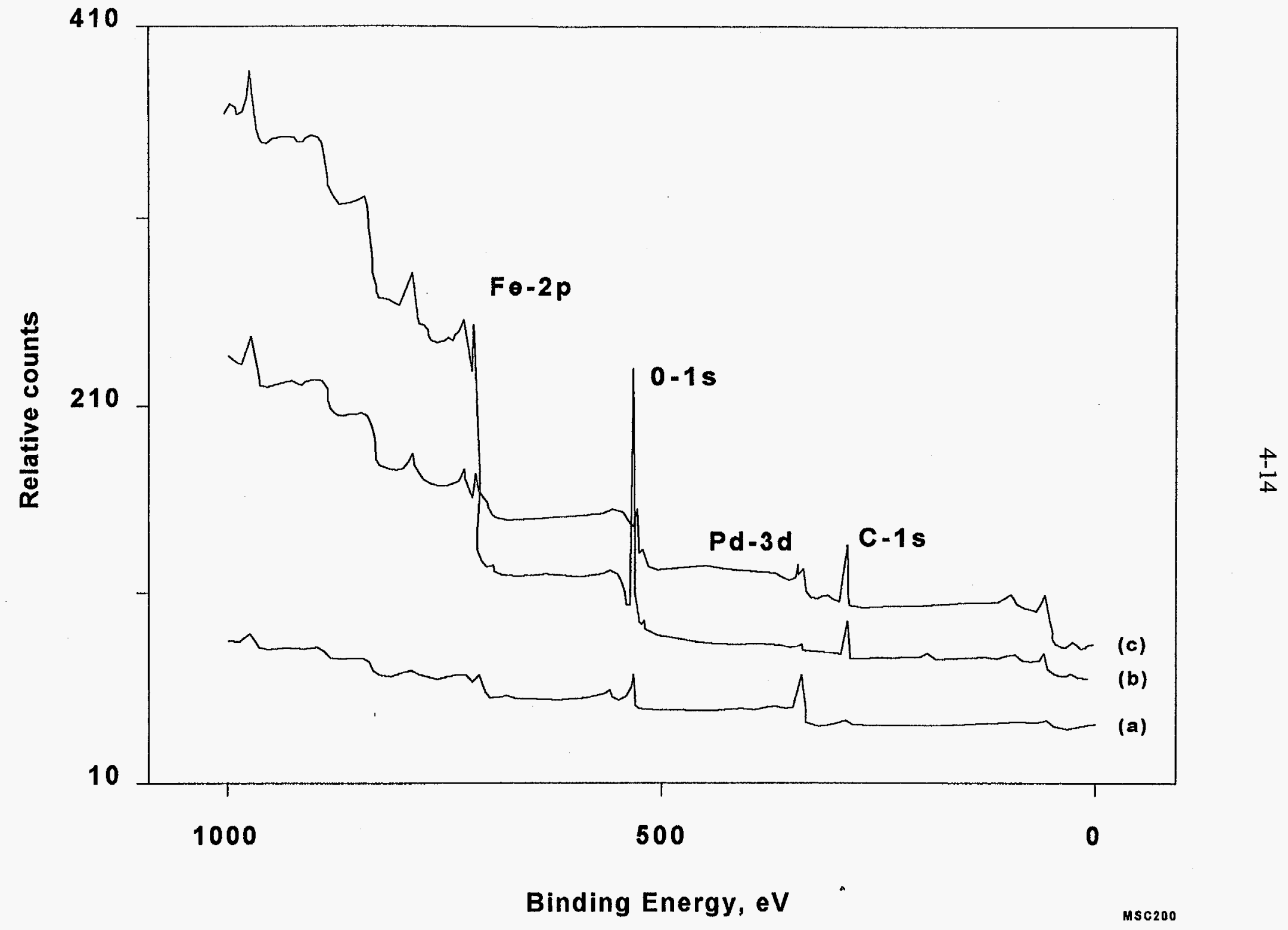

Fig. 4.9. (a) Full-scan photoelectron spectrum of the $\mathrm{Pd} / \mathrm{Fe}$ surface. (b) Full scan photoelectron spectrum of the $\mathrm{Pd} / \mathrm{Fe}$ surface after exposure to an aqueous solution of saturated TCE. (c) Full-scan photoelectron spectrum of the Pd/Fe surface in panel b washed twice with $3 \mathrm{M} \mathrm{HCl}$. 


\section{Pd/Fe Mechanistic Studies}

The high reactivity of the $\mathrm{Pd} / \mathrm{Fe}$ bimetallic system can be attributed to the following sequence of reactions: (a) evolution of hydrogen gas by the reduction of water molecules by elemental $\mathrm{Fe}$, (i.e., the "corrosion" of $\mathrm{Fe}$ in water) (b) the adsorption of the evolved hydrogen gas by $\mathrm{Pd}^{0}$, and the formation of the powerful reducing species " $\mathrm{PdH}_{2}$ ", (i.e., hydrogen gas intercalated into the elemental $\mathrm{Pd}$ lattice), and (c) the reduction of the chlorinated organic compound that is adsorbed on the bimetallic $\mathrm{Pd} / \mathrm{Fe}$ surface.

Electrochemical experiments were devised to confirm that the $\mathrm{PdH}_{2}$ species plays a significant role in the reductive dechlorination reactions at the $\mathrm{Pd} / \mathrm{Fe}$ surface on which the chlorinated species are adsorbed (Cheng et al. 1997). The principal variables that govern these dechlorination reactions are the surface area of the bimetallic $\mathrm{Pd} / \mathrm{Fe}$ system and the amount of $\mathrm{PdH}_{2}$ that is available. Thus, the cathodic reductions of a chlorinated organic compound at electrodes of known surface area in the presence and the absence of evolved hydrogen gas were examined. These experiments have helped in the evaluation of the role of surface bound Pd not only in its role as a hydrogen evolution catalyst but also a facilitator of the reductive dechlorination of organics.

The hydrogen evolution characteristics of platinized iron $(\mathrm{Pt} / \mathrm{Fe})$ and $\mathrm{Pd} / \mathrm{Fe}$ should be similar, but the rate of hydrodechlorination by $\mathrm{Pt} / \mathrm{Fe}$ was found to be much slower than that observed with $\mathrm{Pd} / \mathrm{Fe}$. This finding is apparently due to the ability of Pd to absorb hydrogen. Indeed, Pd metal in conjunction with high-pressure hydrogen have been used over the years in many organic hydrogenation schemes (Marques et al. 1994; Johnston and Wilby 1985; Coq et al. 1993; Bodnariuk et al. 1989). For these experiments, the organic compound used to examine the role of $\mathrm{Pd}$ in reductive dechlorination was 4-chlorophenol (4-CP). This compound was selected for its relative non-volatility and the aqueous solubility of both the reactant and product (phenol). Moreover, 4-CP and phenol can be conveniently determined at ppm levels in aqueous solutions by high-pressure liquid chromatography (HPLC).

Several types of cathodic materials have been evaluated for the catalytic decomposition of halogenated organics (Criddle and McCarty 1991; Zhang 1995; Kulikov et al. 1996). Zhang and Rusling utilized either carbon cloth or $\mathrm{Pb}$ cathodes for the dechlorination of PCBs (Zhang and Rusling 1993). These authors found that $\mathrm{Pb}$ cathodes were superior to carbon and suggested that this was due to the higher hydrogen overpotential of $\mathrm{Pb}$. Matheson and Tratnyek proposed that it should be possible to rapidly dehalogenate chloroorganics by hydrogen gas if a suitable 
dechlorination catalyst is used (Matheson and Tratnyek 1994). Such a process would take place via the following reaction:

$$
\mathrm{H}_{2}+\mathrm{RX} \rightarrow \mathrm{RH}+\mathrm{H}^{+}+\mathrm{X}^{-}
$$

Recently, Kulikov and coworkers used $\mathrm{Zn}$ modified carbon cloth for the reductive dechlorination of lindane in aqueous solution (Kulikov et al. 1996). In their proposed mechanism, lindane was adsorbed on the carbon cloth surface and then reduced by zinc metal. The metallic zinc islands were regenerated by the electrochemical reduction of $\mathrm{Zn}^{2+}$. No mention was made however, of the possibility that lindane may be dechlorinated by hydrogen gas. This route cannot be discounted because zinc metal is a prodigious producer of $\mathrm{H}_{2}$ in aqueous solutions.

\subsection{Experimental}

Materials and chemicals. Carbon cloth (99.9\%) was supplied by Aesar (Ward Hill, Massachusetts). Graphite electrode rods, $(6.15 \mathrm{~mm}$ diameter) designated as ultra-purity "F" were obtained from Ultra Carbon Corporation (Bay City, Michigan). Fe wire of $0.25 \mathrm{~mm}$ ( $99.9 \%$ Aldrich, Milwaukee, Wisconsin), $\mathrm{K}_{2} \mathrm{PdCl}_{6}\left(99 \%\right.$, Aldrich), $\mathrm{K}_{2} \mathrm{PtCl}_{6}$ (99.99\%, Aldrich), sodium acetate (Fisher, Pittsburgh, Pennsylvania), methanol (HPLC grade, Fisher) and Pd gauze (Aesar) were all used as received. All water was of $18.2 \mathrm{M} \Omega-\mathrm{cm}$ quality obtained from a Millipore-Q system.

Metal modification of $\mathrm{Fe}$ wire, carbons cloth, and graphite electrodes. Palladized graphite rod and carbon cloth electrodes were prepared in the following manner. A $2.2 \mathrm{~cm}_{2}(1.0 \mathrm{~cm}$ length $)$ area of graphite rod was exposed to a $35.0 \mathrm{~mL}$ solution of $1.8 \mathrm{mM} \mathrm{K}_{2} \mathrm{PdCl}_{6}(25.0 \mathrm{mg}$ total) in $0.050 \mathrm{M}$ sodium acetate-acetic acid buffer ( $\mathrm{pH} \mathrm{5.0)}$ by tightly wrapping Teflon tape to the remainder of the electrode (see Fig. 5.1). Pd was electrodeposited at a constant current of $5.6 \mathrm{~mA}$ until the characteristic yellow color of the $\mathrm{K}_{2} \mathrm{PdCl}_{6}$ solution disappeared. This process required approximately $4 \mathrm{hrs}$. During this time, vigorous hydrogen evolution was observed from the cathode surface, and large amounts of Pd metal flaked off the cathode surface. The palladized graphite electrode was then removed from the electrolysis solution, dried overnight at room temperature, and weighed to the nearest $0.1 \mathrm{mg}$. The mass of the graphite rod did not change as a result of palladization; hence, it was assumed that the mass of the Pd on the electrode was less than $0.1 \mathrm{mg}$. Carbon cloth was palladized in the same manner with the electrodes also retaining something less than $0.1 \mathrm{mg}$ of Pd. The area of the carbon cloth was $2.0 \mathrm{~cm}^{2}$; but the true surface area is much larger because this is a three dimensional electrode. Electrical contact to the carbon cloth electrode was made 


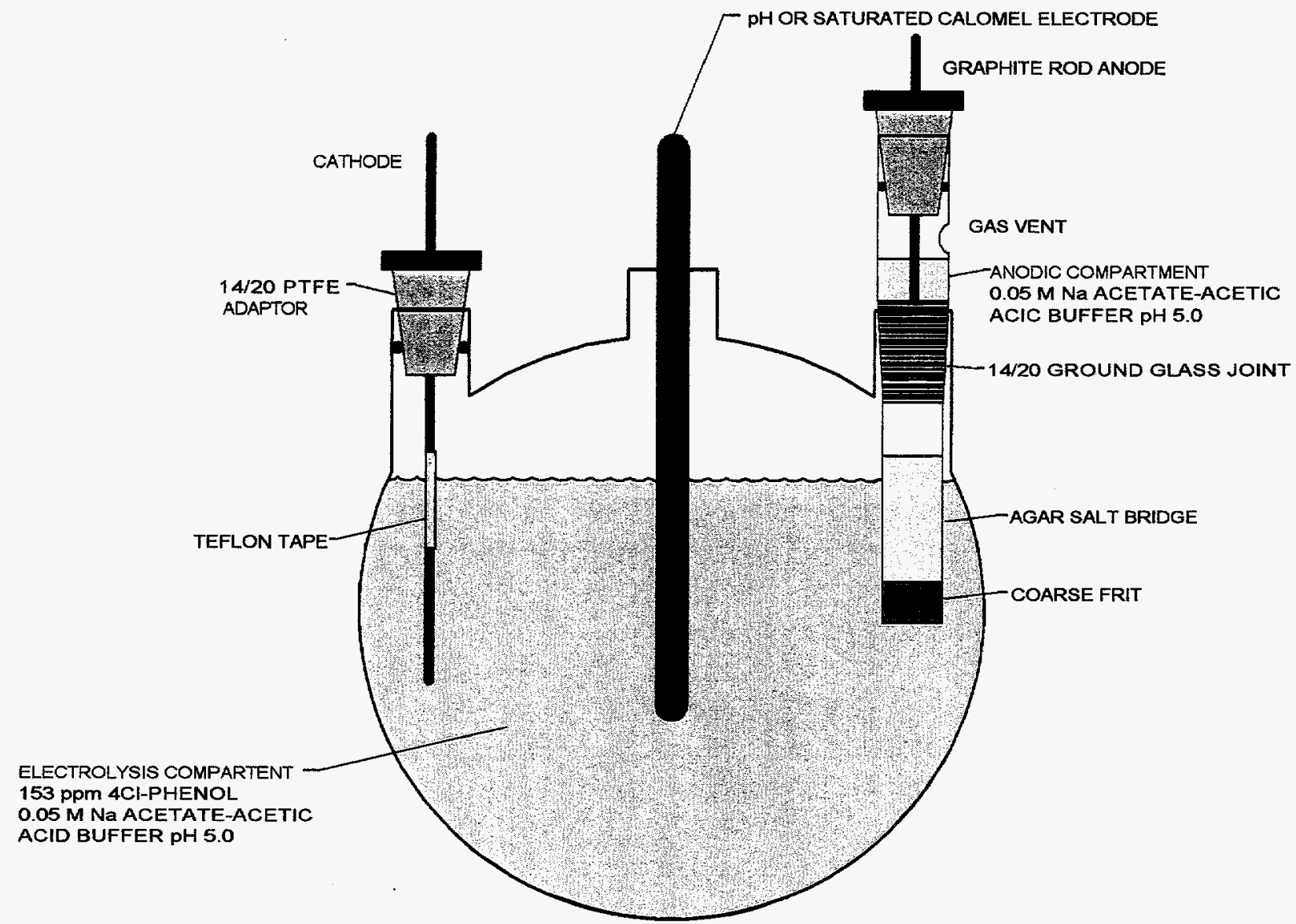

\section{Neck $50 \mathrm{~mL}$ flask $14 / 20$ Joints} PRMO97

Fig. 5.1. Reaction vessel for electrochemical experiments used to evaluate mechanism of reduction by $\mathrm{Pd} / \mathrm{Fe}$. 
with a copper plated alligator clip with its surface isolated from the electrolysis solutions by wrapping with Teflon tape. Platinization of carbon cloth followed the same procedure and conditions used for palladization. The amount of platinum adhering to the surface of carbon cloth after this procedure was also found to be less than $0.1 \mathrm{mg}$.

As shown previously, deposition of $\mathrm{Pd}$ onto $\mathrm{Fe}$ from $\mathrm{K}_{2} \mathrm{PdCl}_{6}$ is a spontaneous process via the reaction:

$$
2 \mathrm{Fe}^{0}+\mathrm{PdCl}_{6}^{-2} \rightarrow 2 \mathrm{Fe}^{+2}+\mathrm{Pd}^{0}+6 \mathrm{Cl}^{-}
$$

Palladization of Fe wire was accomplished by exposure to $20.0 \mathrm{~mL}$ of a solution of $0.072 \mathrm{mM}$ solution of $\mathrm{K}_{2} \mathrm{PdCl}_{6}$ for $30 \mathrm{~min}$. The amount of $\mathrm{Pd}$ deposited on the Fe surface (1 mg) was assumed to be that resulting from $100 \%$ completion of reaction 2 .

Bulk electrolysis of 4-CP solution. The electrode systems described above were used for the constant current electrolysis of 4-CP at ambient temperature $\left(25^{\circ} \mathrm{C} \pm\right.$ $3)$. The cell was a three neck (14/20) round bottom flask $(50 \mathrm{~mL})$. Cathodes were held securely in place with a $14 / 20$ polytetrafluoroethylene (PTFE) o-ring adapter. Electrical contact with the carbon cloth and Fe wire electrodes was maintained by means of the Cu-plated alligator clip wrapped with Teflon tape. The alligator clip was contacted with a copper wire threaded through $5 \mathrm{~mm}$ glass tubing and held in place with a PTFE o-ring adapter. The central 14/20 portal was used for $\mathrm{pH}$ measurements or for the measurement of the cathode potential vs saturated calomel electrode (SCE) (Fisher, Pittsburgh, Pennsylvania). The anode was isolated from the electrolysis solutions by means of a $4 \%$ agar salt bridge $(0.25 \mathrm{M}$ sodium acetate). The anodic compartment was also vented so that oxygen gas was able to escape. Control experiments indicated that no 4-CP migrated across the agar salt bridge over the time scale of the experiments. The solutions were unstirred. Constant current and constant potential experiments were conducted on a Princeton Applied Research Corporation model 173 potentiostat/galvanostat (Princeton, New Jersey). The $\mathrm{pH}$ measurements were made with an Orion model 91-05 combination electrode and a Perkin-Elmer Metrion III pH meter.

HPLC analysis. Samples of the 4-CP solution were analyzed by HPLC during the course of the constant current electrolysis. The HPLC apparatus consisted of a Rheodyne model 720 injection valve, Milton-Roy Constametric 300 isocratic pump, a $5.0 \mathrm{~cm} \mathrm{C}_{18}$ Zorbex column, Waters Associates model 440 absorbance detector set at $254 \mathrm{~nm}$, and a Hewlett-Packard model 3392A integrator. The mobile phase composition was 50/50/2 water, methanol, glacial acetic acid mixture by volume. Phenol $(t=2.54 \mathrm{~min})$ and 4-CP $(t=4.37 \mathrm{~min})$ peaks were 


\section{$5-5$}

identified by using standard solutions. Quantification of phenol production and 4-CP dechlorination was accomplished by the use of calibration curves.

\subsection{Carbon Cloth Cathodes}

A $25.0 \mathrm{~mL}$ solution of $153 \mathrm{ppm} 4-\mathrm{CP}$ in a $0.05 \mathrm{M}$ sodium acetate-acetic acid buffer was electrolyzed at a constant current of $5.6 \mathrm{~mA}$ at a bare carbon cloth cathode. The potential vs saturated calomel electrode was measured throughout the electrolysis and did not vary more than $\pm 10 \mathrm{mV}$ of -1.10 volts. The $\mathrm{pH}$ of the solution increased slowly from 5.0 to 5.6 during the course of the electrolysis (16 hrs) which was performed under aerobic conditions. During this time period, samples of the electrolysis solution were analyzed for phenol and 4-CP content by HPLC. The 4-CP content was found to remain nearly constant throughout the experiment with minimal amounts of phenol produced $(<5 \mathrm{ppm})$ at the end of the electrolysis. A vigorous evolution of hydrogen gas was observed at the carbon electrode throughout the experiment. The results of this experiment indicate that the bare carbon cloth surface is not an efficient substrate for the dechlorination of 4-CP.

The identical carbon cloth electrode was then subjected to palladization by electrodeposition as described in Sect. 5.1. Constant current electrolysis of the 4-CP solution as outlined above with a bare carbon cloth electrode required an initial applied potential of -0.69 volts (vs SCE) which increased gradually to -0.85 volts at the completion of the electrolysis $(15 \mathrm{hrs})$. The solution $\mathrm{pH}$ increased from 5.0 to 5.6 during the $15 \mathrm{hr}$ period. The dechlorination of 4-CP to phenol was found to occur much more rapidly at the palladized carbon cloth electrode. The results of the HPLC analyses of the electrolysis solution are shown in Fig. 5.2. Complete dechlorination of the compound occurred.

Elimination of DO by purging with helium gas yielded identical results for the bare and palladized carbon cloth electrode systems. Thus, DO was not removed in subsequent electrochemical experiments.

Platinized carbon cloth electrodes failed to reduce 4-CP to phenol. No loss of 4-CP and no production of phenol were observed over a $15.7 \mathrm{hr}$ period under conditions of constant current electrolysis $(5.6 \mathrm{~mA})$ of the $153 \mathrm{ppm}$ solution of 4-CP (pH 5.0).

Constant potential electrolysis ( -0.700 volts vs $\mathrm{SCE})$ of $4-\mathrm{CP}$ at the three electrode systems described above gave results that were similar to those obtained with the constant current study. In other words, the rate of electrochemically induced dechlorination at $2.0 \mathrm{~cm}^{2}$ carbon cloth electrodes followed the sequence, palladized $>>$ platinized $=$ unmodified electrode. Figure 5.2 illustrates the results of the constant potential study. 


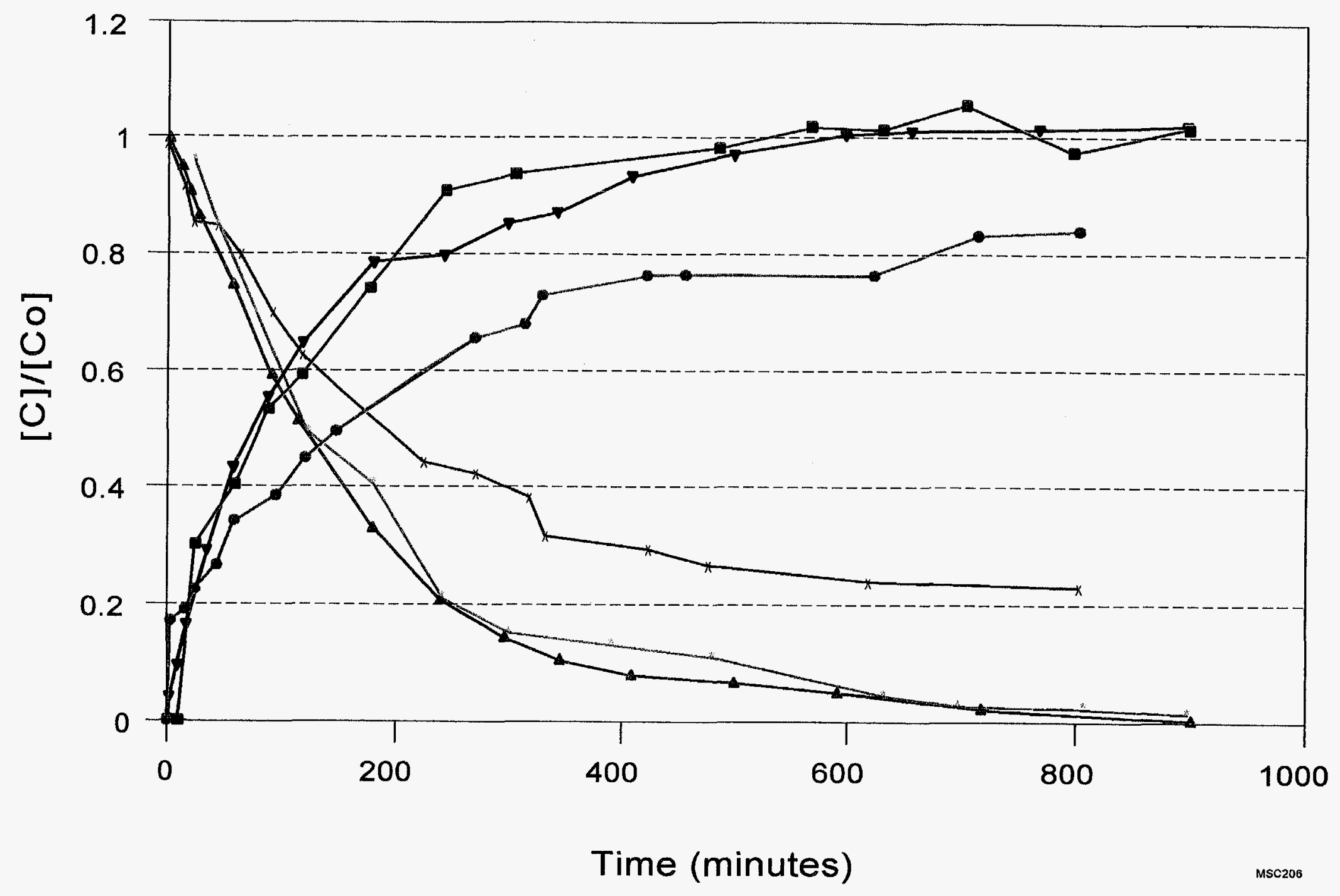

Fig. 5.2. Production of phenol at palladized carbon cloth electrodes under conditions of controlled potential of -0.700 volts vs SCE (-X), controlled current of $5.6 \mathrm{~mA}(---)$, and at a constant current of $5.6 \mathrm{~mA}$ at a palladized graphite cathode (-+-). Degradation of 4-CP at palladized carbon cloth electrodes under conditions of controlled potential of -.0700 volts vs SCE (--), controlled current of $5.6 \mathrm{~mA}(-\nabla-)$, and at a constant current of $5.6 \mathrm{~mA}$ at a palladized graphite cathode (-๑-). 
The complete dechlorination of 4-CP at the palladized carbon cloth electrode required $15 \mathrm{hrs}$, during which time the current decreased from 2.2 to $0.8 \mathrm{~mA}$. Neither the platinized nor the bare carbon cloth electrodes were able to effect dechlorination of 4-CP at a constant potential of -0.700 volts vs SCE during $15 \mathrm{hr}$ time periods.

\subsection{Graphite Rod Electrodes}

A similar constant current $(5.6 \mathrm{~mA})$ electrolysis of $25.0 \mathrm{~mL}$ of the $153 \mathrm{ppm}$ solution of 4-CP was conducted on both bare and palladized graphite rod electrodes. The geometrical surface area of the electrodes exposed to solution was $2.2 \mathrm{~cm}^{2}$. As with bare carbon cloth the unpalladized graphite electrode failed to effect the hydrodechlorination of 4-CP during a period of $13.5 \mathrm{hrs}$. The constant current electrolysis of $5.6 \mathrm{~mA}$ required a potential of -1.5 volts vs SCE for the bare graphite electrode.

Dechlorination of 4-CP at the palladized graphite electrode $(<0.1 \mathrm{mg} \mathrm{Pd})$ was faster than at the bare graphite surface albeit slower than with the palladized carbon cloth cathode. The results of the dechlorination of 4-CP are presented in Fig. 5.2. Approximately $70 \%$ of the 4-CP was found to dechlorinate to phenol during an electrolysis period of $15 \mathrm{hrs}$.

\subsection{Iron Wire Electrodes}

A $0.270 \mathrm{~g}$ sample of $0.25 \mathrm{~mm}$ Fe wire $\left(68 \mathrm{~cm}, 17 \mathrm{~cm}^{2}\right)$ was tightly coiled and used for the electrolysis of $153 \mathrm{ppm} 4-\mathrm{CP}$ at $5.6 \mathrm{~mA}$ for $16 \mathrm{hrs}$. The potential required for this constant current was -0.95 volts vs SCE. No phenol was detected at the end of this time period. The 4-CP concentration remained constant throughout the electrolysis. Palladization of this electrode resulted in only slight increases of phenol production $(<10 \mathrm{ppm})$ with identical electrolysis conditions. The potential required to maintain a constant $5.6 \mathrm{~mA}$ current for the $\mathrm{Pd} / \mathrm{Fe}$ wire electrode was -0.95 volts vs $\mathrm{SCE}$.

\subsection{Palladium Gauze Electrodes}

A $0.0350 \mathrm{~g}$ sample of $\mathrm{Pd}$ (area $\sim 0.5 \mathrm{~cm}^{2}$ ) gauze cathode was used to electrolyze the $153 \mathrm{ppm}$ solution of $4-\mathrm{CP}$ for $16 \mathrm{hrs}$ at both constant current $5.6 \mathrm{~mA}\left(\mathrm{E}_{\text {cathode }}=\right.$ 


\section{$5-8$}

-2.1 volts vs SCE) and a constant potential of -0.700 volts vs SCE $(220 \mu \mathrm{A})$. The $\mathrm{Pd}$ gauze electrode was saturated with hydrogen prior to exposure to the 4-CP solution by applying a constant current of $5 \mathrm{~mA}$ overnight in a $0.05 \mathrm{M}$ sodium acetate acetic acid buffer solution (pH 5.0) (Lawson et al. 1991). Neither phenol production nor dechlorination of the 4-CP was observed during this period of time.

\subsection{Implications for the Reaction Mechanisms}

Direct Electroreduction at the Electrode Surfaces. There are three plausible mechanisms by which electrochemically driven reductive dechlorination may proceed. These routes are shown in Fig. 5.3. The homogeneous reduction of $4 \mathrm{CP}$ in solution was ruled out because of the failure of the control experiments on bare metal surfaces. This conclusion is consistent with recent findings regarding the mechanisms of reduction of surface bound 4-aminoazobenzene by zerovalence iron (Weber 1996).

In the first mechanism (Fig. 5.3a), the reductive dechlorination is a two electron, one proton process which takes place at the electrode surface (equation 12).

$$
\mathrm{RX}+\mathrm{H}^{+}+2 \mathrm{e}^{-} \rightarrow \mathrm{RH}+\mathrm{X}^{-}
$$

Such processes have been mentioned as a possible reaction route for dissolving metal reactions (Matheson and Tratnyek 1994). Indeed, corrosion of $\mathrm{Fe}$ to $\mathrm{Fe}^{2+}$ occurs at a potential of -0.66 volts vs SCE and for this reason metallic $\mathrm{Fe}$ has been frequently claimed to be a facilitator for the reductive dehalogenation of chloroorganics. In this study, the electrode serves as the reducing agent, either in the potentiostatic $(-0.700$ volts vs $\mathrm{SCE})$ or galvanostatic $(5.6 \mathrm{~mA})$ mode. If equation 12 were the reaction route then palladization of electrode surfaces should be of little relevance because the electrode acts as the thermodynamic equivalent of the corroding Fe system. In this role all the unmodified electrodes, including $\mathrm{Fe}$, failed to electrolyze 4-CP to phenol during the time scale of the experiment $(15 \mathrm{hrs})$. This indicates that the route presented by equation 12 is not important for reductive dehalogenation of $4-\mathrm{CP}$.

Dechlorination at Pd Surfaces. In Fig. 5.3b Pd islands formed by the electrodeposition of $\mathrm{Pd}$ act as catalytic surfaces for the mechanisms shown by equation 11. This implies that 4-CP is adsorbed on the Pd surface. This scheme can be eliminated as a significant route for dechlorination of 4-CP because the results obtained at the Pd gauze electrode do not support this conclusion. 


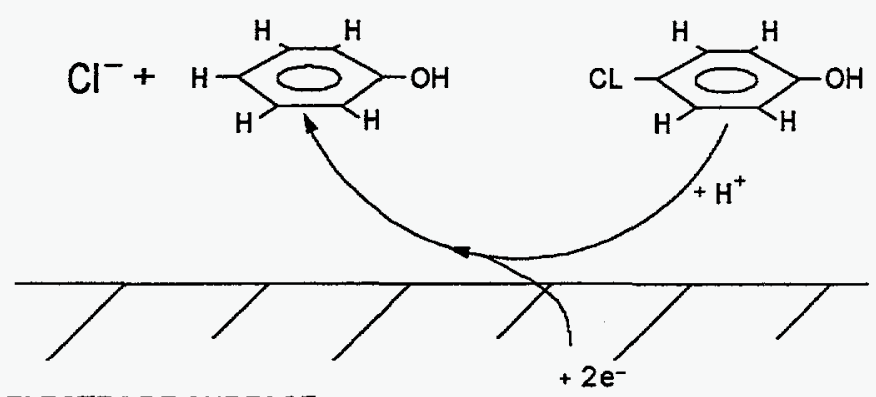

A

ELECTRODE SURFACE
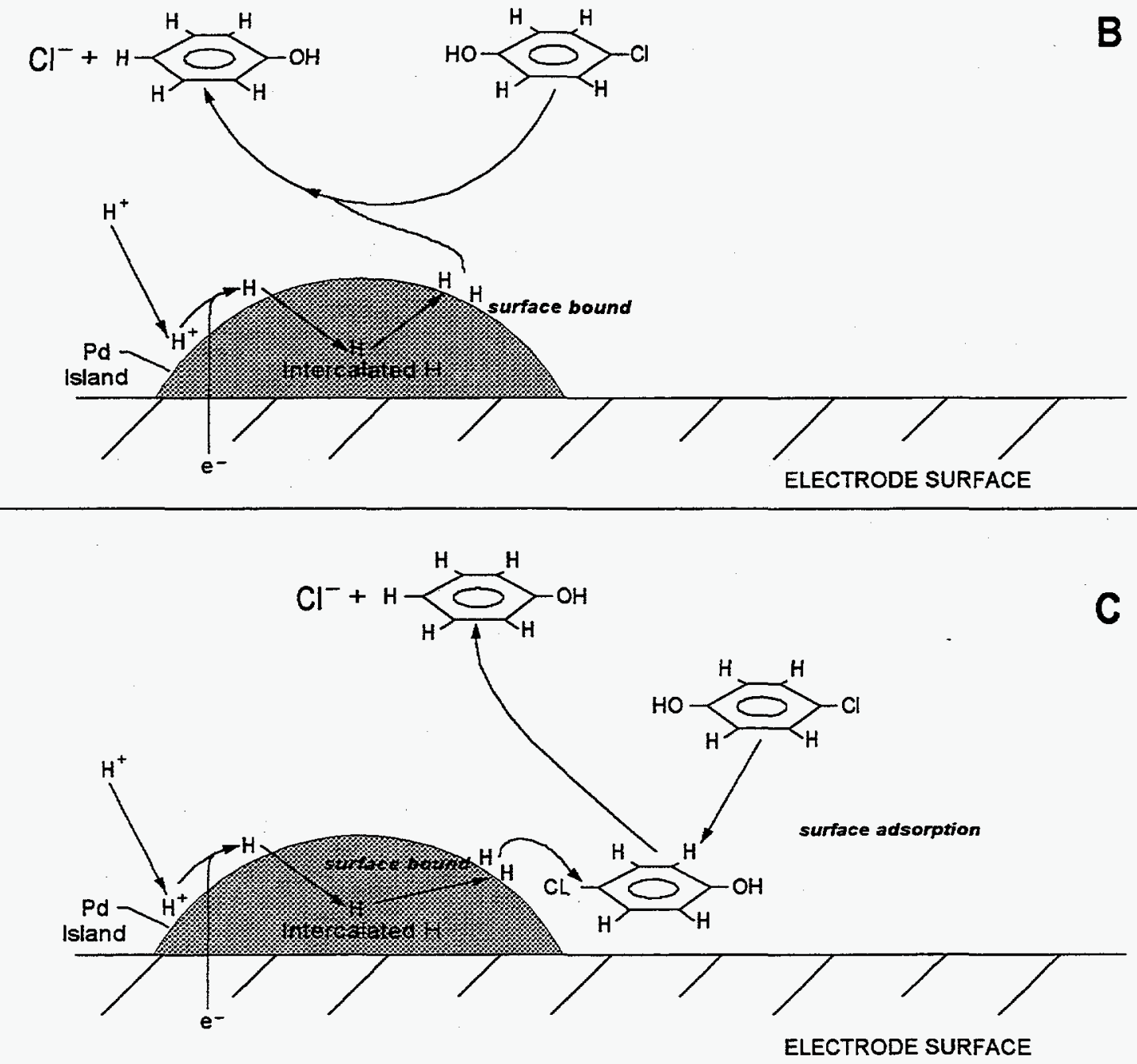

Fig. 5.3. Proposed mechanisms for the hydrodehalogenation of 4-CP to phenol. a) Direct reduction at electrode surface. b) Hydrogenation at palladium catalyst surface. c) Adsorption of 4-CP at electrode substrate followed by hydrogenation at palladium island/electrode surface. 
Despite the pretreatment which ensured that the Pd lattice was saturated with hydrogen, this electrode system failed to effect the dechlorination of 4-CP at a constant current of $5.6 \mathrm{~mA}$. The blockage of 4-CP adsorption by hydrogen gas evolution cannot be discounted, but it should also be noted that at the applied potential of -0.700 volts vs SCE (which resulted in a current of $200 \mu \mathrm{A}$ ), hydrogen evolution was modest as compared to the galvanostatic experiment $(5.6 \mathrm{~mA})$. Yet, there was no evidence of dechlorination at the Pd gauze electrode.

Dechlorination at the Pd-Substrate Interface. Figure 5.3c illustrates a third reaction route for the dehalogenation reaction. In this scheme, 4-CP is adsorbed to the substrate surface and undergoes dechlorination at the Pd island/substrate interface.

The results obtained with the $\mathrm{Pd} / \mathrm{Fe}$, graphite, and carbon cloth electrodes support this scheme. In the latter two cases dechlorination to phenol was relatively successful. Again, as in the Pd gauze system the interior of the Pd islands $(<0.1 \mathrm{mg})$ is saturated with hydrogen gas during the time scale of our experiments. The amount of charge and the diffusion coefficient of hydrogen in the Pd lattice indicates that less than $20 \mathrm{~min}$ is needed for full saturation (Lawson et al. 1991); the hydrodehalogenation products were detected before this time period was completed.

The palladized graphite and carbon cloth electrodes were both able to dechlorinate 4-CP (Fig . 5.2). The scheme outlined in Fig. $5.3 \mathrm{c}$ is therefore a plausible reaction route. The ability of carbon surfaces to adsorb organic compounds probably facilitates the dechlorination reaction because it places the compound in the vicinity of hydrogen-saturated Pd islands. It is apparent that Pd by itself cannot effect the dechlorination probably because of its inability to adsorb 4-CP. Negative results for $\mathrm{Pd} / \mathrm{Fe}$ wire may also be due to the low concentration of adsorbed 4-CP in comparison with concentrations adsorbed on carbon surfaces.

\section{Hydrogen Generation and Pd vs Platinum in Dechlorination Reactions.}

These results demonstrate that hydrogen plays a key role in the dechlorination of 4-CP to phenol. Therefore, the electrochemical evolution of hydrogen gas by the reduction of water aids dechlorination. Both platinum and $\mathrm{Pd}$ are excellent surfaces for the electrochemical evolution of hydrogen gas (Sawyer and Roberts 1974). Indeed, constant current studies generate the same flux of hydrogen at bare electrodes as well as metal-modified electrodes. However, in these experiments, in which platinum was substituted for $\mathrm{Pd}$, the dechlorination reactions ceased under constant potential as well as constant current conditions. Galvanostatic studies on bare and palladized electrode surfaces indicate that only the latter have the ability to reductively dechlorinate 4-CP. In other words, although the flux of hydrogen gas generated at $\mathrm{Pd}$ and $\mathrm{Pt}$ surfaces is approximately equal, $\mathrm{Pd}$ has the 


\section{$5-11$}

unique property of promoting dechlorination of organic compounds. Apparently, the ability of $\mathrm{Pd}$ to absorb hydrogen into its lattice and to maintain a high surface concentration of hydrogen (Lawson et al. 1991) explains this phenomenon.

Neither carbon nor platinum can absorb significant amounts of hydrogen. Carbon and platinum surfaces at which the same flux of hydrogen gas is generated, cannot promote dechlorination reactions because hydrogen gas escapes relatively easily from both surfaces.

In summary, these electrochemical experiments have shown that palladization of cathodic surfaces promotes the dechlorination of 4-CP not by an increased rate of hydrogen evolution but by the Pd islands acting as "pools" of hydrogen that promote dechlorination. The substrate surface on which $\mathrm{Pd}$ is deposited also plays a key role relative to its propensity to adsorb the compound to be dechlorinated. 


\section{Longevity and Regeneration of $\mathrm{Pd} / \mathrm{Fe}$}

The value of $\mathrm{Pd} / \mathrm{Fe}$ as a treatment agent is directly related to the length of time the material remains active and the ease with which it can be regenerated. Accordingly, preliminary experiments and observations throughout this project have considered longevity and regeneration. It should be noted, however, that the project funding and timing did not permit the systematic experiments required to fully understand these two issues.

\subsection{Poisoning}

It is well-known that sulfide poisons hydrogenation catalysts (Freifelder 1971). Fortunately, sulfide occurs naturally only in very anaerobic groundwaters that typically do not have a beneficial use. For that reason, sulfide as a poisoning agent for $\mathrm{Pd} / \mathrm{Fe}$ was not expected to be a problem. Sulfate, however, would be prominent in many waste streams where $\mathrm{Pd} / \mathrm{Fe}$ could be applied. As a simple check, preliminary laboratory batch studies were performed to determine whether $\mathrm{Pd} / \mathrm{Fe}$ reduced sulfate. These studies did not detect any sulfate reduction.

Subsequently, a simulated, reactive-barrier, field experiment (Liang et al. 1996) conducted at PORTS did indicate some formation of sulfide from sulfate. Groundwater at PORTS can contain several hundred ppm of sulfate and was in the range of $350-450 \mathrm{ppm}$ in the simulated reactive-barrier experiment. $\mathrm{Pd} / \mathrm{Fe}$ dechlorinated TCE as designed but the column clogged after approximately 3600 pore volumes had been treated. It should be noted that columns of two-types of zero-valence iron also clogged but at a much lower (approximately 350 ) number of pore volumes. In addition, there was initially a significant problem with trapped air during start-up and air or oxygen is known to be the primary agent for causing clogging (Mackenzie et al. 1997). However, when the $\mathrm{Pd} / \mathrm{Fe}$ column was opened, there was a distinct odor of sulfide. Water samples from the column did not contain soluble sulfide, but reduced sulfur species (sulfide and sulfite), as identified by XPS, were present on the used $\mathrm{Pd} / \mathrm{Fe}$.

The apparent contrary results between the lab and field experiments concerning sulfide formation can be reconciled by considering the possibility that sulfurreducing bacteria (SRBs), using hydrogen as a primary food source, were reducing the sulfate. Subsequent analysis of the water from the column did reveal that SRBs were present. These data, of themselves, are not sufficient to prove that sulfate reduction is a significant process. Experiments under controlled conditions are needed for conclusive evidence. 


\subsection{Loss of Palladium}

Another problem that was evaluated was loss of Pd from the Fe surface. This was not considered to be a problem based on the difference in reduction potentials of $\mathrm{Pd}$ and Fe.

$$
\begin{aligned}
& \mathrm{Pd}^{2+}+2 \mathrm{e}^{-}-\mathrm{Pd}^{0}+0.92 \\
& \left(\mathrm{PdCl}_{4}\right)^{4-}+2 \mathrm{e}^{-} \rightarrow \mathrm{Pd}^{0}+\mathrm{Cl}^{-}+0.62 \\
& \mathrm{Fe}^{+2}+2 \mathrm{e}^{-} \rightarrow \mathrm{Fe}^{0}-0.44
\end{aligned}
$$

Potential loss of the second metal had been addressed by others (Mallat et al. 1991). These authors suggested that the Pd was cemented rather than bound to the Pd. Mallat et al. (1991) stated that "Dissolution of the second metal is negligible. ... When all of the base metal in a single particle is completely consumed, the second metal of the more positive Nernst potential is also dissolved and can be deposited again on another base metal particle." However, as various preparations of $\mathrm{Pd} / \mathrm{Fe}$ were used in this project, loss of $\mathrm{Pd}$ from the surface was evident. The Pd was found in a black precipitate that "flaked off" the Fe surface. Thus, the contention by Mallat et al. (1991) that the Pd would be re-dissolved may not be correct as Pd metal is difficult to dissolve (Cotton and Wilkinson 1966).

To date, the potential problem of Pd loss from the surface has not been fully explained. In particular, this difficulty results from the fact that data from different experiments are contradictory. For example, thin film work suggested that there was not a Pd adherence problem (see Sect. 4) (Muftikian et al. 1996). In contrast, $\mathrm{Pd} / \mathrm{Fe}$ prepared in the field under relatively controlled conditions (see Sect. 7) showed that some amount of Pd is precipitated as Pd metal and is not cemented to the Fe surface. It is suspected, therefore, that Pd cementation and adherence improves under more controlled conditions. In other words, if plating occurs under conditions where the Fe surface is less-clean, that is, in the presence of $\mathrm{Fe}$ oxides/hydroxides and other impurities, then palladization is less successful. Similarly, the condition of the surface with respect to size and variation of pores may also be a factor. Recall that in Sect. 4, data were presented that show that the $\mathrm{Pd}$ is always found on "islands" and does not completely cover the Fe surface. The reason that Pd plates in certain locations only is not known and is the subject of current studies. 


\subsection{Regeneration}

The reactivity of the $\mathrm{Pd} / \mathrm{Fe}$ was expected to decrease with time. Reasons for an expected deterioration with increased contact with site water include: increased coverage of the $\mathrm{Fe}$ surface with hydroxylate ions (see Sect. 4), precipitation of sulfates, carbonates and oxides on the $\mathrm{Pd} / \mathrm{Fe}$ surface, and accumulation of colloidal matter that occurs naturally in the aquifer.

The only regeneration experiments that were conducted were brief tests at a laboratory scale. Promising results were initially obtained with hydrochloric acid $(\mathrm{HCl})$. Figure 6.1 shows results from repetitive experiments performed with Fisher Fe palladized to $0.05 \%$. In reviewing the figure, it should be noted that the solution:mass ratio was approximately $3: 1$. Such a ratio is unfavorable relative to the manner in which $\mathrm{Pd} / \mathrm{Fe}$ would be used in a practical system. For example, the solution:mass ratio on a column is approximately 1:4. The data in Fig. 6.1 show deterioration with time. However, a single rinse with $1 \mathrm{~m} \mathrm{HCl}$ restored the reactivity.

$\mathrm{HCl}$ was chosen for the initial experiments because it was readily available, inexpensive and believed not to dissolve Pd. Unfortunately, subsequent experiments indicated that some $\mathrm{Pd}$ was dissolved by $\mathrm{HCl}$. Indeed, the problem appeared particularly severe with $\mathrm{Pd} / \mathrm{Fe}$ prepared in bulk by JMC. Further experiments, therefore, have focused on the use of mild complexing acids such as citric and oxalic (Fig. 6.2). The expected advantage of mild, complexing acids is that they will dissolve $\mathrm{Fe}^{+2}$ and $\mathrm{Fe}^{+3}$ salts but will not have much effect on $\mathrm{Fe}$ metal. The data obtained to date are preliminary but suggest that less Pd is lost from the surface when it is rinsed with oxalic acid. Nevertheless, some Pd was lost from the surface in every case in which $\mathrm{Pd} / \mathrm{Fe}$ was vigorously rinsed. Such losses were low enough that they may be tolerable. In fact, rinsing a column with a regeneration solution is much less abrasive than the method used in these experiments which was to vigorously shake the flask. Thus, it is hoped that dissolution of oxides/ hydroxides etc., will occur with a simple rinse and that rinsing without abrasion will result in better adherence of the Pd.

It should be noted that regeneration on a column will introduce other considerations. For example, the addition of a solution with a low $\mathrm{pH}$ will accelerate the corrosion of the $\mathrm{Fe}$ and production of hydrogen. Thus, it will be necessary to relieve pressure build-up in a safe manner.

Preliminary data included attempting to regenerate a sample of $\mathrm{Pd} / \mathrm{Fe}$ from the aforementioned simulated barrier project (Sect. 6.1) (Liang et al. 1996) with citric acid. The reactivity of the used $\mathrm{Pd} / \mathrm{Fe}$ had decreased by a factor of 10 and a single 


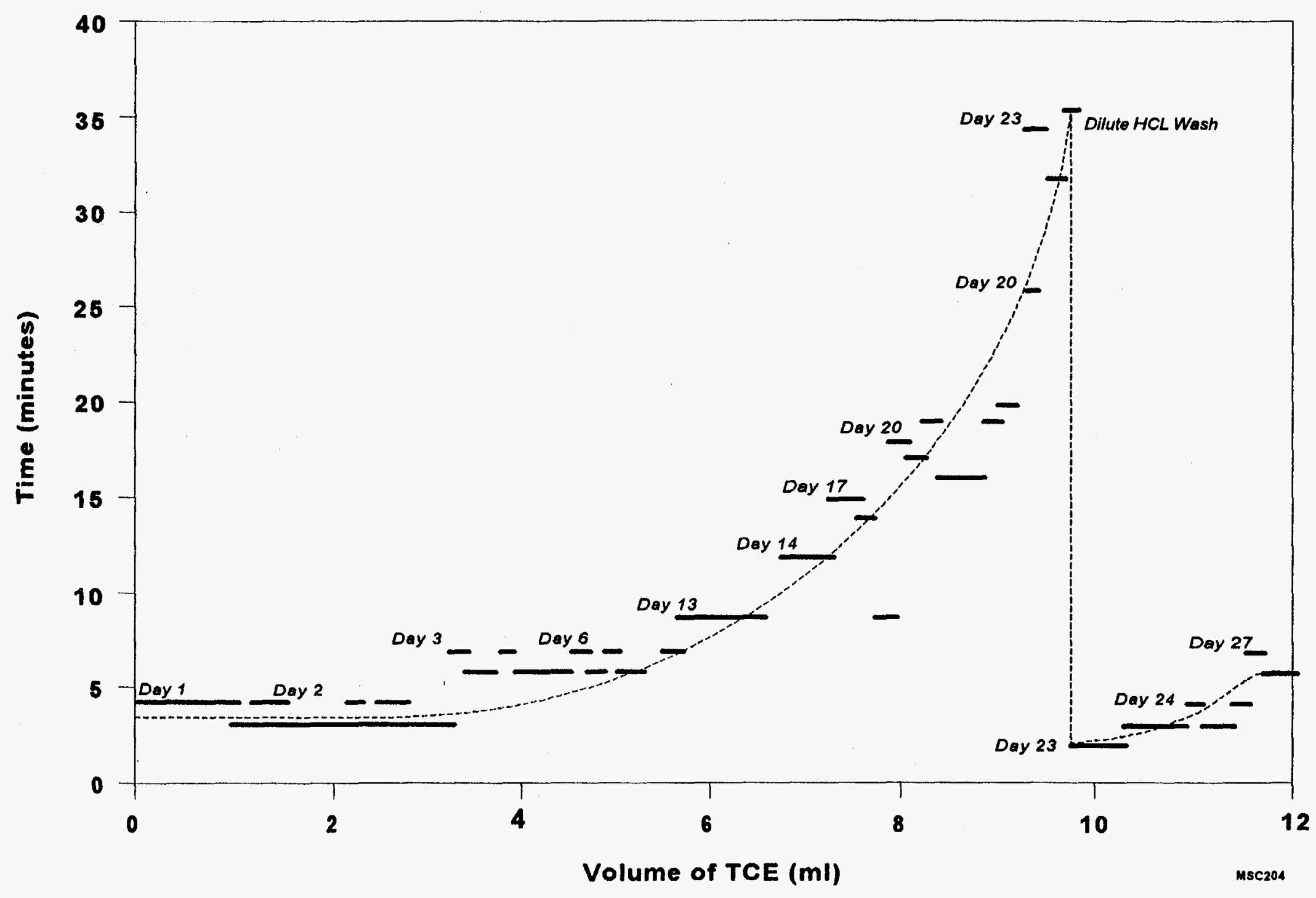

Fig. 6.1. Study of the lifetime of $\mathrm{Pd} / \mathrm{Fe}$ (time vs volume). 


\title{
Complexing Acids Are Proposed for Surface Regeneration and Metal/Radionuclide Removal
}

\author{
$\mathrm{OH}$ \\ Citric Acid<smiles>O=C(O)CC(=O)CC(O)C(=O)O</smiles>

Oxalic Acid<smiles>O=C(O)C(=O)O</smiles>

MSC193 
citric acid (1M) rinse improved reactivity by a factor of 4 . Another brief experiment at ORNL compared a $1 \mathrm{M}$ rinse of the used $\mathrm{Pd} / \mathrm{Fe}$ with $\mathrm{HCl}$, oxalic, and citric acids. Only the oxalic acid extract did not contain any Pd. Funding did not permit a comparison of the restoration of the reactivity.

\subsection{Discussion}

The data obtained to date yield a point of departure for additional research. For example, the thin-film work suggests that a cleaner $\mathrm{Fe}$ surface results in better $\mathrm{Pd}$ adherence. Although XPS shows that a hydroxylate layer forms instantly during palladization, there may be a significant difference in the amount and quality of the layer formed when the $\mathrm{Fe}$ is clean and under vacuum and argon previous to the initial contact with Pd. Perhaps, Pd added in these circumstances adheres better than the bulk preparations tested to date.

The thin-film work (Sect. 4) (Muftikian et al. 1996) showed that Pd-O-Fe bonds formed prior to complete reduction to Pd metal. However, the data showed that both $\mathrm{Pd}$ and $\mathrm{Pd}^{+2}$ were present. It can be speculated that some of the Pd plated directly on the Fe without the intervening step of combining with oxygen. Perhaps, Pd that does not participate in bonding with oxygen is more tightly bound. It also seems, from steric considerations, that the oxygen may affect the quality of the pi-bonding that is presumed to hold the Pd on the Fe surface. Unfortunately, the reaction is too rapid to determine whether or not all of the Pd initially bonds with oxygen or not.

Another issue is with respect to the time required for mixing the $\mathrm{Fe}$ and the palladization solution. It was observed that there was considerable standing water during palladization at JMC. Likewise, there was several min of contact time with interstitial water during the bulk palladization conducted in the field at PORTS (Sect. 7). Perhaps, some of the Pd is reduced in solution by ferrous $\mathrm{Fe}$ before it can plate on the Fe metal. This would account for Pd metal that is found within the Fe matrix but not cemented to the Fe.

The information presented in this section, in conjunction with the results of the field tests (Sect. 7), clearly show that adherence of Pd to the Fe is a critical issue in the further development of this technology. It is emphasized, however, that relatively little testing has been performed. Additional planned research, funded by other programs, will evaluate other base materials (e.g., Fe foams) and plating technologies (e.g., electroless, sputtering) as well as include a comprehensive evaluation of regeneration possibilities. 


\section{Field Experiments}

$\mathrm{Pd} / \mathrm{Fe}$ was tested in three separate phases during the field program at PORTS. Initially, the test was to be full-scale with JMC-prepared $\mathrm{Pd} / \mathrm{Fe}$. As will be discussed, this experiment failed because of manufacturing problems at JMC's New Jersey facility. Thus, a smaller scale experiment, also using JMC-prepared $\mathrm{Pd} / \mathrm{Fe}$ was attempted. This experiment met with some success but was prematurely terminated because of an operator error. Finally, a third phase, relying on field preparation of $\mathrm{Pd} / \mathrm{Fe}$ was attempted. This third phase would have provided the most useful results but equipment malfunction and overall cessation of field activities prevented a complete test. Nevertheless, there were important lessons learned in each phase of activity as described below.

\subsection{Treatment Trailer}

A mobile trailer (Fig. 7.1) was designed for the field tests. All parts for the trailer were provided by RCT (Sect. 2.4) at no cost to DOE and ORNL. Labor for the design and construction were funded by DOE-EM- 50 .

The trailer is $16 \mathrm{ft}$ in length and $8 \mathrm{ft}$ wide. Four large side doors and a double rear door provide convenient access to the treatment system inside the trailer. The system itself consists of six stainless steel columns supported on steel cradles and enclosed behind removable plexiglass windows. The column enclosures are mounted inside spill containment liners equipped with leak detectors and an automatic pump shut-off. As secondary containment, the entire trailer floor is lined and equipped with leak detectors and automatic shut-off.

Two of the columns, used as pre-filters for removing particulates and DO, are $12 \mathrm{in.} \mathrm{long}$ and $12 \mathrm{in.}$ in diameter. The remaining four columns are $30 \mathrm{in.} \mathrm{long}$ and 12 in. in diameter. The column design is shown in Fig. 7.2. The lids on either end were packed with fine and coarse sands as a means of providing both additional filtration and to prevent loss of the reactive media, in this case $\mathrm{Fe}$ or $\mathrm{Pd} / \mathrm{Fe}$.

The columns are connected by stainless steel tubing and valves and can be operated individually, in-series, or in-parallel (Fig. 7.3). Flexible metal tubing and quick disconnects enable rapid changes to be made without shutting off flow

to the entire system. The columns are also easily rotated by means of the support cradles. Even with media as heavy as Fe (approximately $500 \mathrm{lbs}$ in this application), the columns could be rotated by a single person. Each column is 


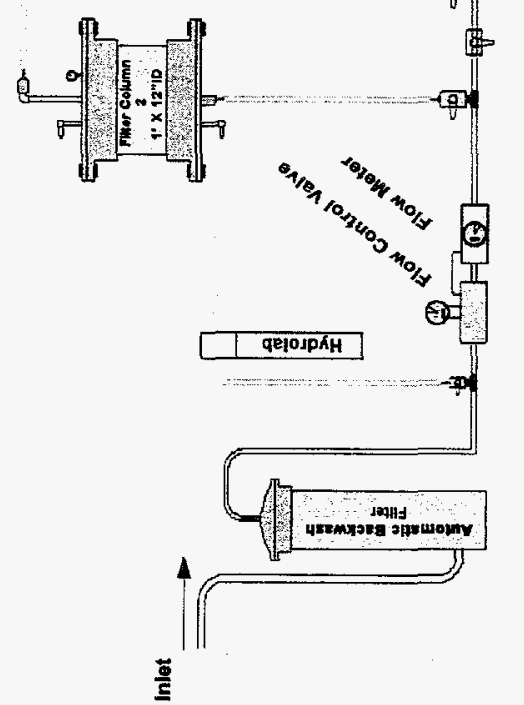

范

을 票完

른 量

일

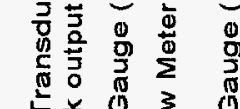

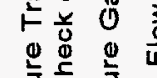

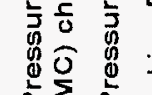

a $\sum 0 \leq$

Fo의 

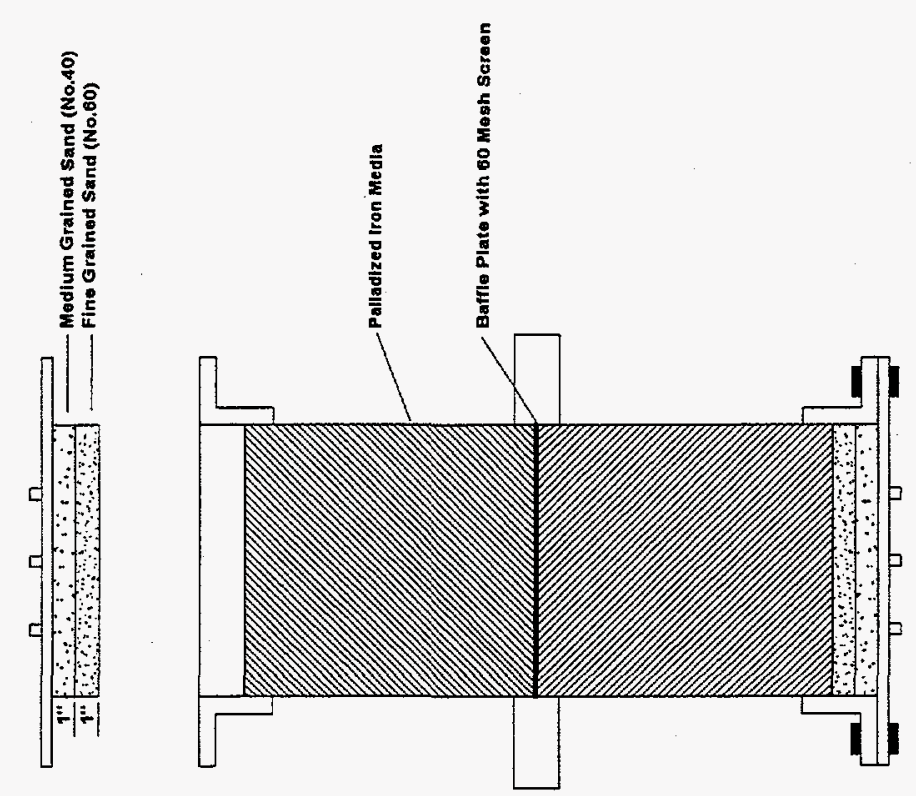

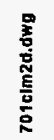
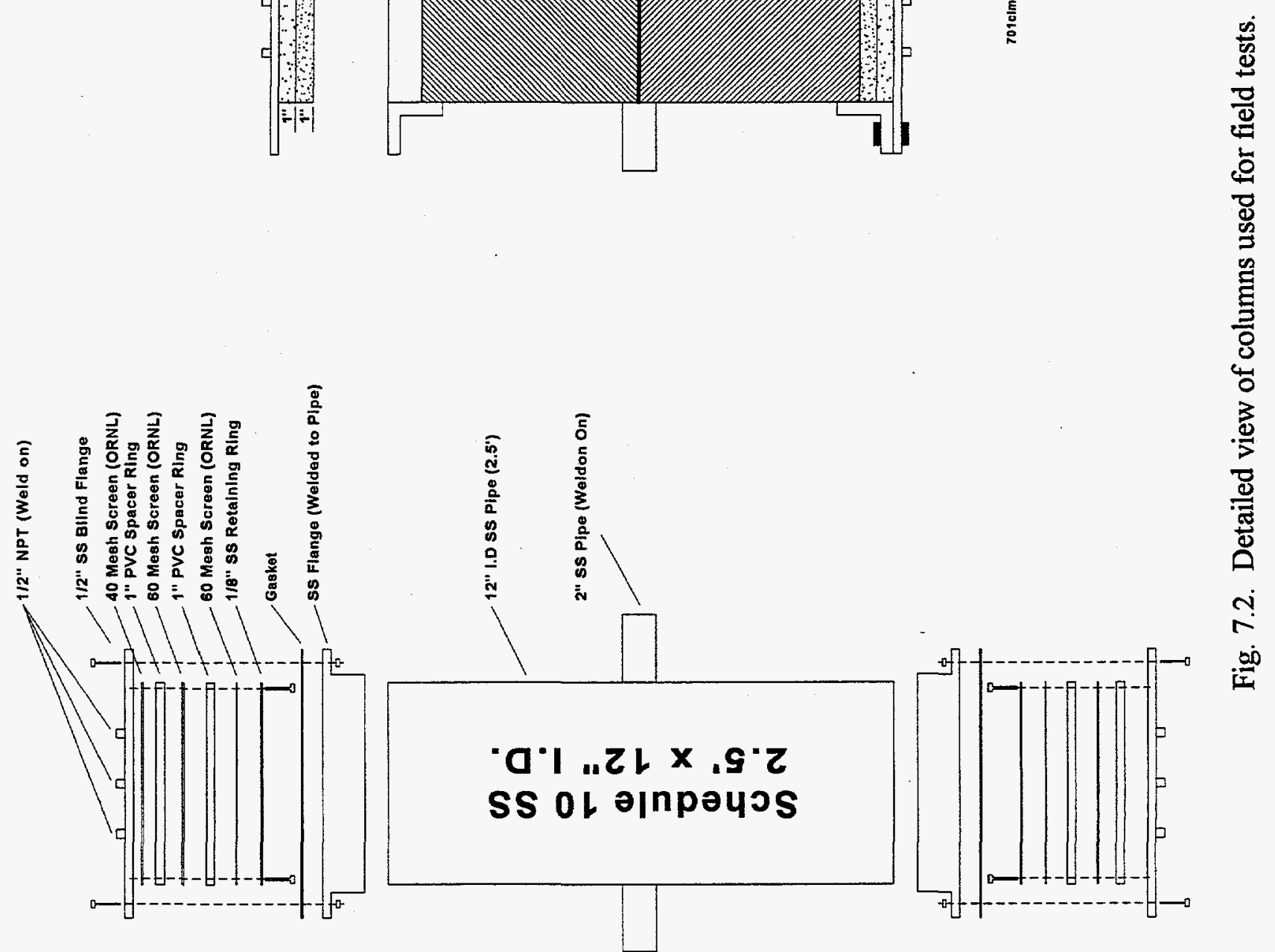


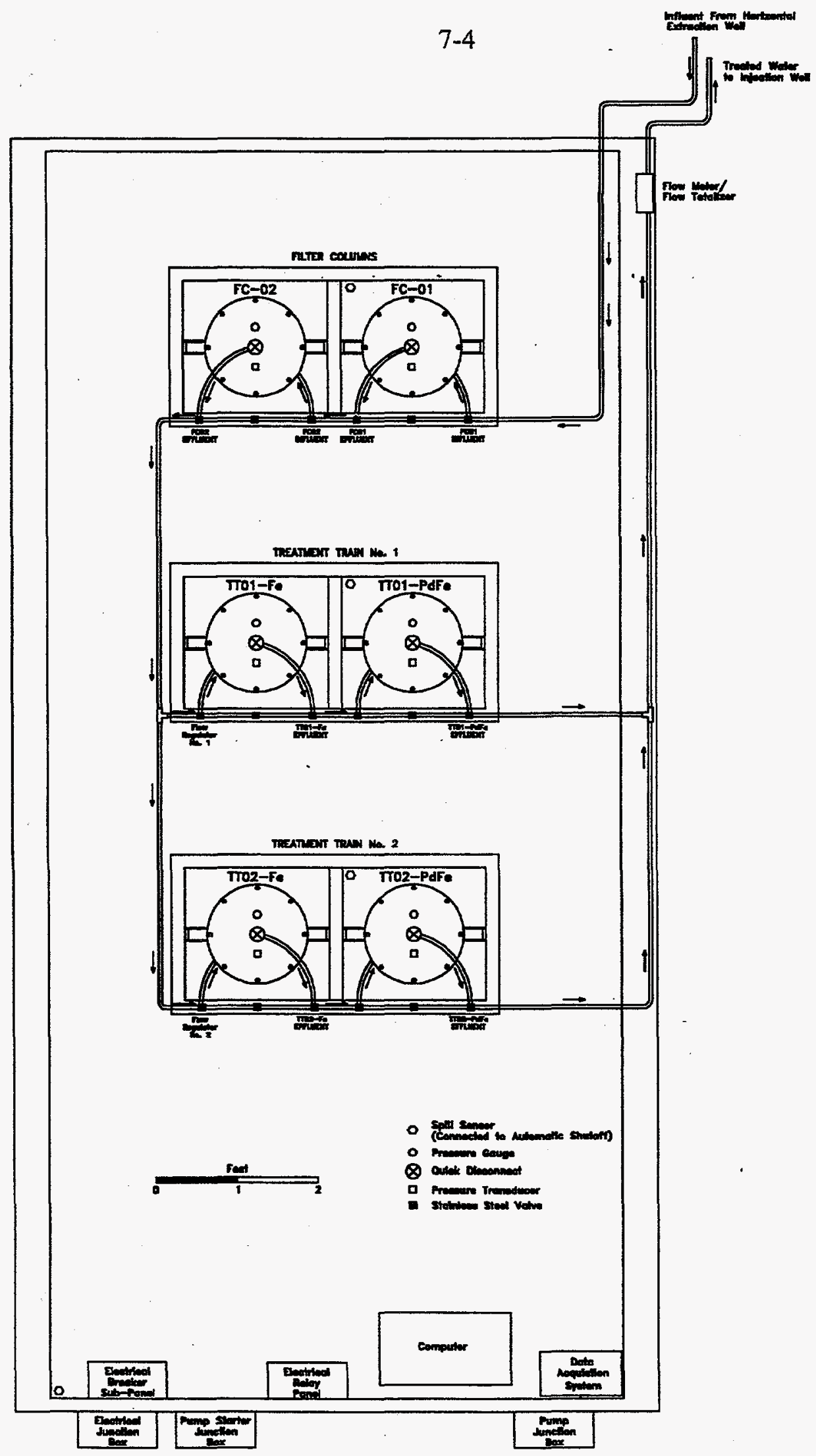

Fig. 7.3. Plan view of treatment trailer layout. 
also equipped with pressure transducers and analog pressure gauges. Flow meters are used to monitor total flow and flow through individual columns.

A data acquisition system was also designed and built to closely monitor treatment system parameters. Flow rates, pressures, treatment time, treated volume, and trailer alarm conditions can be logged at specified intervals. Thus, all of the aforementioned parameters can be compiled and evaluated in real-time. Analytical data derived from samples collected during operation can also be conveniently merged with the operational parameters such that treatment efficiency as a function of time, flow rate, and pressure can be easily viewed.

\subsection{Treatment of $\mathrm{Tc}^{99}$ with Zero-Valence Iron}

As described in Sect. 2, a primary goal of this project was to treat a radioactive $\left(\mathrm{Tc}^{99}\right)$ and a hazardous (TCE) contaminant simultaneously. Certain wells within the flow field contained more than $100 \mathrm{pCi} / \mathrm{L}$ of $\mathrm{Tc}^{99}$ while no $\mathrm{Tc}^{99}$ was detected in others. As soon as the horizontal recirculation system was started, samples were collected for analysis of $\mathrm{Tc}^{99}$. Unfortunately, no $\mathrm{Tc}^{99}$ was detected with a detection limit of $20 \mathrm{pCi} / \mathrm{L}$. However, because $\mathrm{Tc}^{99}$ was within the flow field, it was certain that low concentrations of $\mathrm{Tc}^{99}$ were flowing through the treatment system. The original plan had been to analyze frequently the effluent from the $\mathrm{Fe}$ column to determine when $\mathrm{Tc}^{99}$ breakthrough occurred. Those analyses were not performed because of the low concentrations. However, the columns were dismantled, segmented, and the segments analyzed for their $\mathrm{Tc}^{99}$ content, following the cessation of the pumping and treatment.

Figure 7.4 shows the results of the $\mathrm{Tc}^{99}$ analyses of the Fe segments. Approximately 600,000 gal of water had been pumped through the columns but all of the $\mathrm{Tc}^{99}$ was confined to only $12 \mathrm{in}$. of $\mathrm{Fe}$. These data show that the simultaneous treatment of mixed contaminants was successfully demonstrated. With higher concentrations of $\mathrm{Tc}^{99}$, the $\mathrm{Fe}$ columns would have been periodically changed. These data, in conjunction with the laboratory data (Sect. 3), show that it is possible to select $\mathrm{Fe}$ of varying capacity for $\mathrm{Tc}^{99}$. Thus, the activity of the spent $\mathrm{Fe}$ could be tailored to the particular treatment/storage option that is available. Additional description of the Tc contamination and treatment costs is presented in the horizontal recirculation system report (Korte et al. 1997a).

\subsection{Phase 1 - Full-Scale with JMC-Prepared Pd/Fe}

When the potential benefits of using Pd/Fe were identified, RCT contacted JMC who is one of the world's largest sources for precious metal preparations. JMC 


\section{Tc (pCi/g) Distribution in Fo Columns}

680,000 Gallons of Water Treated

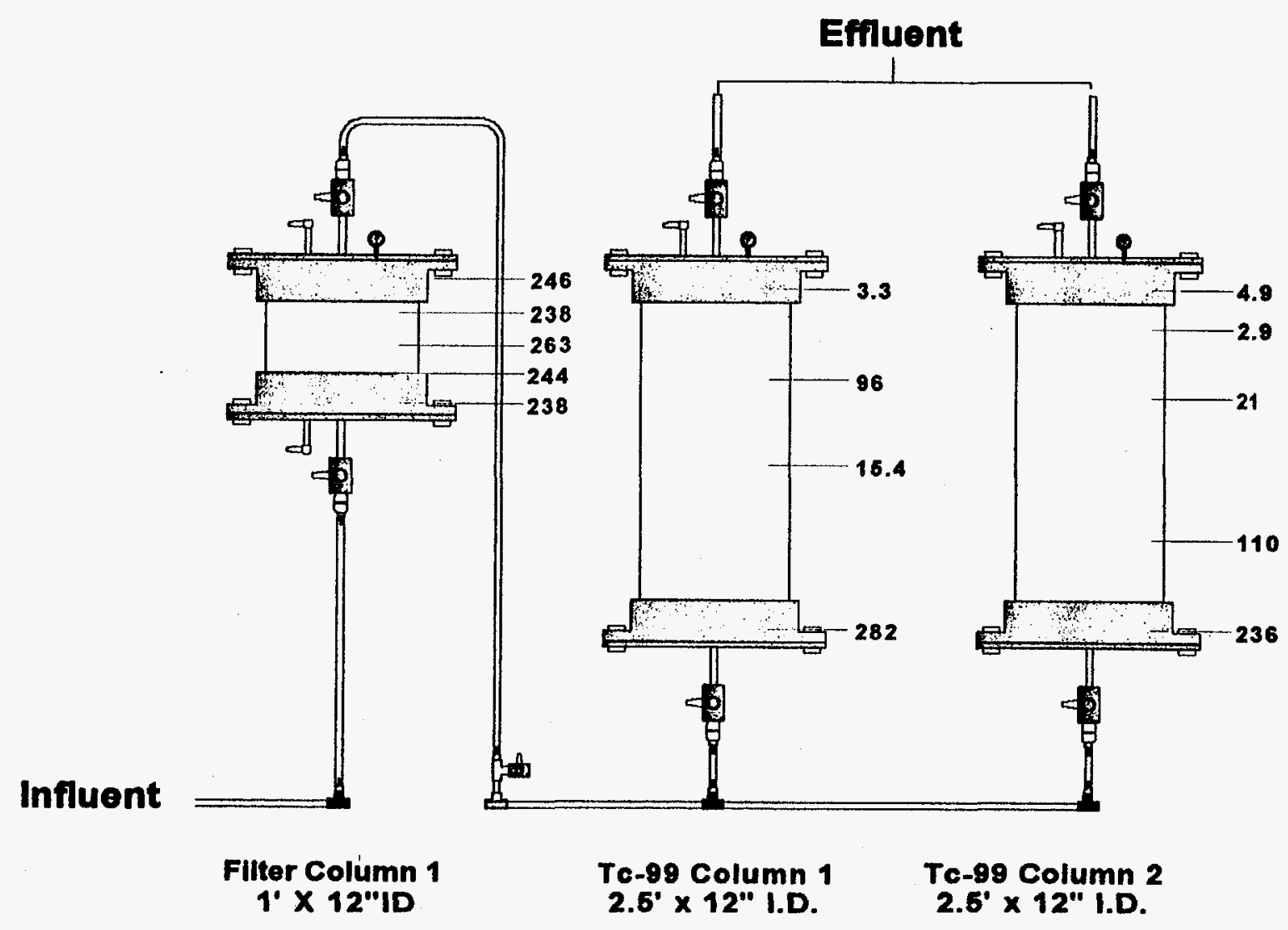

PRMO93

Fig. 7.4. Tc (pCi/g) distribution in Fe columns 580,000 gal of water treated. 
agreed to prepare $\mathrm{Pd} / \mathrm{Fe}$ for laboratory testing. Several different preparations were provided to ORNL but JMC used a proprietary method of preparation and would not confirm whether they were using the published method (Muftikian et al. 1995). Laboratory kinetic data, however, were encouraging in that batch tests with the JMC material closely approximated what was obtained with $\mathrm{Pd} / \mathrm{Fe}$ made in the ORNL and UofA laboratories. RCT desired a full-scale test and agreed to pay $\mathrm{JMC}$ to provide the $\mathrm{Pd} / \mathrm{Fe}$. Thus, the decision was made to use $\mathrm{Pd} / \mathrm{Fe}$ for the fullscale horizontal recirculation program.

\subsubsection{Pd/Fe Design Parameters}

The treatment goal was to reduce the influent TCE concentration by at least $90 \%$ in one pass through the treatment system. Laboratory data had indicated that the influent TCE concentration would be reduced by $1 / 2$ after approximately $23 \mathrm{~s}$ of contact with $\mathrm{Pd} / \mathrm{Fe}$. A $90 \%$ reduction, therefore, requires approximately four reductions by half (e.g., 100-50-25-12.5-6.25). Thus, residence time in the $\mathrm{Pd} / \mathrm{Fe}$ would have to be approximately $2 \mathrm{~min}$. In order to account for varying temperatures and an expected reduction in treatment efficiency with time, the system was designed with a $3 \min (180 \mathrm{~s})$ residence time. Hydrologic testing with the horizontal recirculation system had shown that the minimum flow rate needed for the hydraulic testing was approximately $5 \mathrm{gal} / \mathrm{min}$ although higher flow rates could be accommodated. Based on this information, $6 \mathrm{gal} / \mathrm{min}$ was chosen as the design flow. The lower flow rate was selected because the amount of fine particles in the JMC prepared material was unknown and head loss/pressure build-up in the columns was a concern.

The system design parameters were calculated as follows:

Treatment canisters: $1 \mathrm{ft}$ diameter, $2.5 \mathrm{ft}$ long, $2 \mathrm{ft}$ of $\mathrm{Pd} / \mathrm{Fe}$

$$
\begin{aligned}
& \mathrm{Q}=6 \mathrm{gal} / \mathrm{min}=0.0134 \mathrm{ft}^{3} / \mathrm{s} \\
& \theta=0.6 \text { porosity } \\
& \mathrm{Pd} / \mathrm{Fe} \text { density }=7.87 \mathrm{gm} / \mathrm{cm}^{3} \text { metal only } \\
& 2.60 \mathrm{gm} / \mathrm{cm}^{3} \text { packed density }
\end{aligned}
$$

TCE $1 / 2$ life $=23 \mathrm{~s}$

Residence time:

$$
t_{\text {res }}=\frac{\theta A L}{Q}=\frac{(0.6)\left(0.5 \mathrm{ft}^{2}\right) \pi(2.0 \mathrm{ft})}{0.0134 \mathrm{ft} / \mathrm{s}}=70 \mathrm{~s}
$$


Using two canisters, $t_{\text {res }}=2(70 \mathrm{~s})=140 \mathrm{~s}, \quad \frac{140}{23}=$ half-lives of TCE ( $98 \%$ removal efficiency)

Required volume of $\mathrm{Fe} / \mathrm{Pd}$ :

$$
v=\frac{Q t_{\text {res }}}{\theta}=\frac{\left(0.0134 \mathrm{ft}^{3} / \mathrm{s}\right)(140 \mathrm{~s})}{0.6}=3.13 \mathrm{ft}^{3}
$$

Mass of $\mathrm{Pd} / \mathrm{Fe}$ :

$$
3.13 \mathrm{ft}^{3} \times \frac{\mathrm{m}^{3}}{35.3 \mathrm{ft}^{3}} \times \frac{2600 \mathrm{~kg}}{\mathrm{~m}^{3}}=230 \mathrm{~kg} \mathrm{Pd} / \mathrm{Fe} \approx 510 \mathrm{lb} \text { per canister }
$$

or,

$$
\left(0.5 f t^{2}\right) \pi(2.0 f t)(0.40)=0.628 f^{3} \mathrm{Pd} / \mathrm{Fe} \text { per canister }
$$

The system was designed, therefore, for $6 \mathrm{gal} / \mathrm{min}$ to flow through two canisters connected in series. Once in the field, in order to limit head loss, it was decided to split the input flow of $6 \mathrm{gal} / \mathrm{min}$ such that $3 \mathrm{gal} / \mathrm{min}$ was conducted through each $\mathrm{Pd} / \mathrm{Fe}$ canister after which the flows were combined for reinjection.

\subsubsection{Field Test}

The JMC-prepared $\mathrm{Pd} / \mathrm{Fe}$ was packed in plastic bags and shipped in 5 gal plastic buckets. This $\mathrm{Pd} / \mathrm{Fe}$ shipment was accepted based on a subsample, supposedly representative of the bulk material, that had been supplied to the ORNL laboratory. That subsample did not demonstrate the reactivity expected, being approximately $1 / 2$ as reactive. It was decided that the lower reactivity would be compensated for by the somewhat conservative design of the field system as compared to the goal of $90 \%$ treatment in one pass. A backup system (granular activated carbon) for the $\mathrm{Pd} / \mathrm{Fe}$ had already been selected (Sect. 2). Moreover, schedule and funding considerations would not accommodate further delays in starting the recirculation test. Consequently, the material was accepted and the field trial was initiated.

Knowing that excessive air contact was deleterious to the $\mathrm{Pd} / \mathrm{Fe}$, the field technicians were instructed to pack the $\mathrm{Pd} / \mathrm{Fe}$ with minimal air contact and to immediately begin flow of deoxygenated water through the columns. Water was deoxygenated by being pumped through columns of Fe prior to the $\mathrm{Pd} / \mathrm{Fe}$. Deoxygenation was verified with field measurements of $\mathrm{DO}$. The flow of deoxygenated water, performed at the PORTS clean test site, was continued for three weeks to determine whether clogging would be a problem. When no clogging occurred, the treatment trailer was moved to the contaminated site and the contaminated water was directed through the columns at a rate of approximately $6 \mathrm{gal} / \mathrm{min}$. Effluent 
samples collected after $11 / 2 \mathrm{hrs}$ and again at $8 \mathrm{hrs}$ showed essentially no treatment of VOCs. At this point, the flow rate was decreased by a factor of 10 such that column residence time was approximately $30 \mathrm{~min}$.

Once the poor treatment results were observed, the drums of unused $\mathrm{Pd} / \mathrm{Fe}$ obtained from $\mathrm{JMC}$ were inspected and the personnel who had packed the $\mathrm{Pd} / \mathrm{Fe}$ columns were questioned. It was noted that from drum-to-drum the $\mathrm{Pd} / \mathrm{Fe}$ was highly variable in appearance and moisture content. Some of the $\mathrm{Pd} / \mathrm{Fe}$ was orange in color. All of it was distinctly brown as opposed to appearing black and metallic as expected. The moisture content was also highly variable. Some of the drums were wet, with water droplets visible within the material. Other drums were quite dry. It was also observed that hardened clumps were interspersed with the finer material. The $\mathrm{Pd} / \mathrm{Fe}$ was supposed to be 40 mesh or smaller and $\mathrm{JMC}$ had been requested to remove as many of the fine particles as possible.

To test the material's reactivity, a series of batch experiments were quickly performed in the field. Ten grams of the unused $\mathrm{Pd} / \mathrm{Fe}$ were added to vials that were then filled with $40 \mathrm{~mL}$ of water from the groundwater extraction system. The vials were gently shaken for $5,10,15,20$, and $30 \mathrm{~min}$ at which point aliquots were taken for analysis. The results showed neither the reactivity nor the internal consistency expected. In other words, the $10 \mathrm{~min}$ sample did not dechlorinate twice as much TCE as the $5 \mathrm{~min}$ sample and so on. Indeed, there was little pattern to the data. Subsamples were then collected and shipped to ORNL for additional testing. Testing at ORNL showed similar results.

Unused $\mathrm{Pd} / \mathrm{Fe}$ prepared by $\mathrm{JMC}$ and left over from the previously mentioned simulated barrier experiment (Liang et al. 1996) was also obtained from storage at PORTS. Batch tests showed that it was at least twice as reactive as the new material. A sieve analysis was then performed on the two preparations. The new material was $5-10 \%>$ than 40 mesh as compared to previously received $\mathrm{Pd} / \mathrm{Fe}$ which was $22 \%>40$ mesh. Moreover, the new material had more than twice as much mass in the $<60$ mesh fraction even though JMC had been requested to remove a greater percentage of fine particles.

In the meantime, additional data from the treatment system became available. With a flow of $0.6 \mathrm{gal} / \mathrm{min}$, a $67 \mathrm{ppm}$ TCE influent was reduced to $17 \mathrm{ppm}$. While such data demonstrated that some treatment was occurring, the horizontal recirculation test could not be conducted at such a low flow rate. Consequently, the decision was made to switch to carbon for VOC removal. The Fe columns were retained for removal of Tc.

Additional measurements were made on the various JMC-prepared materials. For example, a total analysis for Pd was performed. The previously-used sample 
(Liang et al. 1996) reportedly contained $0.36-0.52 \% \mathrm{Pd}$. Two separate drums of the new material showed $0.0325-0.047 \% \mathrm{Pd}$ and $0.0098-0.012 \% \mathrm{Pd}$ respectively. These data indicate that the desired coverage $(0.05 \%)$ was obtained for the previously-received preparation but that the Pd content was both low and highly variable in the new material. JMC personnel stated that the only real difference in the two preparations was that the batch size was quite a bit larger for the second one.

\subsubsection{Effects on Other Chemical Constituents}

The purpose of this section is to convey the data related to the use of the $\mathrm{Pd} / \mathrm{Fe}$. Only a minor amount of data were collected regarding the $\mathrm{Fe}-\mathrm{Pd} / \mathrm{Fe}$ treatment system's effect on other groundwater contaminants. The following results, however, may be useful for predicting long-term effects. Samples were also collected from 12 monitoring wells that were located in and near the flow-field and from the influent and effluent of each treatment column. The data from these wells are discussed in detail in the final report for this project (Korte et al. 1997a).

The data discussed in this section are all from field measurements performed within a few minutes to a few hours of sample collection. The analyses were all performed with kits available from Hach Inc. (Loveland, Colorado).

Chloride - Chloride in the monitoring wells ranged from approximately 20 $60 \mathrm{mg} / \mathrm{L}$. The influent to the treatment system was approximately $35 \mathrm{mg} / \mathrm{L}$. Effluent from the Fe columns showed a slight increase (to $40-50 \mathrm{mg} / \mathrm{L}$ ). Effluent from one of the $\mathrm{Pd} / \mathrm{Fe}$ columns ranged to $82 \mathrm{mg} / \mathrm{L}$ suggesting that the rinse of the $\mathrm{HCl}$ wash performed by $\mathrm{JMC}$ was inadequate. If the $\mathrm{Pd} / \mathrm{Fe}$ had been stored at low $\mathrm{pH}$, significant corrosion might have occurred during storage. There was no increase in chloride through the other $\mathrm{Pd} / \mathrm{Fe}$ column but this may be explained by the varying conditions of the $\mathrm{Pd} / \mathrm{Fe}$ as described previously.

Sulfate - Sulfate in the monitoring wells ranged from approximately 130 $300 \mathrm{mg} / \mathrm{L}$. Influent to the treatment system was approximately $215 \mathrm{mg} / \mathrm{L}$. There was no evidence of sulfate removal in the Fe columns but concentrations decreased to approximately $165 \mathrm{mg} / \mathrm{L}$ after passage through the $\mathrm{Pd} / \mathrm{Fe}$. Precipitation of ferrous sulfate in the Fe columns was expected but obviously had not occurred to any significant extent over the length of this experiment. Time and funding did not permit an evaluation of the removal mechanism in the $\mathrm{Pd} / \mathrm{Fe}$.

Others (Mackenzie et al. 1997) have reported a grey-to-white precipitate attributed to ferrous sulfates and carbonates. It is noted that neither the $\mathrm{Fe}$ nor the $\mathrm{Pd} / \mathrm{Fe}$ showed any evidence of this grey color, even after three months of field use in a high sulfate environment. 
Alkalinity - Alkalinity in $\mathrm{mg} / \mathrm{L}$ as $\mathrm{CaCO}_{3}$ in the monitoring wells ranged from 71 (well-80G) to 665 (well-75-G). The influent to the treatment system was approximately $100-150 \mathrm{mg} / \mathrm{L}$ which increased to approximately $250 \mathrm{mg} / \mathrm{L}$ through the $\mathrm{Fe}$ columns but did not change as it passed through the $\mathrm{Pd} / \mathrm{Fe}$. This increase in alkalinity may be an indication of microbial activity. More study, however, is needed to evaluate this speculation.

Ferrous Fe - The detection limit for the ferrous Fe analysis was approximately $0.1 \mathrm{mg} / \mathrm{L}$. Ferrous $\mathrm{Fe}$ in the monitoring wells was either not detected or found in trace concentrations with the exception of well 77-G which contained approximately $8 \mathrm{mg} / \mathrm{L}$. The ferrous Fe influent concentration to the treatment system was unexpectedly high, $15-20 \mathrm{mg} / \mathrm{L}$. As expected, ferrous Fe increased throughout the treatment system, increasing to $110-125 \mathrm{mg} / \mathrm{L}$ as it passed through the $\mathrm{Fe}$ columns and to $200-210 \mathrm{mg} / \mathrm{L}$ after passage through the $\mathrm{Pd} / \mathrm{Fe}$.

\subsection{Phase 2 - Small-Scale Experiment with JMC-Prepared Pd/Fe}

Once the data obtained in Sect. 7.3.2 were provided to JMC, they agreed to permit project personnel to witness the preparation of the Pd/Fe. JMC and RCT agreed to provide the funding and a smaller-scale field test was designed. The goal of the smaller scale test was to obtain some long-term field data with $\mathrm{Pd} / \mathrm{Fe}$ without jeopardizing the data collection or operation of the full-scale horizontal recirculation test which was successfully operating with $\mathrm{Fe}$ and carbon treatment of the mixed waste effluent.

Accordingly, a dilution system was built in a trailer adjacent to the treatment system. Treated water was taken from the carbon system and used to dilute incoming untreated water. This was done so that lower concentrations and lower volumes of TCE would be treated. The horizontal recirculation system was yielding water with $200 \mathrm{ppm}$ TCE which was somewhat higher than expected. None of the laboratory work associated with $\mathrm{Pd} / \mathrm{Fe}$ had been performed at such high concentrations. Hence, a lower concentration was desired so that a direct comparison could be made to the laboratory. The dilution system was designed such that its effluent went back through the carbon in order to eliminate any concerns about reinjecting untreated water.

The preparation of the Pd/Fe at JMC's facility was witnessed by Nic Korte of. ORNL, M.T. Koerner of RCT, and Frank Cheng of the UofA. Instead of using 40-mesh Fe, as used previously, 40-60 mesh, spherical, electrolytic Fe (AlfaAesar, Ward Hill, MA) was used. Alfa-Aesar Fe was selected because of excellent batch study results obtained at the UofA. Discussions revealed that JMC had 
departed from the published procedure in several ways. They were using a sodium salt rather than a potassium salt and were not thoroughly washing the $\mathrm{Fe}$ with acid prior to palladization (personal communication Kevin Donnegan and Bob McNair, JMC, to Nic Korte, ORNL, October 22, 1996). Use of the Na salt was not likely to pose a problem but an inadequate acid rinse probably was. At this time, $\mathrm{JMC}$ agreed to use a $1 \mathrm{~N} \mathrm{HCl}$ rinse as opposed to the $6 \mathrm{~N} \mathrm{HCl}$ that had been published (Muftikian et al. 1995). This acid rinse was to be followed by a thorough water rinse.

The on-site observations revealed that there were a number of shortcomings with respect to the preparation method at JMC. The following is an unprioritized list of the potential problems that were observed:

- The stirrer blade in the reactor did not agitate the bottom. Thus, only the top layer of $\mathrm{Fe}$ was well-mixed.

- Deionized water was not readily available and there were several long periods of waiting while it was obtained. In the meantime, the Fe corroded with air, water or acid.

- The reactor was not bottom-draining, meaning that a pipe had to be inserted to remove the excess water. The pipe could not remove the bottom 1-3 in. of solution. Thus, the acid rinse was very inefficient and the quality of the preparation of the Fe surface was questionable. Moreover, the water rinse to remove the acid had to be conducted several times to raise the $\mathrm{pH}$ above that of the palladizing solution (2.54). Thus, instead of a simple acid rinse and drain, acid was added and then drained as much as possible followed by several more rinses with water. Two hours passed from the time the Fe was added to the acid until the palladizing step could be performed. In addition, the rinse water was not deoxygenated so the Fe would have been subject to much more corrosion than at the laboratory.

An obvious result of this preparation process was that a clear solution was not obtained following the palladization step. Instead, the solution was yellow-green which was indicative of a high concentration of dissolved ferrous Fe. Chief among the concerns regarding the high concentration of ferrous $\mathrm{Fe}$ is that it could reduce the $\mathrm{Pd}^{+4}$ to $\mathrm{Pd}$ metal without the metal plating on the Fe surface.

The packaging of the $\mathrm{Pd} / \mathrm{Fe}$ was not observed but discussions with plant personnel indicated that previous batches had been subjected to significant air contact. It was requested, therefore, that this material be packaged wet and immediately shipped to PORTS. Samples were taken to ORNL and to the UofA for batch 
testing. The batch testing again showed approximately half of the reactivity as the laboratory-prepared $\mathrm{Pd} / \mathrm{Fe}$.

The $\mathrm{Pd} / \mathrm{Fe}$ preparation that was observed accounted for half of what was to be used in this test. A second batch was prepared the next day in which JMC personnel stated that air contact and time delays were much shorter. Because the batches were to be used in different columns, one item of interest was to determine if there was a performance difference.

The columns, as shown in Fig. 7.2, were cleaned and prepared for the $\mathrm{Pd} / \mathrm{Fe}$. Sand in the lids and all screens, etc. were removed and replaced with fresh materials. Less than half of each column was to be used. The procedure for packing the columns was to connect them to the treatment system and begin the flow of water until it just began to appear in the half of the column to which the $\mathrm{Pd} / \mathrm{Fe}$ was to be added. At that point, the containers (sealed, plastic jars) sent by $\mathrm{JMC}$ were opened and the $\mathrm{Pd} / \mathrm{Fe}$ added to the column. Once the $\mathrm{Pd} / \mathrm{Fe}$ was added, the lid was put on the column, the column was rotated so that the $\mathrm{Pd} / \mathrm{Fe}$ was now at the bottom and immersed in the deoxygenated water. Water flow through the system was started immediately. The entire packing process required less than 10 min. Visual inspection of the $\mathrm{Pd} / \mathrm{Fe}$ indicated no obvious deterioration from the samples that were collected during manufacture. There was also no obvious difference in the batches from the two preparation periods. There was approximately $10 \%$ less material in batch 2 . Thus, column TT01-Pd contained approximately 12 in. of $\mathrm{Pd} / \mathrm{Fe}$ and column TT02-Pd contained approximately 10 in.

Data from this test are presented in Table 7.1. The system flow rate was approximately $0.5 \mathrm{gal} / \mathrm{min}$ and the influent concentration was nominally $1 \mathrm{ppm}$ $(1000 \mathrm{ppb})$. Based on the reactivity measured in the laboratory, the expectation was that the concentration reduction would be approximately 5 half-times. In other words, a concentration of $1000 \mathrm{ppb}$ would be reduced to approximately $30 \mathrm{ppb}$ (e.g., 1000-500-250-125-62.5-31.75). It is evident from the table that the amount of reduction approximated that expected from the laboratory measurements. The other primary feature of interest was that column TTO2-Pd generally outperformed TTO1-Pd. In 17 of the 20 measurement periods, there was greater reduction with TT02-Pd. The last nine measurements, constituting almost $46 \mathrm{hrs}$ of operation all showed TT02-Pd with a lower effluent concentration. It is noted that the influent to TTO1-Pd was slightly higher than for TTO2-Pd, but the differences were $5-10 \%$ not factors of 5 to 10 as observed in the effluent. Also, recall that there was approximately $10 \%$ less $\mathrm{Pd} / \mathrm{Fe}$ in TT02-Pd. The number of half-time reductions is plotted in Fig. 7.5. The differences seem especially striking in the last nine measurements where the data suggest successively poorer treatment with TTO1-Pd. It should be noted that in the final $24 \mathrm{hr}$ period, there was a significant drop in air temperature (from $55^{\circ}$ to $20^{\circ}$ ) and the dechlorination 
Table 7.1. Phase 2 results, ppb - low concentration influent, $0.5 \mathrm{gal} / \mathrm{min}$

\begin{tabular}{|c|c|c|c|c|c|}
\hline $\begin{array}{c}\text { Time, } \\
\mathrm{h}\end{array}$ & $\begin{array}{c}\text { Influent to } \\
\text { TT01 }\end{array}$ & $\begin{array}{c}\text { Influent to } \\
\text { TT02 }\end{array}$ & TT01-Pd & TT-02-Pd & Total gal \\
\hline 0.25 & 938 & 874 & 46 & 59 & 15 \\
\hline 1.25 & 1050 & 873 & 32 & 22 & 47 \\
\hline 2.5 & $-\cdots$ & $-\cdots$ & 105 & 36 & 125 \\
\hline 4.7 & 1224 & 1217 & 63 & 13 & 271 \\
\hline 7.8 & 1037 & 990 & 33 & 7 & 457 \\
\hline 23.7 & 1039 & 986 & 93 & 69 & 1411 \\
\hline 27.3 & 1420 & 1441 & 66 & 32 & 1599 \\
\hline 31.5 & 1537 & 1496 & 50 & 16 & 1856 \\
\hline 34.7 & 1504 & 1450 & 67 & 43 & 2049 \\
\hline 47 & 1478 & 1338 & 44 & 66 & 2780 \\
\hline 51 & 1282 & 1264 & 44 & 57 & 3020 \\
\hline 55 & 1279 & 1202 & 53 & 6 & 3255 \\
\hline 57 & 1210 & 1067 & 63 & 26 & 3374 \\
\hline 70 & 1040 & 1053 & 74 & 10 & 4092 \\
\hline 74 & 928 & 873 & 74 & 23 & 4334 \\
\hline 78 & 1092 & 984 & 92 & 16 & 4581 \\
\hline 80.5 & 987 & 960 & 108 & 81 & 4733 \\
\hline 93 & 919 & 760 & 128 & 17 & 5438 \\
\hline 98 & 815 & 183 & 10 & 5744 \\
\hline 101 & 1098 & 161 & 49 & 5929 \\
\hline
\end{tabular}


7-15

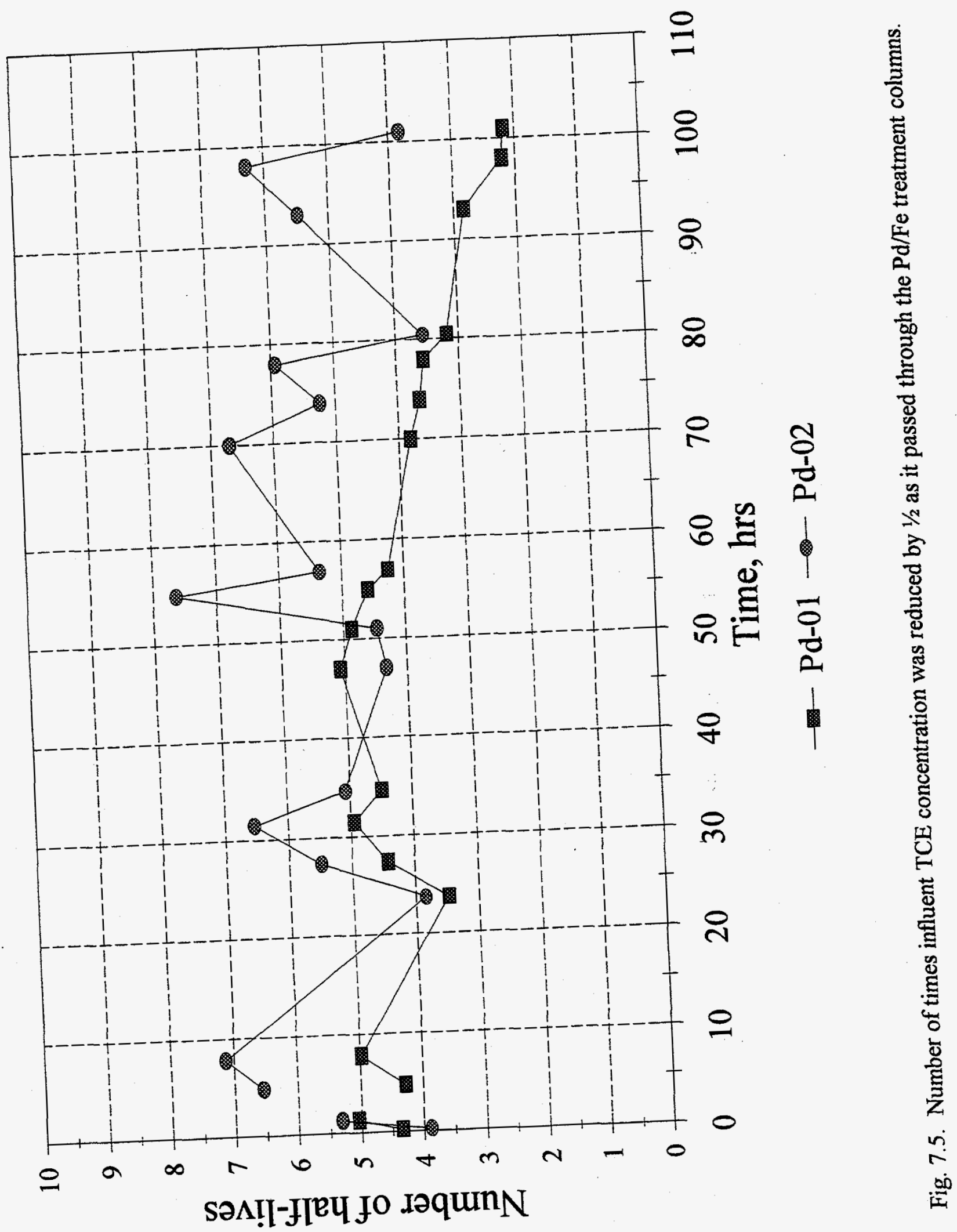


reaction is temperature sensitive (West et al. 1996). Thus, the improved performance of TT02-Pd suggests, but certainly does not prove, that $\mathrm{Pd} / \mathrm{Fe}$ performs better when prepared under more controlled conditions (principally less air contact).

Encouraged by this success, the decision was made to decrease the dilution and increase the influent concentration. Unfortunately, an error was made with the valving in the dilution system. The columns drained and air was pumped through them overnight. Upon resaturation with water, treatment was very poor and the experiment was terminated.

The columns were then taken apart and inspected. The $\mathrm{Pd} / \mathrm{Fe}$ had solidified. When the column was drained and then the flow slowly resumed, it was evident that water was passing through only a small part of the bulk mass. Indeed, the $\mathrm{Pd} / \mathrm{Fe}$ was now so hard that it had to be chipped out. Some of this $\mathrm{Pd} / \mathrm{Fe}$ was removed, ground, and shipped to the laboratory. The half-life was now reduced by another factor of two. However, this was still approximately twice as reactive as was being observed in the field indicating that poor contact between the contaminated groundwater and the solidified mass of $\mathrm{Pd} / \mathrm{Fe}$ was primarily responsible for the deteriorated performance.

The phase 2 test was considered to be a very positive development. The data demonstrated that laboratory kinetic data could be related to field reactivity and that $\mathrm{Pd} / \mathrm{Fe}$ from a commercial manufacturing environment could be shipped and packaged without apparent loss of performance. In addition, the differences observed between the two production batches suggested that the observations at $\mathrm{JMC}$ regarding air contact during manufacture might account for the difference between the performance of laboratory and bulk-production.

\subsection{Phase 3 - Small-Scale Field Test with Pd/Fe Prepared On-Site}

The decision was made to produce some $\mathrm{Pd} / \mathrm{Fe}$ in the field without any air contact such that the best laboratory-measured reactivity could be obtained in the field columns. The overall project was nearing its scheduled termination, however, such that only 10-12 days were available. Nevertheless, JMC agreed to provide

the base Fe and the Pd salt. Accordingly, a small reactor was built as shown in Fig. 7.6. The reactor was approximately $30 \mathrm{in}$. long and $8 \mathrm{in}$. in diameter with eight baffles arranged in a criss-cross fashion. The reactor was mounted in a cradle so that it would rotate about its center. During rotation, the baffles would assist in breaking up and mixing the $\mathrm{Pd} / \mathrm{Fe}$. Each side of the reactor had a gauge and pressure relief valve such that any buildup of hydrogen could be released. There was also an inlet for bathing the material in nitrogen. 


\section{Pd Fe Production Chamber}

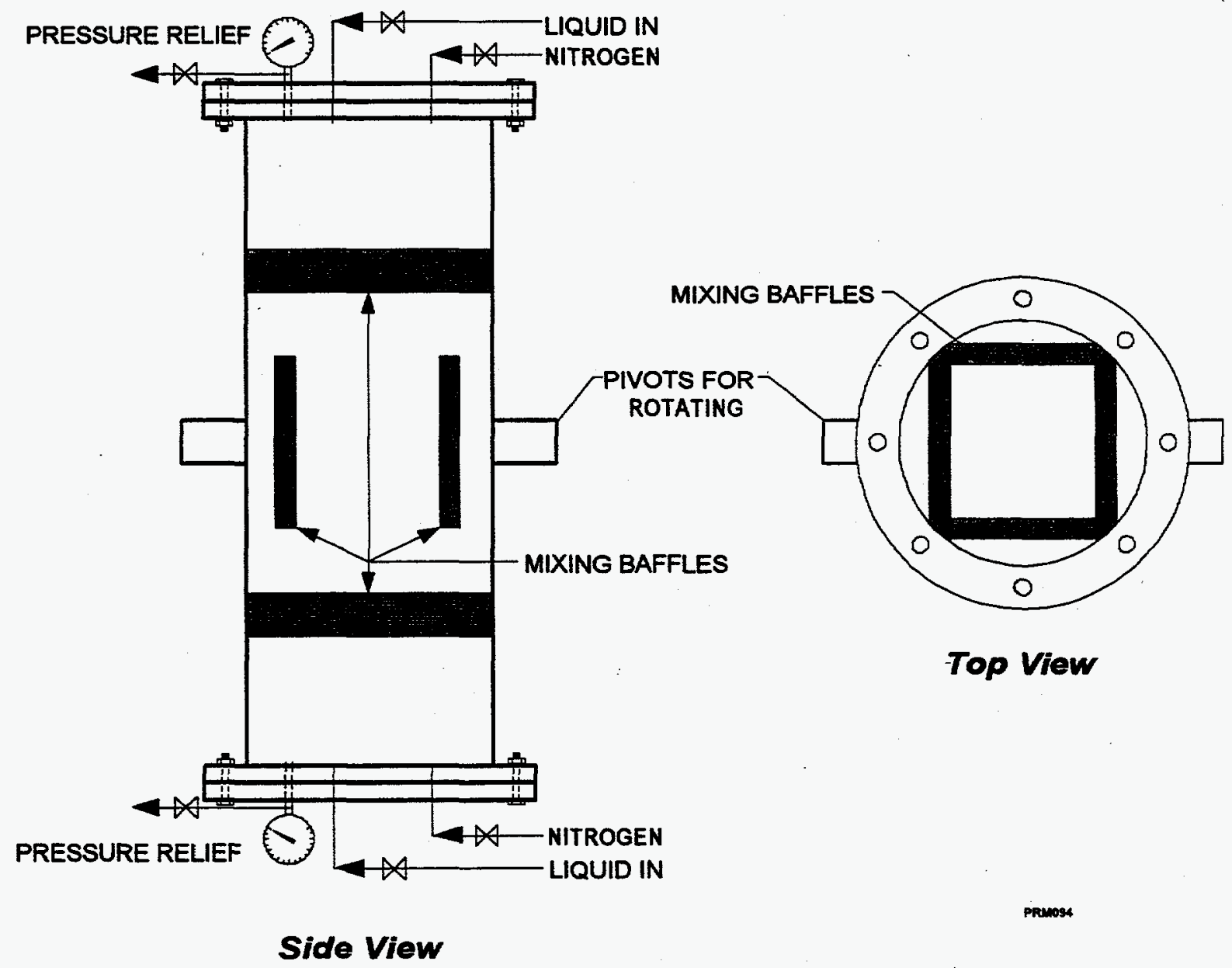

Fig. 7.6. $\mathrm{Pd} / \mathrm{Fe}$ production chamber used for field bulk preparation of $\mathrm{Pd} / \mathrm{Fe}$. 
The process used was as follows:

- The reaction vessel was purged with nitrogen and $30 \mathrm{~kg}$ of Alfa-Aesar Fe was added. A positive nitrogen pressure was then maintained throughout the remainder of the procedure.

- Deionized water was deoxygenated by vigorous bubbling with nitrogen. A nitrogen pressure was maintained over three vessels of water. One of these was used for the acid rinse solution, another for the water rinse, and the third for the palladization solution.

- Three gal of deoxygenated $10 \% \mathrm{HCl}$ were added. The cylinder was then rotated repeatedly for $20 \mathrm{~min}$ to perform the acid wash.

- The acid was drained from the bottom with a positive pressure of nitrogen maintained at all times. Draining required approximately $5 \mathrm{~min}$.

- A single water rinse, with two gal of deionized, deoxygenated water was performed. The column was rotated for approximately $5 \mathrm{~min}$ and drained as with the acid rinse.

- $163 \mathrm{~g}$ of $18.44 \% \mathrm{Pd}$ (sodium chloropalladate, a hydrated salt, assay provided by JMC), was added to three gal of deionized, deoxygenated water. This vessel was stirred with a magnetic stirrer for approximately $5 \mathrm{~min}$ and the entire contents were added to the $\mathrm{Fe}$ in the reactor vessel.

- The reactor vessel was then rotated repeatedly. After approximately $5 \mathrm{~min}$, the supernatant appeared clear and was drained off under nitrogen pressure.

- The $\mathrm{Pd} / \mathrm{Fe}$ was immediately transferred to a nitrogen-purged treatment canister. After several minutes a small amount of black precipitate formed in the supernatant. (Subsequent analyses by JMC showed that the precipitate was pure $\mathrm{Pd}$. Nevertheless, bulk analysis of the $\mathrm{Pd} / \mathrm{Fe}$ indicated that coverage was the expected $0.05 \%$. Because Pd was added in slight excess, it appeared that approximately $90 \%$ plated on the Fe). The lid to the canister was screwed on and the contaminated water flow was initiated.

The entire production process required approximately $30 \mathrm{~min}$ and the only air contact that could have occurred was when the $\mathrm{Pd} / \mathrm{Fe}$ was carried to the treatment canister. That activity required less than $1 \mathrm{~min}$.

During this experiment, only 4 - 6 in. of $\mathrm{Pd} / \mathrm{Fe}$ were to be used. Some baffles and screens were added to the field canisters to hold the material in place. A subsample of the material was also collected and shipped to the ORNL laboratory. Laboratory kinetic data (Fig. 7.7) indicated that this material was similar in 


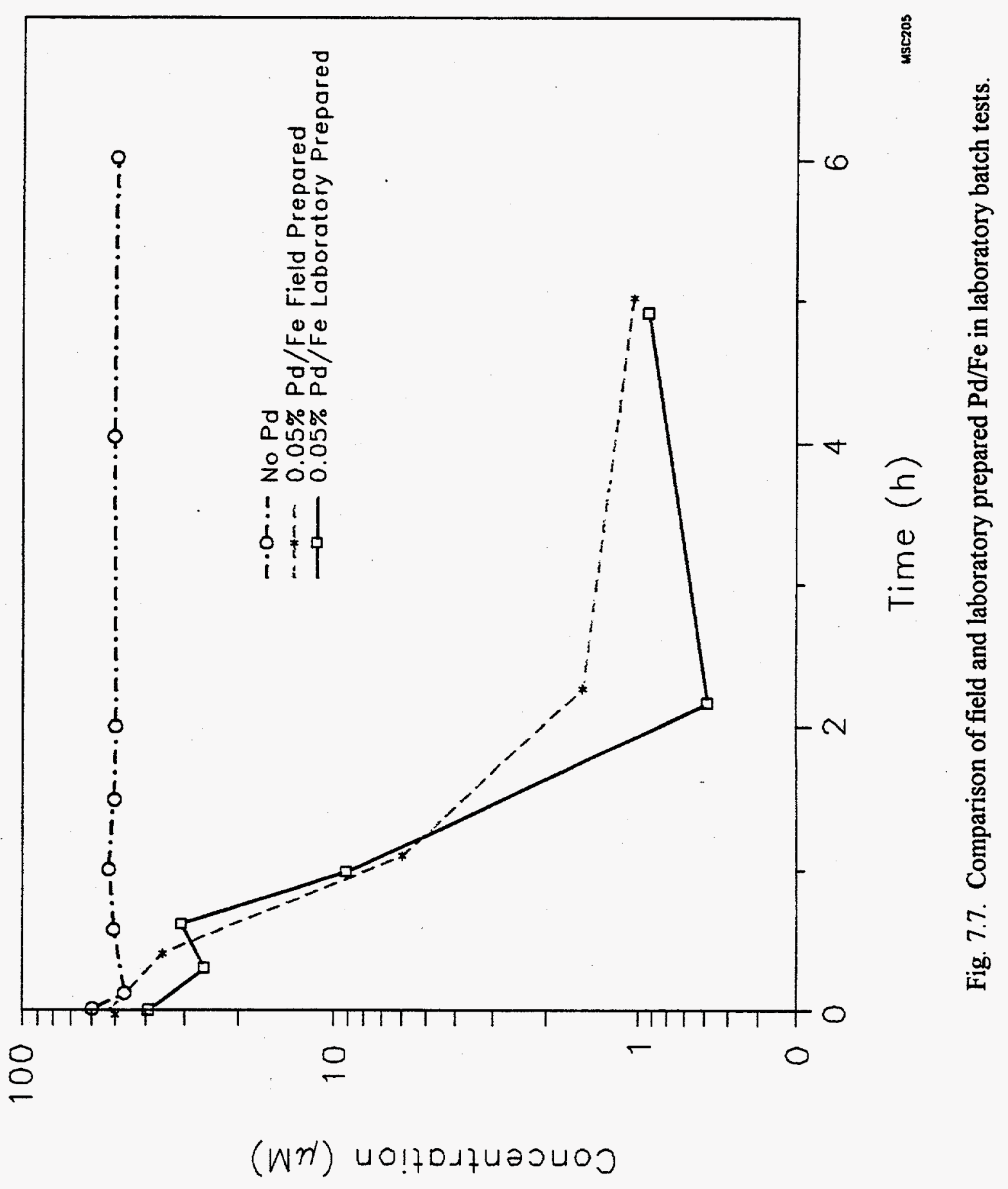


reactivity to laboratory-prepared $\mathrm{Pd} / \mathrm{Fe}$, that is, twice as reactive as that provided by JMC and used in phase 2 . In other words, the careful exclusion of oxygen did improve the reactivity of the catalyst.

Treatment using the packed canister was then initiated. The preliminary results, those from the first 1-3 hrs of operation, indicated that treatment was approximately at the level expected. At that point, however, the treatment deteriorated significantly and remained at less than $50 \%$ removal for the next week. (Flow through the column was continued in order to observe whether the $\mathrm{Pd} / \mathrm{Fe}$ solidified in the absence of the air contact that occurred in phase 2.) When the column was opened, there was no apparent solidification or oxidation of the $\mathrm{Pd} / \mathrm{Fe}$ and no apparent reason why treatment was so much less than expected. To check for preferential pathways, a slow stream of nitrogen was injected into the bottom of the column. It was observed that all of the gas escaped around the side of the baffles instead of passing through the $\mathrm{Pd} / \mathrm{Fe}$. As noted above, these baffles and screens were inserted to hold the $\mathrm{Pd} / \mathrm{Fe}$ in place because the columns were designed to hold quite a bit more material. Unfortunately, these did not seal as tightly as was necessary and permitted the contaminated water to flow around the catalyst. At this point, funds for the overall field experiment had been expended and the project was terminated.

Although the field-prepared material was not tested under field conditions during phase 3, several important lessons were learned. First, although the supernatant was clear, some Pd (10\%) did not plate on the Fe. Whether or not Pd precipitation is occurring in the laboratory is unknown. Perhaps the more rapid laboratory plating step results in more efficient plating or precipitation may be occurring but the amounts are too small to be noticed. Second, no solidification occurred, although the $\mathrm{Pd} / \mathrm{Fe}$ was in contact with water for more than a week. Third, even with the improvements in the production procedure, it was not possible to perform the plating and rinsing steps nearly as quickly as in the laboratory.

\subsection{Summary}

The PORTS experiments yielded considerable useful information and results concerning $\mathrm{Pd} / \mathrm{Fe}$. The ability to take commercially-prepared material and measure the kinetics in the laboratory and then obtain the same performance in the field is an important step. The fact that the material did not solidify during exposure to deoxygenated water is important. The reactor design used in the field provided good mixing and a convenient means of preventing air contact. Finally, proving that some of the $\mathrm{Pd}$ is being reduced but not plating on the Fe was an important discovery. 
Unfortunately, the PORTS experiments did not provide a thorough field test of the $\mathrm{Pd} / \mathrm{Fe}$. The initial test was marred because of poorly prepared and packaged $\mathrm{Pd} / \mathrm{Fe}$. The second test provided the best data but an equipment malfunction cut the test short. The third test was inconclusive because of equipment malfunction.

On the other hand, zero-valence iron, used throughout the more than four month field period effectively removed $\mathrm{Tc}$ and there was no evidence of clogging. The concept of simultaneous treatment of mixed contaminants with $\mathrm{Fe}-\mathrm{Pd} / \mathrm{Fe}$ has been proven but the full-scale test of the $\mathrm{Pd} / \mathrm{Fe}$ was not accomplished.

\section{Plans}

New funding has recently become available from EM-50's Efficient Separations Program. This funding will permit approximately one-year's laboratory effort regarding material development. The focus of that effort is to determine the nature of the $\mathrm{Pd}$ adherence to $\mathrm{Fe}$ and to determine the optimum methods for plating, use, and regeneration. Experiments are being conducted with different materials (particle size, purity) and with different plating approaches (e.g., electroless plating). Kinetic studies and measurements of surface areas and surface composition will be investigated during this project. 


\section{References}

Barbee, G. C. 1994. Fate of chlorinated aliphatic hydrocarbons in the vadose zone and ground water. Ground Water Monitoring and Remediation, 14(1):129-140.

Bodnariuk, P., B. Coq, G. Ferrat, and F. Figueras. 1989. Carbon chlorine hydrogenolysis over Pdrh and Pdsn bimetallic catalysts. Journal of Catalysis, 116(2):459-466.

Bostick, W. D., J. L. Shoemaker, P. E. Osborne, and B. Evans-Brown. 1990. "Treatment and Disposal Options for Heavy Metals Waste Containing Soluble Technetium-99." In Emerging Technologies for Hazardous Waste Treatment, ACS Symposium Series No. 422. D. W. Tedder and F. F. Pohland, eds., 345367.

Bostick, W. D., and B. S. Evans-Brown. 1988. Sorptive Removal of Technetium from Heavy Metals Sludge Filtrate Containing Nitrate Ion. K/QT-160. Oak Ridge National Laboratory, Oak Ridge, Tennessee.

Bowen, H. J. N. 1966. Trace Elements in Biochemistry. Academic Press, London.

Briggs, D., and M. Seah. 1983. Practical Surface Analysis, John Wiley and Sons, New York, New York.

Cantrell, K. J. 1995. Zero-valent iron for the in situ remediation of selected metals in groundwater. Journal of Hazardous Materials, 42(2):0201-0212.

Cataldo, D. A., R. E. Wildung, and T. R. Garland. 1978. Technetium Accumulation, Fate, and Behavior in Plants. In Environmental Cycling Processes, eds., D. C. Adriano and I. L. Brisbin, 207-220.

Cheng, F., Q. F. Fernando, and N. Korte. 1997. Electrochemical Dechlorination of 4-Chlorophenol to Phenol. Environmental Science and Technology, 31(4):1074-1078.

Clausen, J. L., W. L. Richards, N. E. Korte, and L. Liang. 1995. ORNL/MMES Research into remedial applications of zero-valence metals: 3) Removal of TCE, cis-1,2-DCE, vinyl chloride, and technetium. In American Chemical Society Division of Environmental Chemistry, presented at the 209th ACS National Meeting, April 2-7, 1995, Anaheim, California, 35(1):755. 
Clausen, J. L., and W. L. Richards. 1994. Work Plan for Batch and Column Studies Using Iron Filings to Treat Trichloroethylene and Technetium. KY/ER-51. Paducah Gaseous Diffusion Plant, Paducah, Kentucky.

Coq, B., S. Hub, F. Figueras, and D. Tournigant. 1993. Conversion under hydrogen of dichlorodifluoromethane over bimetallic palladium catalysts. Applied Catalysis A: General, 101(1):41 - 50.

Cotton, F. A., and G. Wilkinson. 1966. Advanced Inorganic Chemistry. Interscience Publishers, New York, NY.

Criddle, C. S., and P. L. McCarty. 1991. Electrolytic model system for reductive dehalogenation in aqueous environments. Environ. Sci. Technol., 25(5):973 978.

Del Cul, G. D., W. D. Bostick, D. R. Trotter, and P. E. Osborne. 1992. Technetium-99 removal from process solutions and contaminated groundwater. In Separation Science and Technology, 7th Symposium on Separation Science and Technology for Energy Applications, October 20-25, Knoxville, Tennessee.

Freifelder, M. 1971. Practical Catalytic Hydrogenation. Wiley, New York, NY.

Gillham, R. W. and S. F. O'Hannesin. 1994. Enhanced degradation of halogenated aliphatics by zero-valent iron. Ground Water, 32:958-967.

Gillham, R. W. and S. F. O'Hannesin. 1992. Metal-catalyzed abiotic degradation of halogenated organic compounds. IAH conference, Modern Trends in Hydrogeology, Hamilton Ontario, Canada.

Grittini, C., G. A. Romeo, Jr., Q. Fernando, and N. E. Korte. 1996. Rapid dechlorination of pentachlorophenol. American Chemical Society, 212th National Meeting, Orlando, Florida. Environmental Chemistry Preprints of Extended Abstracts, 36(2):19-20. August.

Grittini, C., M. Malcomson, Q. Fernando, and N. Korte. 1995. Rapid dechlorination of polychlorinated biphenyls on the surface of a $\mathrm{Pd} / \mathrm{Fe}$ bimetallic system. Environmental Science \& Technology, 29(11):2898-2900.

Gu, B., K. E. Dowlen, L Liang, and J. L. Clausen. 1996. Efficient separation and recovery of technetium-99 from contaminated groundwater. Sep. Technol., 6:123-132. 
Gu, B., O. R. West, and R. L. Siegrist. 1995. Using ${ }^{14} \mathrm{C}$-labeled radiochemicals can cause experimental error in studies of the behavior of volatile organic compounds. Environmental Science and Technology, 29(5):1210.

Haitko, D. A., and S. S. Baghel. 1995. Enhanced trichloroethylene dechlorination by $\operatorname{Fe}\left({ }^{\circ}\right)$. Presented before the Division of Environmental Chemistry, American Chemical Society, April 2-7, Anaheim, California.

Horney, D. P., P. D. McKenzie, J. J. Salvo, and T. M. Sivavec. 1995. Zerovalent iron treatability study for groundwater contaminated with chlorinated organic solvents at the Paducah, Kentucky GDP Site. Report submitted to Lockheed Martin Energy Systems. GE Corporate Research and Development, Schenectady, New York.

Johnston, R. A., and A. H. Wilby. 1985. Chem. Rev., 85:129.

Korte, N., M. T. Muck, P. M. Kearl, R. L. Siegrist, R. M. Schlosser, M. E. Mumby, D.T. Davenport, D. W. Greene, D. A. Pickering, C. A. Muhr, and J. Strong-Gunderson. 1997a. In Situ Treatment of Mixed Contaminants in Groundwater, Final Report on Engineering, Cost, and Hydrodynamic Aspect of the Project. Oak Ridge National Laboratory, Grand Junction, Colorado, in preparation.

Korte, N. E., L. Liang, R. Muftikian, C. Grittini, and Q. Fernando. 1997b. The Dechlorination of Hydrocarbons: Palladized iron utilised for ground water purification. Platinum Metals Review, 41(1):2-7.

Korte, N. E., M. T. Muck, J. L. Zutman, L. Liang, J. D. Goodlaxson, and J. Clausen. 1995a. Zero-Valence Metal Reduction of Chlorinated Hydrocarbons Technology Screening Report Portsmouth uranium Enrichment Plant Piketon, Ohio. Oak Ridge National Laboratory, Grand Junction, Colorado.

Korte, N. E., R. Muftikian, C. Grittini, Q. Fernando, J. L. Clausen, and L. Liang. 1995b. ORNL/MMES Research into Remedial Applications of Zero-Valence Metals. 2: Bimetallic Enhancements. In American Chemical Society Division of Environmental Chemistry, presented at the 209th ACS National Meeting, April 2-7, 1995, Anaheim, California, 35(1):752. 
Korte, N. E., R. L. Siegrist, M. Ally, B. Bischoff, W. Bostick, J. M. StrongGunderson, P. Kearl, L. Liang, D. Marsh, A. Mattus, A. Palumbo, J. Stockdale, P. Taylor, and O. F. Webb. 1994. In Situ Treatment of Mixed Contaminants in Groundwater: Review of Candidate Processes, ORNL/TM12772, Oak Ridge National Laboratory, Oak Ridge, Tennessee.

Korte, N., J. Skopp, W. H. Fuller, E. E. Niebla, and B. A. Alesii. 1976. Trace element movement in soils: influence of soil physical and chemical properties. Soil Science, 122:350.

Kulikov, S. M., V. P. Plekhanov, A. J. Tsyganok, C. Schlimm, and E. Heitz. 1996. Electrochemical reductive dechlorination of chlororganic compounds on carbon cloth and metal modified carbon cloth cathodes. Electrochimica Acta, 41:527.

Kurbatov, Cr., E. Darque-Cerett, and M. Acouturier. 1992. Surf. Interface Anal., 18:811.

Lawson, D. R., M. J. Tierney, I. F. Cheng, L. S. Van Dyke, M. W. Espenscheid, and C. R. Martin. 1991. Use of a coulormetric assay technique to study the variables affecting deuterium loading levels with palladium electrodes. Electrochimica Acta, 36(9):1515 - 1522.

Lee, S. Y., and E. A. Bondietti. 1983. Technetium behavior in sulfide and ferrous iron solutions. Material Research Society Symposium Proceedings, 15:315-321.

Liang, L., N. E. Korte, J. D. Goodlaxson, J. Clausen, Q. Fernando, R. Muftikian. 1997. Byproduct formation during the reduction of TCE by zero-valence iron and palladized iron. Ground Water Monitoring and Remediation, Winter:122127.

Liang, L., O. R. West, N. E. Korte, J. D. Goodlaxson, D. A. Pickering, J. L. Zutman, F. J. Anderson, C. A. Welch, and M. J. Pelfrey. 1996. The X-625 Groundwater Treatment Facility. A Field-Scale Test of Trichloroethylene Dechlorination Using Iron Filings for the X-120/X-749 Groundwater Plume. Oak Ridge National Laboratory, Oak Ridge, Tenn.

Liang, L., J. D. Goodlaxson, N. E. Korte, J. L. Clausen, and D. T. Davenport. 1995. ORNL/MMES Research into Remedial applications of Zero-Valence Metals. 1: Laboratory Analysis of Reductive Dechlorination of Trichloroethene. 209th National Meeting, Anaheim, Calif. American Chemical Society, 35(1):728-731. 
Lieser, K. H., and C. H. Bauscher. 1987. Technetium in the hydrosphere and in the geosphere: 1 . Chemistry of technetium and iron in natural waters and influence of the redox potential on the sorption of technetium. Radiochimica Acta, 42:205-213.

Mackenzie, P. D., T. M. Sivavec, and D. P. Horney. 1997. Extending Hydraulic Lifetime of Iron Walls. Presented at International Containment Technology Conference and Exhibition, St. Petersburg, Florida, February 9 - 12.

Mallat, T., Z. Bodnar, and J. Petro. 1991. Reduction by dissolving bimetals. Tetrahedron, 47:441-446.

Marques, C. A., M. Selva, and P. Tundo. 1994. Facile hydrodehalogenation with $\mathrm{H}-2$ and $\mathrm{Pd} / \mathrm{C}$ catalyst under multiphase conditions. 2. Selectivity and kinetics. J. Org. Chem., 59(14):3830 - 3837.

Matheson, L. J. and P. G. Tratnyek. 1994. Reductive dehalogenation of chlorinated methanes by iron metal. Environmental Science and Technology, 28:2045-2053.

Meyer, R. E., W. D. Arnold, and F. I. Case. 1987. The Solubility of Electrodeposited Tc(IV) Oxides. ORNL-6374. Oak Ridge National Laboratory, Oak Ridge, Tennessee.

Muck, M. T., P. M. Kearl, R. L. Siegrist, N. E. Korte, R. M. Schlosser, M. E. Mumby, D.T. Davenport, D. W. Greene, D. A. Pickering, C. A. Muhr, and J. Strong-Gunderson. 1996. Pilot Test of a Horizontal Well Recirculation System at the Clean Test Site, Portsmouth Gaseous Diffusion Plant. Oak Ridge National Laboratory, Grand Junction, Colorado.

Muck, M. T., N. E. Korte, L. Liang, D. Marsh, J. L. Zutman, and J. Clausen. 1995. Technology Screening Report for Tc Removal from Groundwater Portsmouth Uranium Enrichment Plant, Piketon, Ohio. Oak Ridge National Laboratory, Grand Junction, Colorado.

Muftikian, R., K. Nebesny, Q. Fernando, and N. Korte. 1996. X-ray photoelectron spectra of the palladium-iron bimetallic surface used for the rapid dechlorination of chlorinated organic environmental contaminants. Environmental Science \& Technology, 30(12)3593-3596.

Muftikian, R., Q. Fernando, and N. E. Korte. 1995. A method for the rapid dechlorination of low molecular weight chlorinated hydrocarbons in water. Water Research 24(10):2434-2439. 
O'Hannesin et al. 1995. TCE degradation in groundwater using zero-valent iron. Presented Before the Division of Environmental Chemistry, American Chemical Society, September 17 - 20, Atlanta, Georgia.

O'Hannesin, S. F. 1993. A Field Demonstration of a Permeable Reaction Wall for the In Situ Abiotic Degradation of Halogenated Aliphatic Organic Compounds. M.S. Thesis, University of Waterloo, Ontario, Canada.

O'Hannesin, S. F. And R. W. Gillham. 1992. A permeable reaction wall for in situ degradation of halogenated organic compounds. 45th Canadian Geotechnical Society Conference. Toronto, Ontario, Canada.

Orth, W. S., and R. W. Gillham. 1995. Chloride and carbon mass balances for iron-enhanced degradation of trichloroethene. Presented before the Division of Environmental Chemistry, American Chemical Society, April 2-7, Anaheim, California.

Puls, R. W., R. M. Powell, and C. J. Paul. 1995. In Situ Remediation of Ground Water Contaminated with Chromate and Chlorinated Solvents Using Zerovalent Iron: A Field Study. 209th National Meeting, Anaheim, Calif. American Chemical Society. 35(1):788.

Riley, R. G., J. M. Zachara, and F. J. Wobber. 1992. Chemical Contaminants on DOE Lands and Selection of Contaminant Mixtures for Subsurface Science Research. DOE/ER-0547T.

Sawyer, D. T., and J. L. Roberts. 1974. Experimental Electrochemistry for Chemists, John Wiley and Sons, New York, New York, p. 61.

Schulte, E. H., and P. Scoppa. 1987. Sources and behavior of technetium in the environment. Science of the Total Environment, 64:163-179.

Siegrist, R. L., O. R. West, C. K. Bayne, R. A. Jenkins, and C. A. Muhr. 1997. Anintegrated study of sampling and measurement error for soil VOCs. Manuscript in preparation.

Siegrist, R. L., M. I. Morris, O. R. West, D. D. Gates, D. A. Pickering, R. A. Jenkins, T. J. Mitchell, D. W. Greene, C. A. Muhr, S. Herbes, T. M. Gilliam, H. L. Jennings, A. J. Lucero, J. L. Zutman, and others. 1993. Full-Scale Field Demonstration and Testing of Physicochemical Processes for In Situ Treatment of Soil Contaminated by Volatile Organic Compounds in the Presence of Radio-active Substances. Presented at Waste Management '93, Tucson, Arizona, February 28 - March 4, 1993. 
Sivavec, T. M., P. D. Mackenzie, D. P. Horney and S. S. Baghel. 1997. RedoxActive Media for Permeable Reactive Barriers. Presented at International Containment Technology Conference and Exhibition, St. Petersburg, Florida, February $9-12$.

Sivavec, T. M. and D. P. Horney. 1995. Reductive Dechlorination of Chlorinated Ethenes by Iron Metal. Presented before the Division of Environmental Chemistry, American Chemical Society. Anaheim, California, April 2-7, 1995.

Vogan, J. L., J. K. Seaberg, B. Gnabasik, and S. F. O'Hannesin. 1994. Evaluation of in Situ Groundwater Remediation by Metal Enhanced Reductive Dehalogenation-laboratory Column Studies and Groundwater Flow Modeling. 87th annual meeting, Air \& Waste Management, Cincinnati, Ohio.

Walton, F. B., J. Paquette, J. P. M. Ross, and W. E. Lawrence. 1986. Tc(IV) and $\mathrm{Tc}$ (VII) interactions with iron oxyhydroxides. Nuclear and Chemical Waste Management, 6:121-126.

West, O. R., L. Liang, W. L. Holden, N. E. Korte, Q. Fernando, and J. L. Clausen. 1997. Degradation of Polychlorinated Biphenyls (PCBs) Using Palladized Iron. ORNL/TM-13217. Oak Ridge National Laboratory, Oak Ridge, Tennessee.

West, O. R., R. L. Siegrist, T. J. Mitchell, and R. A. Jenkins. 1995. Measurement error and spatial variability effects on characterization of volatile organics in the subsurface. Environmental Science and Technology, 29(3):647.

Wildung R. E., T. R. Garland, K. M. McFadden, and C. E. Cowan. 1986. Technetium Sorption in Surface Soils. In Technetium in the Environment, G. Desmet and C. Myttenaere, eds., 115-129, Elsevier Applied Science Publishers.

Wildung, R. E., K. M. McFadden, and T. R. Garland. 1979. Technetium sources and behavior in the environment. Journal of Environmental Quality, 8:156161.

Wildung, R. E., T. R. Garland, and D. A. Cataldo. 1977. Accumulation of technetium by plants. Health Physics, 32:314-317.

Zhang, S. P. 1995. Dechlorination of polychlorinated biphenyls on soils and clay by electrolysis in a biocontinuous microemulsion. Environ. Sci. Technol., 29:1195. 


\section{8-8}

Zhang, S. P. and J. F. Rusling. 1993. Dechlorination of polychlorinated biphenyls by electrochemical catalysis in a biocontinuous microemulsion. Environ. Sci. Technol., 27(7):1375 - 1380. 


\section{INTERNAL DISTRIBUTION}

1. B. Berven

2. J. H. Cushman

3. T. Early

4. D. E. Fowler

5-9. B. Gu

10. S. G. Hildebrand

11. G. K. Jacobs

12. P. Kanciruk

13. P. Kearl

14. C. Kendrick

15-19. N. Korte

20. C. A. Little

21. J. M. Loar
22. R. Mann

23-27. M. Muck

28. T. E. Myrick

29. D. E. Reichle

30. C. Rightmire

31-33. R. Schlosser

34. D. S. Shriner

35-39. R. Siegrist

40-42. J. Zutman

43. Central Research Library

44-46. ESD Library

47-48. Laboratory Records Dept.

49. Laboratory Records, ORNL-RC

\section{EXTERNAL DISTRIBUTION}

50. F. Anderson, Lockheed Martin Energy Systems, Portsmouth Gaseous Diffusion Plant, 3930 US Route 23 S, Piketon, $\mathrm{OH} 45661$

51. J. Baker, Environmental Protection Specialist, AlliedSignal, Inc., 2000 E. 95th Street, Kansas City, MO 64131

52. M. Broido, Director, Environmental Sciences Division, ER-74, U.S. Department of Energy, 19901 Germantown Road, Germantown, MD 20874

53. G. Budzin, Lockheed Martin Energy Systems, Portsmouth Gaseous Diffusion Plant, 3930 US Route $23 \mathrm{~S}$, Piketon, OH 45661

54. F. Bullock, Lockheed Martin Energy Systems, Portsmouth Gaseous Diffusion Plant, 3930 US Route 23 S, Piketon, OH 45661

55. S. Chamberlain, U.S. Department of Energy, 19901 Germantown Rd.-CLOV, Germantown, MD 20874-1290

56. J. Clausen, Ogden Environmental \& Energy Services, 239 Littleton Road, Suite 1B, Westford, MA 01886 
57. P. Cross, Lockheed Martin Energy Systems, Portsmouth Gaseous Diffusion Plant, 3930 US Route 23 S, Piketon, OH 45661

58. E. G. Cumesty, ORNL Site Manager, U.S. Department of Energy, Oak Ridge National Laboratory, P.O. Box 2008, Oak Ridge, TN 37831-6269

59. K. Donnegan, Johnson-Matthey, 2001 Nolte Drive, West Deptford, NJ 08066

60. J. Douthitt, Lockheed Martin Energy Systems, Environmental Restoration and Waste Management, 761 Veterans Ave., Kevil, KY 42053

61-65. Q. Fernando, Department of Chemistry, University of Arizona, Tucson, AZ 85710

66. D. G. Hager, Heritage Partners, 6030 N. Camino Esplendora, Tucson, AZ 85718

67. J. Harness, Program Manager, Environmental Technology Group, U.S. Department of Energy, Oak Ridge Operations, 55 Jefferson Street, Oak Ridge, TN 37831

68. R. Helferich, Cercona of America, Inc., 5911 Wolf Creek Pike, Dayton, OH 45428-2439

69-73. T. Houk, Technology Applications Program Manager, Lockheed Martin Energy Systems, Portsmouth Gaseous Diffusion Plant, 3930 US Route 23 S, Piketon, OH 45661

74. D. Kaback, Colorado Center for Environmental Management, 19th Street, Suite 2750, Denver, CO 80202

75. L. Kantner, U.S. Department of Energy, Portsmouth Gaseous Diffusion Plant, 3930 US Route 23 S, Piketon, OH. 45661

76. M. Koerner, Research Corporation Technologies, 101 N. Wilmar Road, Suite 600, Tucson, AZ 85711

77. L. Liang, Department of Earth Sciences, University of Wales, Cardiff, P.O. Box 914, Cardiff, U.K.

78. M. C. MacCracken, Director, Office of the U.S. Global Change Research Program, Code YS-1, 300 E Street, SW, Washington, D.C. 20546

79. R. Miller, Lockheed Martin Energy Systems, Environmental Restoration and Waste Management, 761 Veterans Ave., Kevil, KY 42053

80. Office of Assistant Manager for Energy Research and Development, U.S. Department of Energy Oak Ridge Operations, P. O. Box 2001, Oak Ridge, TN 37831-8600

81-82. Office of Scientific and Technical Information, P. O. Box 62, Oak Ridge, TN 37831 
83. A. Patrinos, Associate Director, Office of Health and Environmental Research, ER-70, U.S. Department of Energy, 19901 Germantown Road, Germantown, MD 20874

84. E. Phillips, U.S. Department of Energy, Oak Ridge Operations, 55 Jefferson Street, Oak Ridge, TN 37831.

85. J. Powers, U.S. Department of Energy, Portsmouth Gaseous Diffusion Plant, 3930 US Route 23 S, Piketon, $\mathrm{OH} 45661$

86. J. Sheppard, Deputy Site Manager, U.S. Department of Energy, Portsmouth Gaseous Diffusion Plant, 3930 US Route 23 S, Piketon, $\mathrm{OH}^{2} 45661$ 